\title{
The role of pressure solution creep in the ductility of the Earth's upper crust
}

\author{
Jean-Pierre Gratier ${ }^{1}$, Dag K. Dysthe ${ }^{2,3}$, and François Renard ${ }^{1,2}$ \\ ${ }^{1}$ Institut des Sciences de la Terre, Observatoire, CNRS, Université Joseph Fourier-Grenoble I, BP 53, 38041 \\ Grenoble, France \\ ${ }^{2}$ Physics of Geological Processes, University of Oslo, Norway \\ ${ }^{3}$ Laboratoire Interdisciplinaire de Physique, BP 87, 38041 Grenoble, France
}

The aim of this review is to characterize the role of pressure solution creep in the ductility of the Earth's upper crust and to describe how this creep mechanism competes and interacts with other deformation mechanisms. Pressure solution creep is a major mechanism of ductile deformation of the upper crust, accommodating basin compaction, folding, shear zone development, and fault creep and interseismic healing. However, its kinetics is strongly dependent on the composition of the rocks (mainly the presence of phyllosilicates minerals that activate pressure solution) and on its interaction with fracturing and healing processes (that activate and slow down pressure solution, respectively). The present review combines three approaches: natural observations, theoretical developments, and laboratory experiments. Natural observations can be used to identify the pressure solution markers necessary to evaluate creep law parameters, such as the nature of the material, the temperature and stress conditions or the geometry of mass transfer domains. Theoretical developments help to investigate the thermodynamics and kinetics of the processes and to build theoretical creep laws. Laboratory experiments are implemented in order to test the models and to measure creep law parameters such as driving forces and kinetic coefficients. Finally, applications are discussed for the modelling of sedimentary basin compaction and fault creep. The sensitivity of the models to time is given particular attention: viscous versus plastic rheology during sediment compaction; steady state versus non-steady state behaviour of fault and shear zones. The conclusions discuss recent advances for modelling pressure solution creep and the main questions that remain to be solved.

Gratier, J-P., D. Dysthe, F. Renard, 2013 The role of pressure solution creep in the ductility of the Earth's upper crust. Advances in Geophysics, 54, doi: 10.1016/B978-0-12-3809407.00002-0. 


\section{1 - Introduction}

In order to investigate the role of pressure solution creep in the ductility of the Earth's upper crust the various mechanical behaviour patterns of the upper crust must first be discussed. Two types of approach can be considered on this topic.

1 - The mechanical behaviour of the upper crust is modelled using brittle theories, that include friction laws (Byerlee, 1978; Marone, 1998). This modelling approach is supported by two kinds of observations: (i) the maximum frequency of earthquakes is located within the first $15-20 \mathrm{~km}$ of the upper crust (Chen and Molnar, 1983; Sibson, 1982); (ii) laboratory experiments run at relatively fast strain-rates (faster than $10^{-7} \mathrm{~s}^{-1}$ ) indicate a transition from frictional to plastic deformation at pressure and temperature conditions appropriate for a depth of 10-20 km (Kohlstedt et al., 1995; Paterson, 1978; Poirier, 1985).

2 - Conversely, the behaviour of the upper crust is also modelled by ductile behaviour with creep laws (Wheeler, 1992). This modelling approach is supported by two kinds of observations: (i) geological structures exhumed from depth, such as compacted basin, folds and shear zones, and regional cleavage, indicate ductile behaviour throughout the upper crust (Argand, 1924; Hauck et al., 1998; Schmidt et al., 1996) (Fig. 1a); (ii) laboratory experiments run at very low strain-rates (slower than 10-

${ }^{9} \mathrm{~s}^{-1}$ ) with possible fluid rock interactions show that stress-driven mass transfer or chemical corrosion control the creep processes (Atkinson, 1984; Chester et al., 2007; Rutter, 1976; Spiers et al., 1990).

The two types of rheology do not occur over the same time scales. Fracturing, and more generally brittle deformation, mostly occurs over short time scales. Conversely, because they are most often controlled by stress-driven diffusive mass transfer and chemical effects, ductile processes in the upper crust take place over much longer time scales. Brittle and ductile mechanisms are very often spatially associated in the upper crust. For example, they occur in fault-related folds or along faults at the seismic to aseismic transition depth and they can strongly interact. It should be noted that ductile deformation within the entire upper crust mostly occurs near plate boundaries in collision (mountain ridges), and in transform (vertical shear) zones or extension zones (basins). A detailed discussion of why massive internal deformation develops throughout the upper crust in these particular zones is outside the scope of this review study. However, the main reason is probably that stress-driven mass transfer processes commonly associated with ductile deformation require the presence of fluids to relieve tectonic stress build-up efficiently, and these zones are likely to be the places where fluids circulate from depth (Kennedy et al., 1997; Kerrich, 1986; McCaig, 1988; Sibson et al., 



Figure 1: (a) Outcrop-scale markers of pressure solution creep (from right to left: impressed pebbles, stylolites, elongated belemnites and folded veins, pressure solution cleavage and veins in granite). These markers were formed through the entire upper crust of the French Alps mountain range, from 0 to 10-12 km depth. They now outcrop from the Pelvoux to Vercors massifs due to exhumation and erosion: light grey $=$ eroded part, medium grey $=$ present-day sedimentary cover, dark grey $=$ basement, blue = Trias; (b) competition between the three main deformation mechanisms in the crust in a strength versus depth diagram, adapted from (Gratier and Gamond, 1990; Kohlstedt et al., 1995): friction regime (blue curve), pressure solution creep (red curve, at a given strain rate of $10^{-14} \mathrm{~s}^{-1}$ ) and plastic deformation (green curve), high fluid pressure decreases the strength for friction.

1988). Even in these particular zones of upper crust ductile deformation, friction laws are often used to describe brittle to ductile transition from the upper crust to the lower crust (Fig. 1b). The brittle part implies a linear increase in strength with depth according to friction laws (Byerlee, 1978), up to 10-15 km (Fig. 1b). However, to fully model the ductile behaviour of the upper crust, stress-driven mass transfer creep laws (e.g. pressure solution) must be used, since it will be seen that this process is the one that most often accommodates ductile deformation. Such creep laws occur at much lower strainrate values and require much smaller differential stress values than friction (Cox and Etheridge, 1989; Gratier and Gamond, 1990) (Fig. 1b). Both brittle and ductile mechanisms are not very sensitive to the effect of temperature and both tend to disappear below 15-20 km depth where other temperatureactivated plastic mechanisms become dominant, such as dislocation glide processes (Poirier, 1985) (Fig. 1b).

As indicated above, there is very good evidence, from geological observations, that ductile deformation occurs through the entire upper crust, more or less closely associated with brittle deformation. Large-scale internal deformation is manifested by shearing and folding processes in collision and transformation zones and by compaction in sedimentary basins. Thanks to both uplift and erosion processes, deformation markers indicative of such ductile deformation from near the surface to 
several tens of kilometres depth can be seen directly on outcrops when going from foreland to hinterland in collision zones. An example of such ductile upper crust deformation can be found in a geological cross-section from foreland to hinterland in the French Alps (Fig. 1a). The same type of ductile deformation is found in the cross-sections of other mountains ranges (Hauck et al., 1998; Schmid et al., 1996; Yeats and Huftile, 1994).

The various types of pressure solution markers can be seen in the upper crust (Fig. 1a), now exhumed, such as impressed pebbles, aseismic sliding in faults, stylolites, solution cleavage associated with veins, in the folded and sheared sedimentary cover and basement. They are found ubiquitously from near the surface down to $10-15 \mathrm{~km}$ depth, reflecting the crucial role of this mechanism in ductile crustal deformation. It is also a major mechanism of compaction: mechanical processes alone cannot reduce the porosity to almost zero as often seen in sedimentary basins.

Pressure solution is a deformation mechanism where solid material in the presence of its solution fluid responds to applied non-hydrostatic stresses by dissolution in the zone of largest normal stress (pitted pebble, stylolite, cleavage), mass transfer in the fluid phase and deposition in the zone of smallest normal stress (pores, veins). It is therefore also known as dissolution precipitation creep. Such stress driven mass transfer around blocks, grains or elements of grains of various sizes (from microns to decimetres) enables major internal deformation to be accommodated in association with shearing and folding processes in the upper crust. The blocks and grains may slightly deform (see below) but most often they do not.

Several deformation processes could be candidates to accommodate strain in the upper crust.

- Fracturing is very common in the upper crust. However, rigid block sliding cannot accommodate large strain values unless the blocks are very small. In such a case intense fracturing may lead to cataclastic creep (or flow) (Hadizadeh et al., 1983) that can be seen in the form of intense, very localized deformation along some active faults. When blocks are larger, block rotation is often accommodated by pressure solution (stylolites or veins), see $\S 2$. Moreover, fracturing can boost pressure solution kinetics (Gratier et al., 1999).

- Stress corrosion may be an important process in time-dependent phenomena, for example in the initiation of earthquakes in the upper crust (Anderson and Grew, 1977). However while it may reduce the size of blocks, it cannot alone accommodate large deformations.

- Grain-boundary sliding in superplasticity processes (Ashby and Verrall, 1973; Konstantinidis and Herrmann, 1998; Wheeler, 2010), which can accommodate large strain values, is traditionally considered as a high-temperature mechanism when sliding is accommodated by diffusion at dry grain boundaries (Boullier and Guéguen, 1975). So it is not expected to be commonly found in the upper crust. However, it will be seen that pressure solution creep may accommodate grain boundary sliding when a trapped fluid phase activates diffusion along the grain boundary. In this case it is an efficient 
deformation mechanism in the upper crust since the activation energy of fluid phase diffusion is much lower that along dry grain boundaries (Fischer and Elliott, 1974).

- Conversely, the presence of a trapped fluid phase along grain boundaries, or in cracks, may promote grain boundary or crack healing (Hickman, 1989) that drastically inhibits the possibility of mass transfer by reducing the kinetics of stress-driven mass transfer such as pressure solution. The effect of such healing processes will be discussed. It will also be seen that the presence of phyllosilicates could prevent such healing and thus keep fast diffusive paths around the grains.

- Calcite twinning is an efficient intracrystalline deformation mechanism that develops at low shear stress with almost no temperature dependence, consequently it is commonly observed in the upper crust. However, twinning alone cannot lead to large strains because only one independent slip system is available (Burkhard, 1992). Observations show that incompatibilities at grain boundaries are most often eliminated by pressure solution on the grain scale.

- Other intracrystalline deformation mechanisms, such as dislocation glide processes, easy to recognize as they lead to the reorientation of the optical crystal axes (Poirier, 1985), cannot be seen at less than $400-500^{\circ} \mathrm{C}$ for most of the minerals of the upper crust so are more likely to be found in the lower crust.

In order to build and use pressure solution creep laws, three different approaches are needed that are successively presented in this paper:

- Thanks to observations of natural structures the deformation can be recognised and quantified and some key parameters of the creep laws evaluated (geometry of path transfer, temperature and stress conditions, nature of solid and fluid, etc.).

- A theoretical approach can be used to investigate the thermodynamics and kinetics of the processes (particularly the specific behaviour of fluid phase trapped under stress) and build theoretical creep laws.

- Laboratory experiments can be performed to test the models and to measure creep law parameters such as driving forces and kinetic coefficients. They also very often produce evidence of new phenomena that may lead to the development of new models.

Finally, applications are discussed for modelling sedimentary basin compaction and fault creep. The sensitivity of the models to time is particularly discussed: viscous versus plastic rheology during compaction of the sediment; steady state versus non-steady state behaviour of faults and shear zones. 


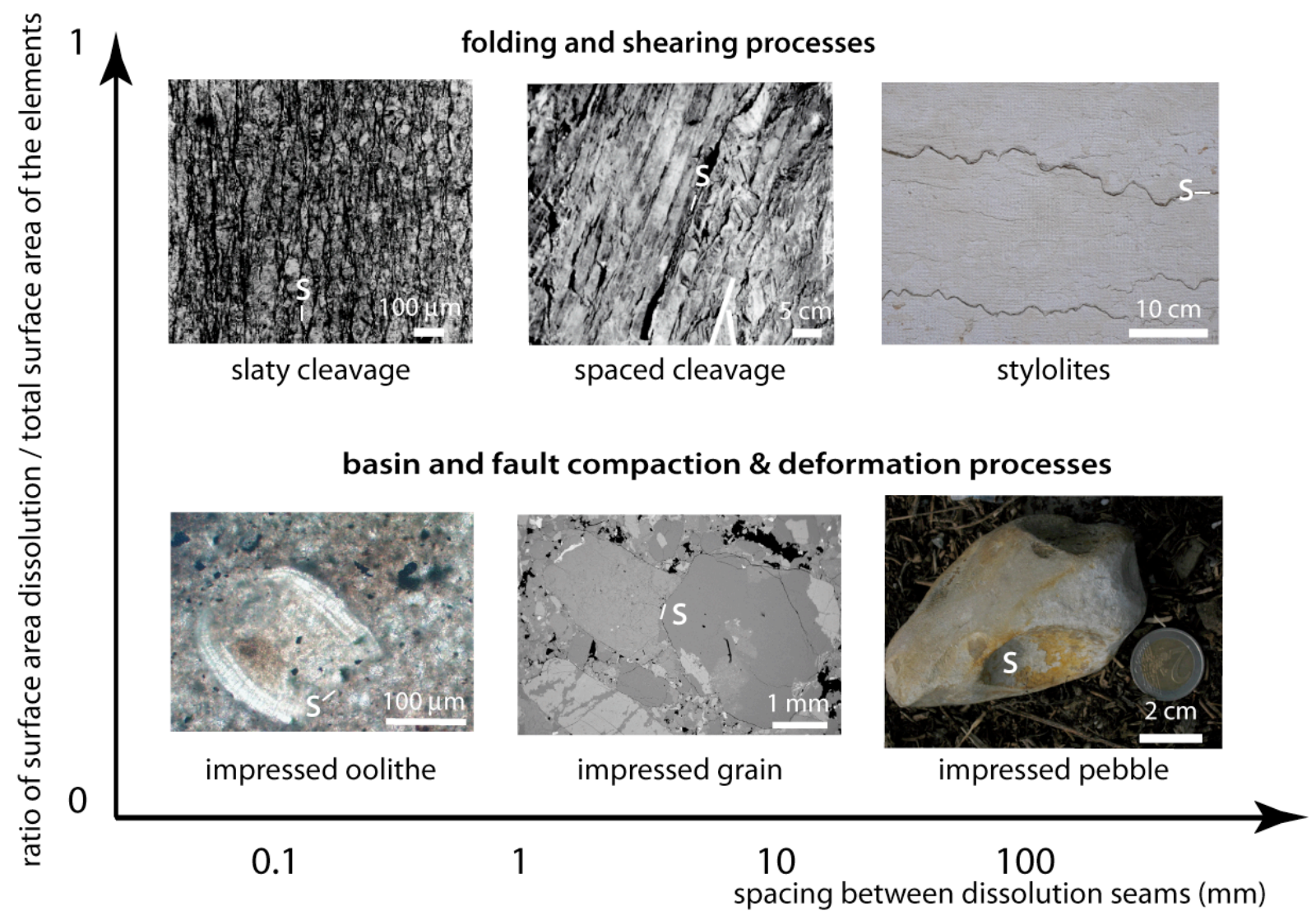

Figure 2: Classification of natural stress-enhanced dissolution patterns: dissolution seam (S) in a diagram showing the ratio of "surface area dissolution / total surface area of the elements" versus "spacing between dissolution seams": at low values of this ratio the change from grain dissolution to impressed pebbles can be seen; at the highest values the change from slaty cleavage to spaced cleavage to stylolites can be seen. All these markers are discussed in the text.

\section{2 - Natural pressure solution creep: description and quantitative analysis}

Identifying natural pressure solution implies evaluating both local volume loss in the dissolution zone and local volume increase in the deposition zone: the specific geometric and chemical methods involved are discussed in this review. It is also of major interest to evaluate the overall volume change at all levels from outcrop to basin and in the entire upper crust. This is why techniques for evaluating overall volume changes are also presented, mostly following the pioneering work of Ramsay (1967). In the first part of this study, criteria for recognizing natural pressure solution are presented together with the types of parameters that can be used to model the ductility of the upper crust. For this 
1

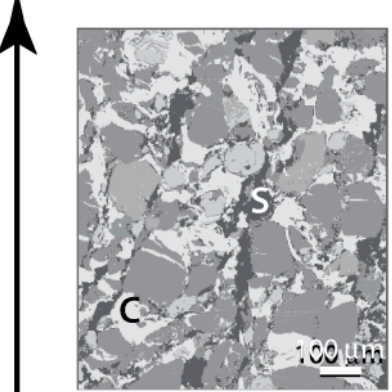

sealed fractures at all scales


\section{crystallizations at all scales in pressure shadow}
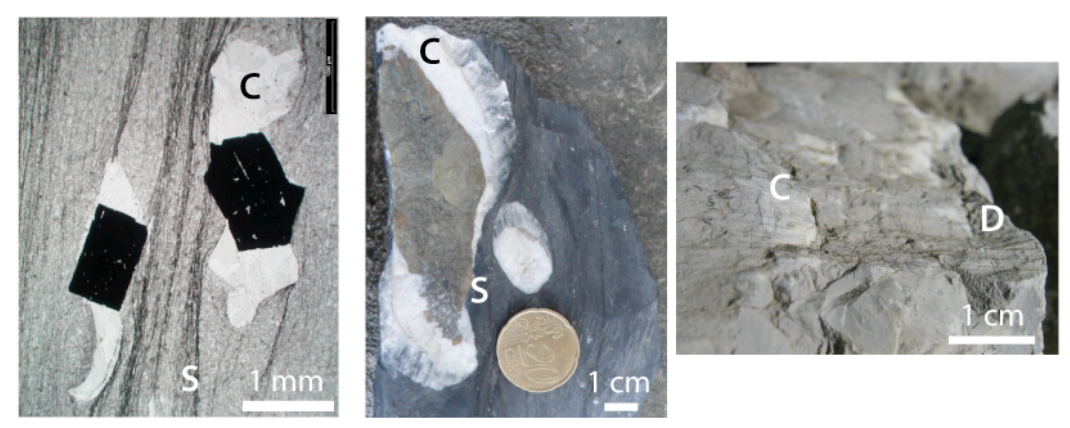

0

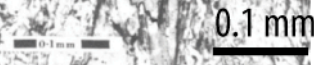

0.1

10

10000

width of deposition zones $(\mathrm{mm})$

Figure 3: Classification of natural deposition patterns: pressure shadow (C) and veins (V) in a diagram showing the ratio of "surface area of deposition / total surface area of the elements" versus "spacing between deposition zones": at low values of this ratio the change from grain size to pressure shadow and fibres $(C)$ vs dissolution (S) along faults can be seen, at the highest value the change from truncated belemnite to strata boudinage to hectometre veins $(V)$ can be seen. All these markers are discussed in the text.

purpose, the natural markers have to be classified. Two parameters can be combined to classify dissolution markers (Fig. 2):

- The degree of development of the dissolution zones, which can range from a single contact point to a planar surface. This is expressed by the ratio between the surface area of dissolution and the total surface area of the solid, and ranges from 0 to 1 .

- The spacing between the dissolution zones, which can range from grain size to much larger blocks (up to several metres).

This classification is used to present the natural markers of pressure solution. Then, for each of these markers, the manner in which associated deposition markers can be identified is discussed (Fig. 3). Similar parameters are applied: 
- The degree of development of the deposition zones, which can range from a deposition zone in pressure shadows at the grain scale to well-developed planar veins. This is expressed by the ratio between the surface area of deposition and the total surface area of the solid, and ranges from 0 to 1 .

- The spacing between the deposition zones, which can range from grain size to much larger blocks (up to several hundred metres).

Several different spatial scales are involved when observing natural pressure solution creep patterns. The aim of this Section is to help the reader answer several questions about pressure solution creep: How can pressure solution markers be recognized on the field? What are their common characteristics? Where can they be found? What pressure and temperature conditions are required for their development? What are their links with large deformation structures such as folds and faults? And finally, how can they be used to model the ductile behaviour of the Earth's upper crust?

The main types of natural pressure solution creep markers are described and, for each type, the geometry of mass transfer and key parameters of pressure solution creep laws that support the various pressure solution creep models are quantified.

\section{1 - Basic concepts}

Pressure solution creep is a stress-driven mass transfer process (Fig. 4a) that involves three kinds of parameters that will be described in more detail in Sections 3 and 4, but are presented here to better understand the use of natural pressure solution markers in order to model the ductile behaviour of the Earth's upper crust.

i) The driving force is the stress difference in chemical potential of the solid between the dissolution zone and the deposition zone, causing mass transfer through a fluid phase (Paterson, 1973; Weyl, 1959), (Fig. 4a).

ii) The kinetics of the pressure solution process implies three successive steps: dissolution, transfer and deposition (Fig. 4a). As in all en-serie processes, if the rate of a given step is much slower than the others, then it controls the rate of the entire process and corresponds to a specific creep law. Thismeans that several pressure solution creep laws are possible (Raj, 1982) depending on the limiting step.

iii) The mass transfer mechanism that carries the soluble species from dissolution to deposition sites controls the length scale of the process. In most pressure solution processes, one step of the en-serie process is diffusion through a fluid phase, which is trapped under compressive stress (Fig. 4b). There are two basic models of trapped fluid phases: either a thin fluid of some nanometres width (Renard and Ortoleva, 1997; Weyl, 1959) or an island-channel network (Lehner, 1990; Raj and Chyung, 1981; Spiers and Schutjens, 1990). The diffusion flux (product of the diffusion by the thickness of the 

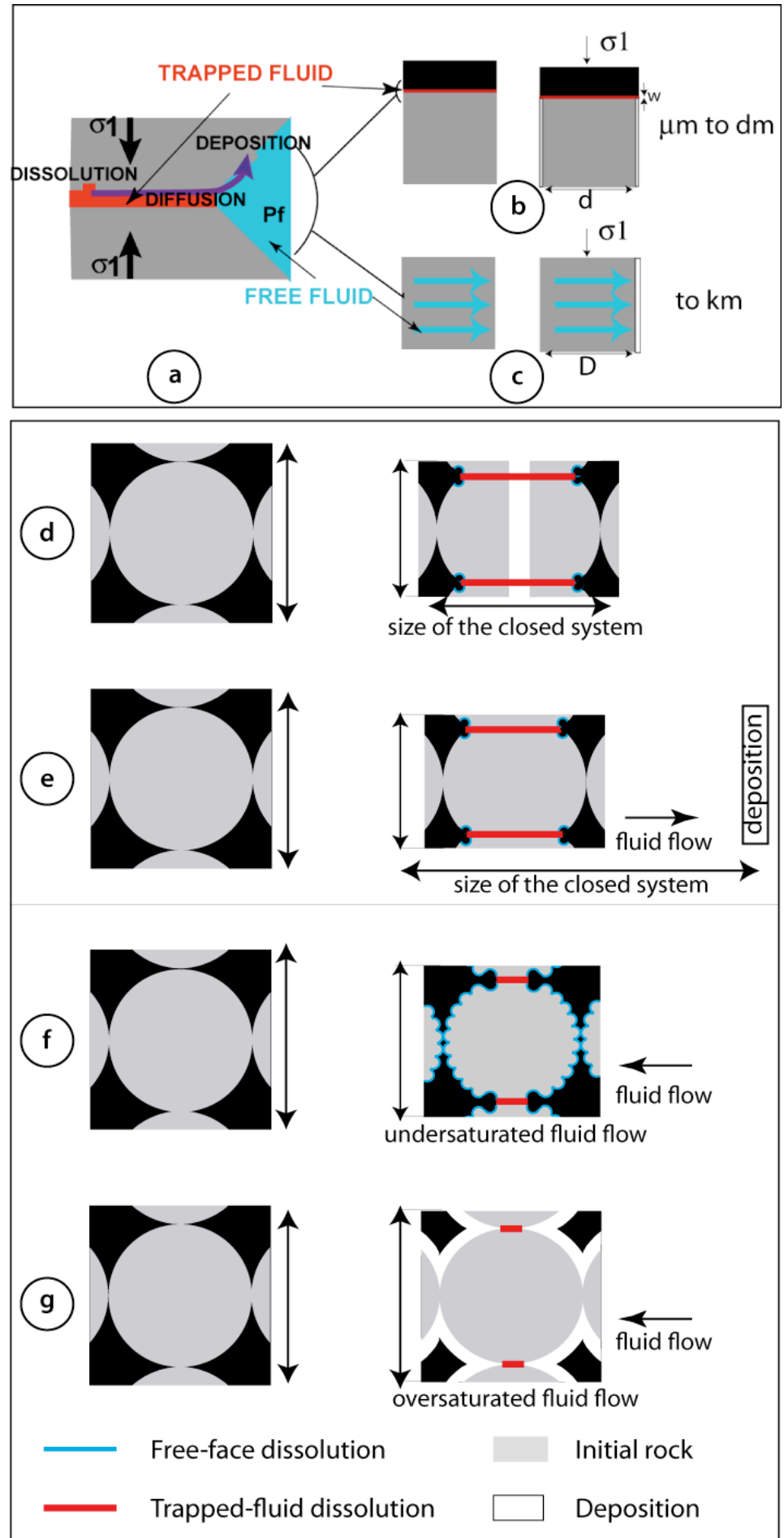

Figure 4: (a) Basic concept of pressure solution at the grain scale, with diffusive mass transfer along a confined trapped fluid phase of thickness $w$ (red), with diffusion along the trapped fluid: length $d$ (b), or with fluid advection along a distance $D(\boldsymbol{c})$. The normal stress on the grain boundary is $\sigma_{I}$ and the fluid pressure is $p_{f}$. Schematic representation of closed system at grain scale (d) with diffusion or at of larger size (e) with fluid advection. Schematic representation of the effect of undersaturated fluid (with free-face dissolution, $\boldsymbol{f}$ ) or of oversaturated fluid (with deposition, $\boldsymbol{g}$ ). 
diffusive pathway) along a trapped fluid phase is always very slow in contrast with diffusion flux in a free fluid with large pores or open fractures that may be part of the diffusive path (with a much larger width of the diffusive pathway). In this case, the length of the trapped fluid phase (thin fluid and/or island-channel network) is the key parameter that may control the kinetics of the pressure solution process and that appear in the creep law as the mass transfer distance (noted $d$ in the figures and later in the text). Moreover, the free fluid in the pores and fractures may even move and fluid advection may carry the soluble species kilometres away from the dissolution zone. Therefore, it is worth evaluating the size of the closed system, or in other words the size of the system for which the amount of dissolution is equal to the amount of deposition. This size depends on the possibility of mass transfer away from the dissolution sites. This ranges from micrometres to kilometres (Fig. 4b-c).

According to the creep laws derived from thermodynamic and kinetic analysis (Section 3) and tested under laboratory conditions (Section 4), several creep law parameters can be measured in the field from the analysis of natural deformation (this Section):

- The stress orientation and deformation path are deduced from the orientation of the structures. The value of stress, which is of course a key parameter for all the creep laws, may be evaluated from the geometry of the dissolution structure, e.g. stylolite roughness or cross-over of successive cleavages.

- The solubility of the solid in solution is also a key parameter and may be evaluated from the nature of the dissolved mineral, the pressure and temperature conditions of deformation and the composition of fluid inclusions trapped in the veins associated with solution seams.

- The mass transfer distance, which appears in creep laws, may be given by the spacing between fractures or the grain size.

- The size of the closed system gives an evaluation of possible mass transfer away from the dissolution sites (Fig. 4d-e).

- Finally, in case of fluid advection, the fluid saturation is not necessarily in equilibrium with the solid: non-equilibrium may drive chemical reactions that combine with the stress effect (Lehner, 1995). However, the kinetics of the fluid-rock reactions are faster on the free faces than on the faces under stress. This is because the flux of matter along a fluid phase trapped under stress is the product of the diffusion times the thickness of the path and because this path is most often very thin (some nanometres) versus the thickness of the paths of free fluid. Consequently, evidences of fluid reaction are likely to be seen on the free faces on the natural structures either as dissolution (indicating undersaturated fluid, Fig. 4f) or deposition (indicating oversaturated fluids, Fig. 4g). Such reactions modify the porosity of the rocks.

Unless it were possible to precisely date syn-deformation growth of associated precipitated minerals and consequently the duration of tectonic phases, which is not currently the case yet, there cannot be 
any access to the kinetic parameters (reaction rate, diffusion rate, strain rate) of the creep laws from the observation of natural structures. At the present time, we must rely only on laboratory data in order to evaluate such parameters (Rutter, 1976), see Section 4. However, new methods for the absolute dating of tectonic minerals might help in the future evaluation of such kinetic parameters from natural structures. Such methods include either paleomagnetic measurements (Piper et al., 2007) or radiogenic dating such as U/Th (Gratier et al., 2012; Watanabe et al., 2008) and Rb/Sr (Muller et al., 2000).

A discussion is given below of how to recognize pressure solution markers in the field and how to deduce the values of creep law parameters and the finite deformation that they are able to accommodate. However, the first general problem is to know how mass transfer and volume changes may be revealed and evaluated for all these geological markers.

\section{2 - How to reveal pressure solution deformation and evaluate volume change?}

The problem that arises when trying to observe pressure solution patterns is that when a mono-mineral rock dissolves in solution, no trace of the dissolution process is left. Stress-driven pressure solutions may be revealed by the observation of some specific geometry of the dissolution contacts such as a succession of interpenetrations that define stylolite surfaces. But this is not always the case and, anyway, at grain scale undulating contacts may also develop with other mechanisms such as recrystallization processes. The only case where it is possible to reveal dissolution without any doubt is when it occurs in a poly-mineral rock that contains soluble and insoluble species. In this case, the passive concentration of the insoluble species reveals mass transfer in a deformed (exposed) zone if this zone can be compared with a zone that has been relatively protected from the deformation. For example, mass transfer may be demonstrated by a variation in chemical content of rocks across a heterogeneously deformed zone (Gratier, 1983). Chemical composition differences are observed in a layer that has been cut by a normal fault, and composed of both soluble (calcite and quartz) and insoluble (illite) minerals (Fig. 5a-b). This behaviour can be explained as follows. Before faulting, the chemical composition and density of zones A \& B were the same: it is the same sedimentary layer. During the slow displacement of the fault, soluble species were removed from the "exposed" zone B leading to a concentration of insoluble species in this zone and thus to a difference in chemical composition between the two zones A \& B. Schematically, the relative mass balance $\Delta M / M_{o}$ can be calculated using the passive concentration of insoluble minerals due to dissolution in the exposed zone (B) compared with the (relatively) protected zone (A):

$$
\Delta M / M_{0}=\left(I_{p} / I_{e}\right)-1,
$$

$I_{p}$ and $I_{e}$ being the concentration of all insoluble minerals in the protected and in the exposed 

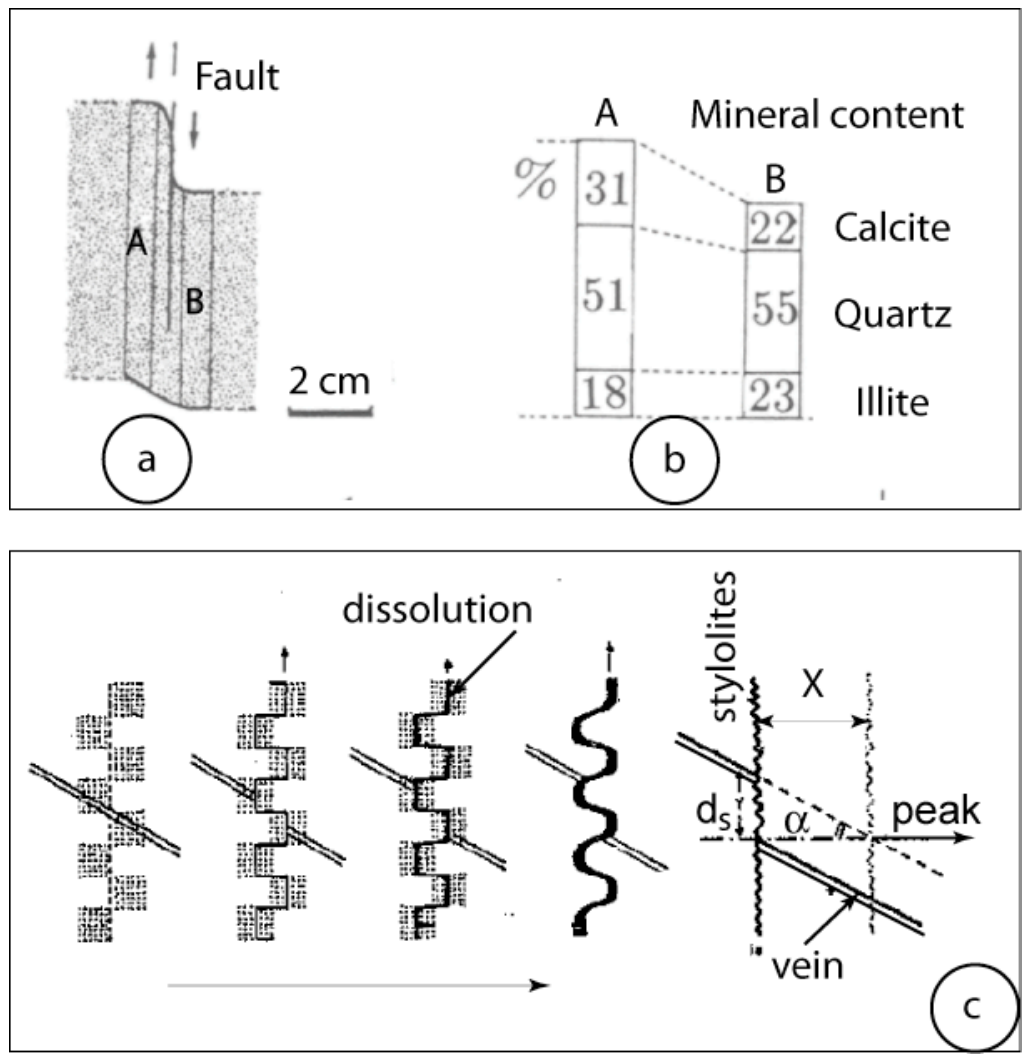

Figure 5: (a) Example of pressure solution mass transfer along the same initial layer due to normal faulting; (b) comparison of the mineral composition in the protected (A) and in the exposed (B) zones, adapted from (Gratier and Gamond, 1990); (c) use of the apparent shift in vein (ds) along dissolution seams to evaluate the amount of dissolution $X=d_{s} \tan (\alpha)$.

zones respectively, and $M_{o}$ the mass of a representative elementary volume before deformation. Following the same mass balance approximation, the mass decrease of each soluble mineral in the dissolution areas is:

$$
\Delta M_{m} / M_{m_{o}}=\left(I_{p} / I_{e}\right)\left(S_{e} / S_{p}\right)-1,
$$

$S_{p}$ and $S_{e}$ being the percentage of each soluble mineral in the protected and in the exposed zones, respectively (Gratier et al., 2003). The volume change may also be calculated if the difference in density between the two parts of the rock is known (Gresens, 1967). Applications of such mass balance calculations can be seen for the various pressure solution markers. For an open system, the protected zone is the true initial (undeformed) zone (Eqs. 1\&2). For a closed system, the dissolved mineral in the exposed zone may precipitate in the protected (Eqs $3 \& 4)$. In such case:

$$
\begin{aligned}
& \left.\Delta M / M_{o}=\left(\left(I_{p} / I_{e}\right)-1\right) /\left(I_{p} / I_{e}\right)+1\right), \\
& \Delta M / M_{o}=\left(\left(I_{p} / I_{e}\right)\left(S_{e} / S_{p}\right)-1\right) /\left(\left(I_{p} / I_{e}\right)\left(S_{e} / S_{p}\right)-1\right) .
\end{aligned}
$$


.The only limitation of such a method is to be sure that other mass transfer processes have not modified the mass balance. One can think of metamorphic or diagenetic processes that involve volume changes (dehydration or phase transformation). However, such processes may occur without changing the calculation if the associated mass transfer distance is smaller than the mean transfer distance associated with pressure solution. This must be verified carefully in the field (Wintsch et al., 1991).

A geometric method used to determine the amount of dissolution of any localized dissolution seam (stylolites or spaced cleavage) involves the measurement of the apparent displacement of veins due to the dissolution. The principle is explained in Fig. 5c. The progressive dissolution leads to an apparent shift of the veins $\left(d_{s}\right)$. The dissolved width $X$ is equal to the product of the measured shift $\left(d_{s}\right)$ by the tangent of the angle of the veins with the solution seam. It is often convenient to use conjugated veins in two directions in order to avoid confusion with a fault shift.

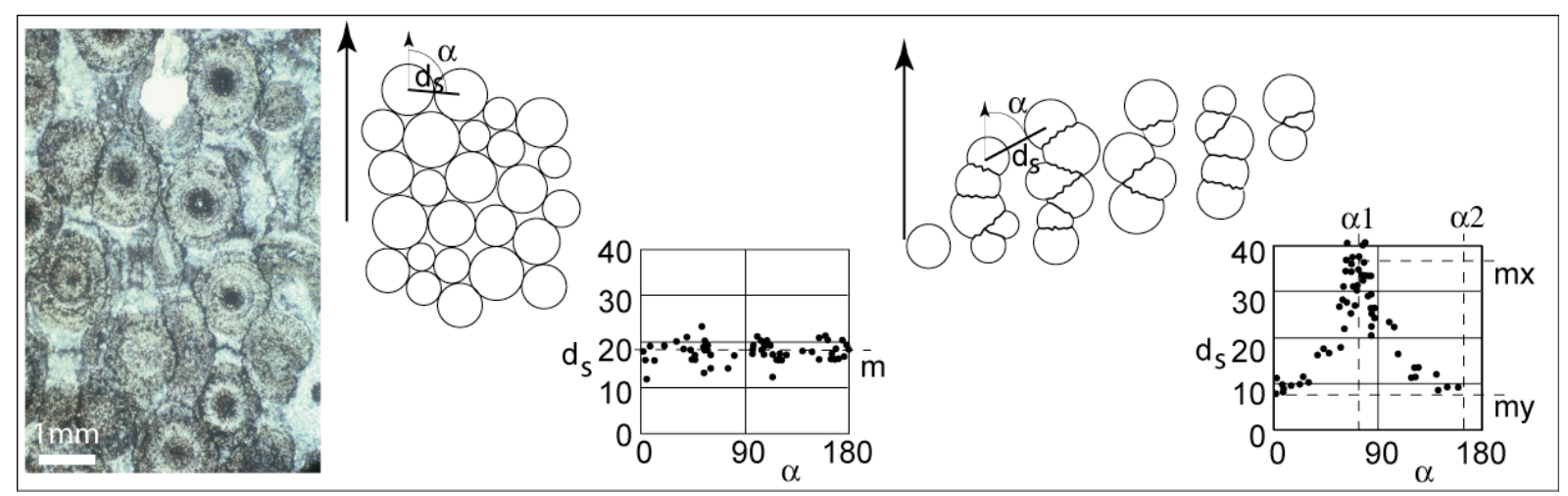

Figure 6: The centre-to-centre technique to evaluate strain and volume change values from oolites deformed by pressure solution. The distance $d_{s}$ between couples of oolites is plotted against the angle $\alpha$ between a given direction and the segment between the centre of the two oolites, adapted from (Ramsay, 1967).

Another very convenient method to quantify pressure solution mass transfer is to evaluate the way in which the centres of particles, for example oolites, have been displaced relative to each other (Ramsay, 1967). In Fig. 6, a section through an undeformed rock, with uniform spherical oolite distribution, is compared with a section that has been deformed by pressure solution of the oolites. A line is drawn joining the centres of any two adjacent circular oolite sections; the distance is measured and plotted versus the angle with a fixed azimuth of the thin section. In undeformed material, the points on the graph would scatter along a certain mean distance that depends on the size distribution of the oolites. When the material is deformed, the distance between the oolites is modified and the plot shows a distribution with a peak, which is proportional to the amount of longitudinal strain. From the graph of Fig. 6, the direction of maximum and minimum extension $m$ can be determined and the ratio 
between the principal strains $(m X / m Y=X / Y)$ is obtained by measuring the distances $m X$ and $m Y$. If the original size and distribution of the oolites are known, or if it is possible to restore the deformed shape of the oolites to their initial shape, the value of $m$ can be determined and the two principal quadratic extensions calculated: $\lambda=\left(l_{x-z} / l_{0}\right)^{2}$. Fry (1979) proposed another centre-to-centre technique that gives directly the strain ellipse in favourable conditions.

Finally, and from a more general point of view, any geometric method that allows mass or volume change to be evaluated may be used to estimate the amount of mass transfer by pressure solution - see (Ramsay, 1967) for a thorough presentation of most of the possible methods. Methods worthy of mention are the measurement of angle change of fossils (Fig. 7a), or the measurement of line length changes in stretched fossils and folded veins (Fig. 7b). An example is given in Fig. 7c of the use of angles changes in a shear zone (Ramsay, 1980b). It is then possible to plot the volume change as a function of the change in finite deformation value in a Flinn diagram modified by Ramsay and Wood (1974), see Fig. 7d.
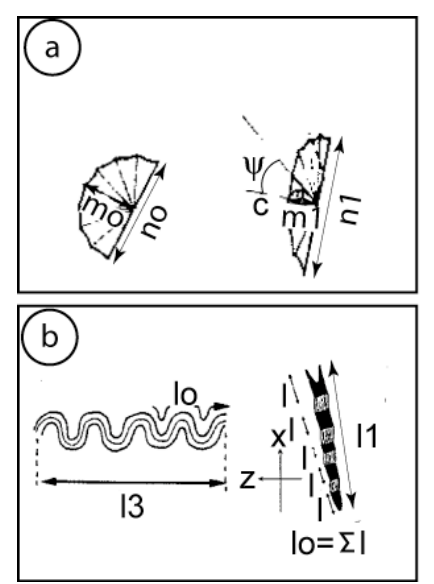
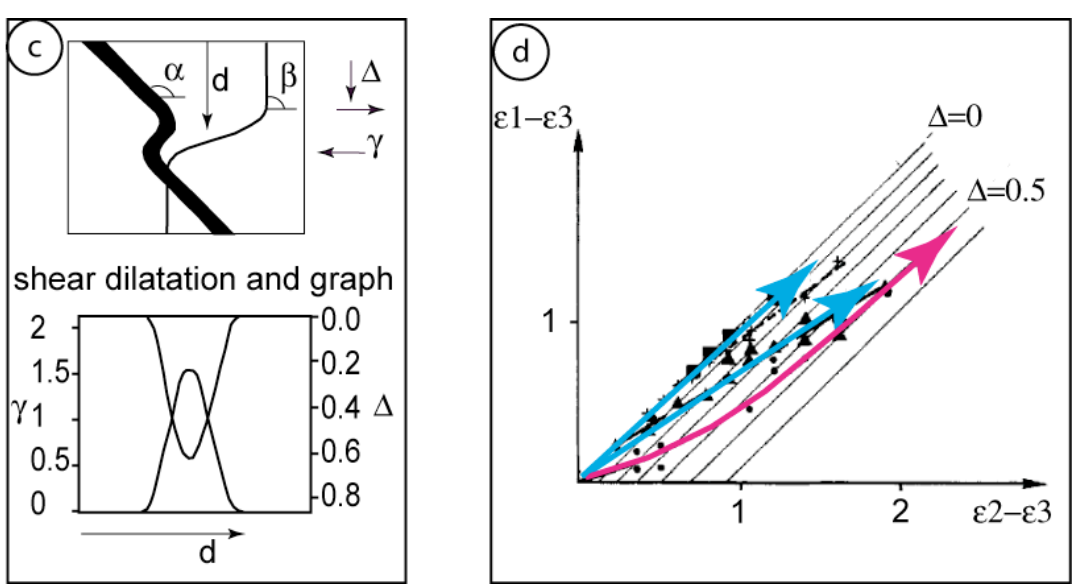

Figure 7: Various techniques for calculating strain and global volume change values by pressure solution from deformed rocks: (a) change in angle of fossils $(\psi): m_{o}, n_{o} \& m_{1}, n_{1}=$ initial and final length; (b) change in line lengths (ptygmatic fold and truncated belemnites) $l_{o} \& l_{l}=$ initial and final length, $Z \& X=$ principal strain axes; (c) change in angle in shear zones $(\alpha, \beta), \Delta \& \gamma=$ volume and shear values; (d) graphical plot of finite deformation $\left(\varepsilon_{1}=\int_{l_{0}}^{l_{1}} d l / l\right)$ showing various paths of volume change from the top to bottom layers of Fig. 22. Adapted from (Ramsay, 1967; Ramsay and Wood, 1974)Contrary to dissolution, precipitation is much easier to identify and quantify. Cathodoluminescence techniques, for example, have been used extensively to distinguish successive deposition phases (Marshall and Mariano, 1988; Milliken, 1994; Shimamoto et al., 1991).

\section{3 - Impressed pebbles and grains with associated veins}


Impressed pebbles in limestone rocks were among the first markers of pressure solution ever described, for example by Sorby (1865) in the molasse conglomerates of the Alpine foreland. Limestone pebbles originating from the erosion of alpine relief were deposited in foreland basins and pressed together due to alpine tectonic stress (Fig. 1a). The process began several millions years ago and is still active. The impressed pebble presented in Fig. 1a was found outcropping in presently deforming Quaternary formations in the external French Alps mountain range. The same mechanism is described in other collision zones (Mosher, 1976). Pressure dissolution markers are observed at the surface of the limestone pebbles as pits of varying size, from a few millimetres to several centimetres, due to stress-enhanced dissolution on contact with another pebble. This shows that stress dissolution processes may occur at very shallow depth (less than one hundred metres deep). This indication of the pressure-temperature conditions for pressure solution development demonstrates that, at least for limestone, this process does not require a minimum temperature or confining pressure to develop.

The same stress-driven dissolution process also occurs at the grain scale through the entire upper crust. When considering polycrystalline grains, it can be shown by chemical measurements that the depletion in soluble minerals leads to the passive concentration in relatively insoluble minerals. For example, in Fig. 8a, maps of chemical composition at grain contacts are displayed and show the distribution of elements on thin rock sections. Several Ca-Na-feldspar grains were dissolved against a quartz grain in the damaged zone of the San Andreas Fault at a depth of about $3 \mathrm{~km}$ (samples collected from SAFOD borehole). Stress-driven dissolution is demonstrated here by the dissolution (depletion) of $\mathrm{Ca}$ and $\mathrm{Na}$ within the grain contacts along a pressure solution seam associated with horizontal contraction, whereas $\mathrm{K}, \mathrm{Mg}, \mathrm{Fe}, \mathrm{Ti}$ (phyllosilicates, $\mathrm{Fe}$ and $\mathrm{Ti}$ oxides, sulphur) are passively concentrated (Fig. 8a). There is no evidence here of redeposition: fluid flow carried the soluble species away from the dissolution zone. The same mass transfer process around grains occurs at greater depth, for example (Fig. 8b) in metamorphic conditions at about $13 \mathrm{~km}$ depth (Elliott, 1973). Another example is the dissolution of oolites by pressure solution, allowing the strain value and possibly the volume change to be clearly quantified (Ramsay, 1967) (Fig. 6).

\subsubsection{Nature and volume of dissolved minerals}

The nature of minerals that can be dissolved under stress has been investigated by Heald (1955) and Trurnit (1968) who proposed a scale of mobility. However, great care must be taken with such a rule because the solubility of minerals under stress strongly depends on the thermodynamic conditions. For example, at $25^{\circ} \mathrm{C}$ the solubility in water decreases from halite to gypsum, calcite, feldspar and quartz. Conversely, at $300^{\circ} \mathrm{C}$ feldspar and quartz have a much higher solubility than calcite or dolomite and are therefore much more mobile under stress. The amount of dissolved species is determined using Eq. (1). 



Figure 8: (a) Maps showing the constrasting behaviour of chemical elements in sandstones of the San Andreas creeping fault: either soluble ( $\mathrm{Al}, \mathrm{Ca}, \mathrm{Si}, \mathrm{Na}$ ) or insoluble (passively concentrated, $\mathrm{K}, \mathrm{Fe}, \mathrm{Ti}$ ) adapted from (Gratier et al., 2011); (b) Remnant of clastic grain dissolved by pressure solution with preserved boundary of dust rings, adapted from (Elliott, 1973); (c) dissolution of fracturated grains; (d) dissolution of a fractured pebble, adapted from (Mc Ewen, 1981).

\subsubsection{Effect of the fracturing of grains and pebbles}

Mc Ewen (1981) showed how the development of different types of fracture is related to the dissolution of pebbles, either localized along the contact or affecting a large volume of the pebble, depending on the mineralogy, the strength of the matrix and the amount of deformation suffered by the conglomerate. Evidence of the interaction between fracturing and grain dissolution is seen everywhere (Fig. 8) and may even be demonstrated experimentally (see Section 4). The role of fracturing is to open paths for diffusion and precipitation sites. In this case the mass transfer distance, that can be the limiting step for deformation (see Section 3), is the distance between the fractures since the diffusive flux through the fluid in open fractures is several orders of magnitude larger than along the trapped fluid phase. However, if the fractures are progressively sealed, this effect slowly disappears as sealing 
increases the mass transfer distance and consequently reduces the displacement rate (Renard et al., $2000 \mathrm{~b}$ ) and finally closes the open paths for fast diffusion. So another idea is that pressure solution, at least when activated by fracturing, is not necessarily a steady state process but more a cyclical process: fracturing activates the creep rate, fracture sealing progressively reduces this rate (Gratier et al., 1999).

\section{4 - Stylolites with associated veins}

Stylolites are rock-rock surfaces of localized dissolution that are well known since (Sorby, 1863) who rightly interpreted these structure as being linked to a stress-driven process, which was almost about the same time as the theoretical study by Gibbs (1877). Historical studies of stylolites are given in several papers such as (Bathurst, 1971; Dunnington, 1954; Kerrich, 1977; Park and Schot, 1968; Stockdale, 1922). Stylolites exhibit complex mutual column-and-socket interdigitation at millimetre to centimetre scale but they extend laterally for tens to hundreds of metres. They are often parallel to the bedding (Fig. 9a) and the stylolitization process during diagenesis of the sediments may considerably change the shape and reduce the thickness of a sedimentary body (Baron and Parnell, 2007; Bathurst, 1971; Ehrenberg, 2006; Tada and Siever, 1989). They can also be linked to tectonic processes (Fig. 10 a-c) and cut across bedding (Arthaud and Mattauer, 1969). Bedding-parallel stylolites can predate or postdate transverse stylolites that they intersect, illustrating that bedding-parallel stylolites can also be of tectonic origin (Andrews and Railsback, 1997) for example associated with folding processes that most often reinforce initial diagenetic stylolites or solution seams. Stylolite seams are often highlighted by a thin concentration of darker material, usually assumed to be insoluble material but at least in some cases shown to be authigenic (Merino et al., 1983; Thomas et al., 1993) or even post deformation mineralization (Gratier, 1979; Sinha-Roy, 2004).

\subsubsection{Nature and amount of dissolved minerals}

Stylolites occur most often in sets, in carbonates and other essentially soluble rocks including mainly calcite but also dolomites (Carrio-Schaffhauser et al., 1990; Ebner et al., 2009; Ebner et al., 2010b; Karcz and Scholz, 2003; Pennock et al., 2006), quartz (Heald, 1955; Wangen, 1998; Weibel and Keulen, 2008), feldspars (Thomas et al., 1993), gypsum and halite (Bauerle et al., 2000). Therefore, stylolites play an important role in compaction and in creep processes and therefore in the rheological properties of the upper crust (Dewers and Ortoleva, 1990). It is also often considered that the maximum length of the stylolite peaks gives an indication of the dissolved part. However, this is not a very accurate method since the passive concentration of insoluble species most often tends to smooth the dissolution surface and because the roughness of the surface can grow non-linearly with time 

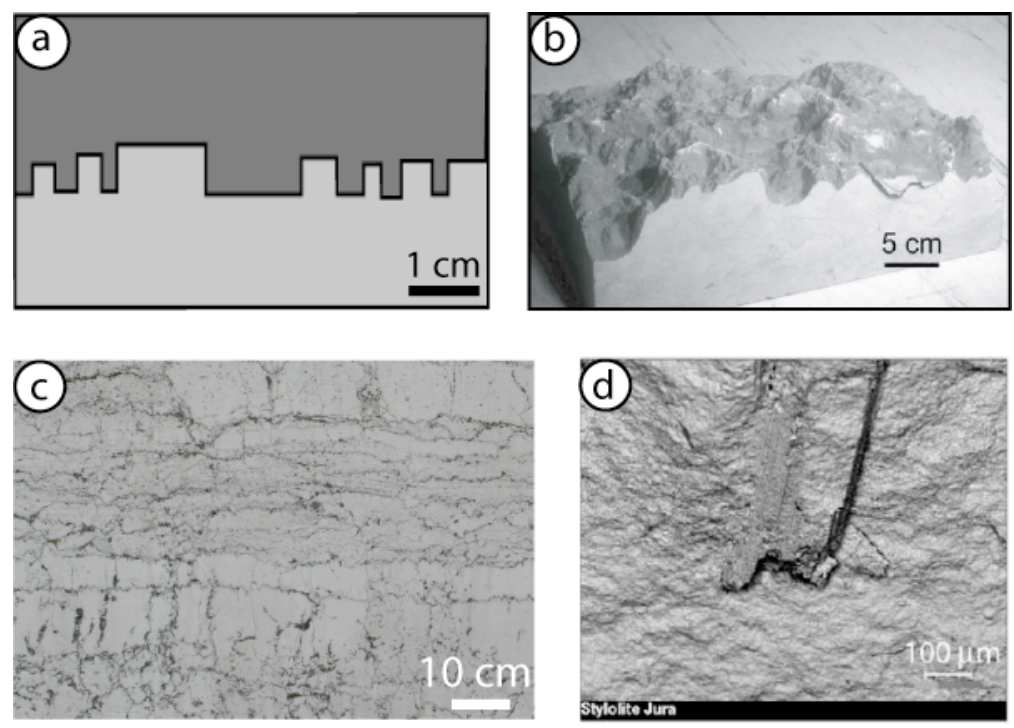

Figure 9: Various morphologies of stylolites: (a) contact between two different layers showing square patterns; (b) open stylolite surface in limestone; (c) dense arrays of stylolites with various spacings; (d) stylolite peak bounded by microfractures.

(Schmittbuhl et al., 2004). Quantifying the nature and amount of the dissolved matter at stylolite level is much more reliable as it is based on the methods presented previously. For example, when using geometric markers (Figs. 5, 7), it can be shown that a dense network of stylolites in marble may be associated with a degree of shortening as high as $50 \%$ (Gratier, 1976). Other such high values up to 50 to $60 \%$ have been evaluated in North Sea chalk and from the absence of visible veins (Safaricz and Davison, 2005) this dissolution was interpreted as being linked with a large amount of fluid in an open system. It should be noted, however, that veining in chalk may exist even if it is difficult to image, see Fig. 10b (Hellmann et al., 2002a). In most cases, veins associated with stylolites represent only a small part of the dissolved and redeposited volume. This is probably because stylolites, especially diagenetic stylolites, develop in relatively high-porosity rocks so that mass transfer away from the dissolution seams may be relatively easy either by diffusion in the free fluid of the pores or even by fluid advection.

\subsubsection{Relation between stylolite geometry and stress magnitude}

It is generally considered that the principal maximum compressive stress is parallel to the stylolite peaks (Koehn et al., 2007). However, this can only be true in the case of co-axial deformation. Actually, natural observation of stylolite peaks indicates the incremental displacement of the two serrated blocks. It can be seen in Nature that there is a continuous transition between (i) stylolite surfaces orthogonal to the displacement direction; (ii) slickolite surfaces orthogonal to the displacement direction; and (iii) solution striations parallel to displacement (Simon, 2007). The 


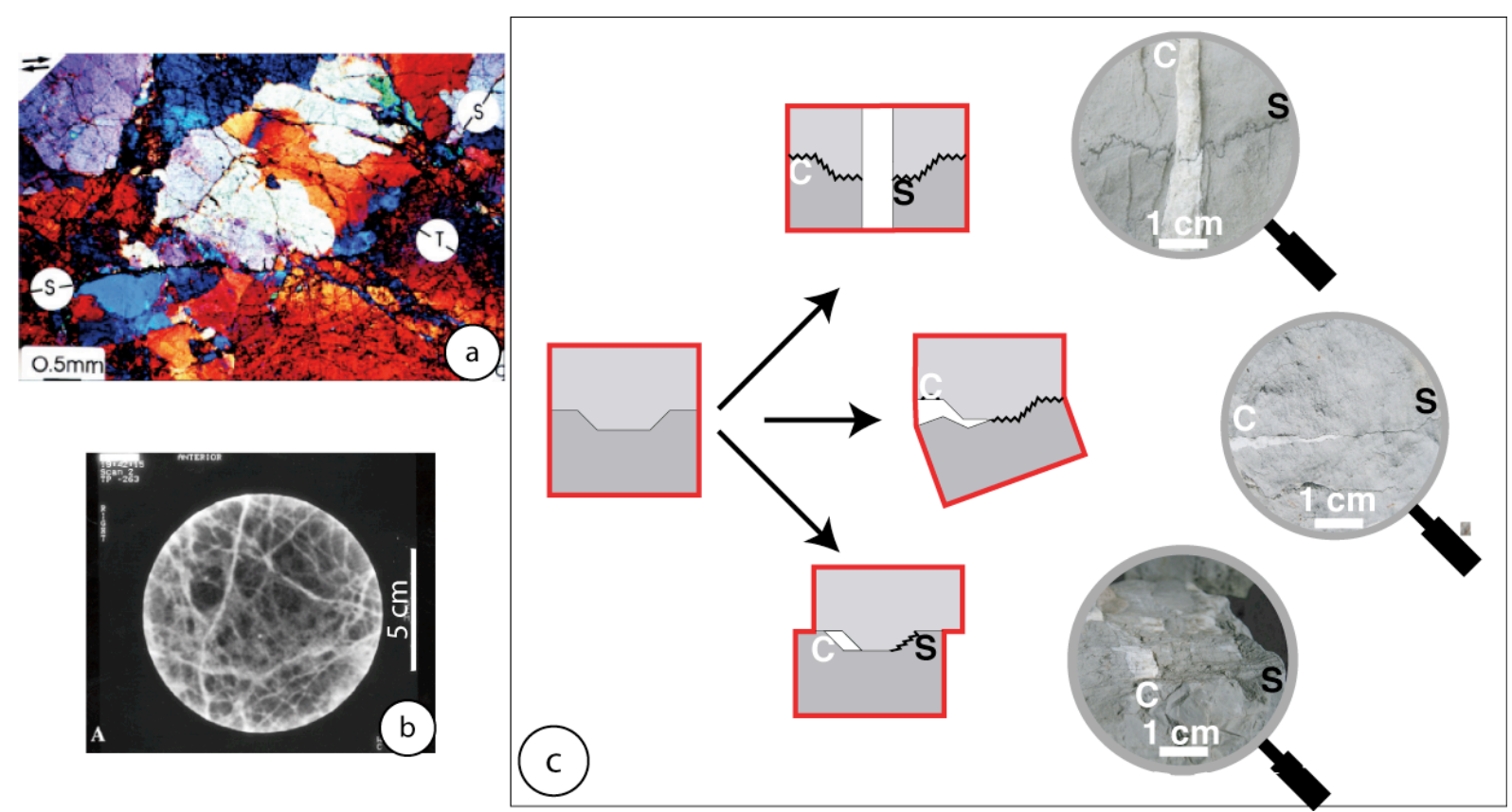

Figure 10: Interaction between fractures and stylolites: (a) stylolites $(S)$ and fractures $(T)$ in granite in the damaged zone of the San Andreas Fault, adapted from (Renard et al., 2000b); (b) sealed fractures in a chalk core sample revealed by X-ray computed tomography, adapted from (Hellmann et al., 2002a); (c) various geometries of mass transfer from stylolite (S) to veins $(C)$ allowing flattening, rotating, or shearing deformation and more generally accommodating folding processes as in the Vercors - Chartreuse massifs (see also Fig. 1).

relation between stylolite geometry and stress orientation is easier to visualise in laboratory experiments with the transition between stylolite and slickolite surfaces (Gratier et al., 2005), where all the peaks are parallel to the imposed maximum compressive stress in a co-axial regime (Fig. 11a). However, this experiment also shows that solution striations may develop obliquely to the maximum compressive stress in the same regime in case of grain rotation (Fig. 11b).

It even seems possible to evaluate the paleo-stress value associated with stylolites from a roughness statistical analysis (Fig. 12a-b). Analysis of stylolite roughness shows that these structures have a fractal morphology over 4 - 5 orders of magnitude in spatial bandwidth, with an average fractal dimension D (obtained by spectral and scaled windowed variance analyses) clustering at 1.5 (Karcz and Scholz, 2003), 1.3 (Drummond and Sexton, 1998) or 1-1.3 (Hassan et al., 2002). High resolution measurements at laboratory scale (Renard et al., 2004b; Schmittbuhl et al., 2004) showed an even more complex roughness (Fig. 12c). Stylolite topography was shown by these authors to be described by two self-affine scaling invariance regimes. They used the Hurst exponent $(\mathrm{H})$, which is linked to the fractal dimension $(D)$ as $D=2-H$. At large length, the Hurst exponent is equal to 0.5 and very different from its value at small length, which is close to 1 . A crossover length scale at around $1 \mathrm{~mm}$ 

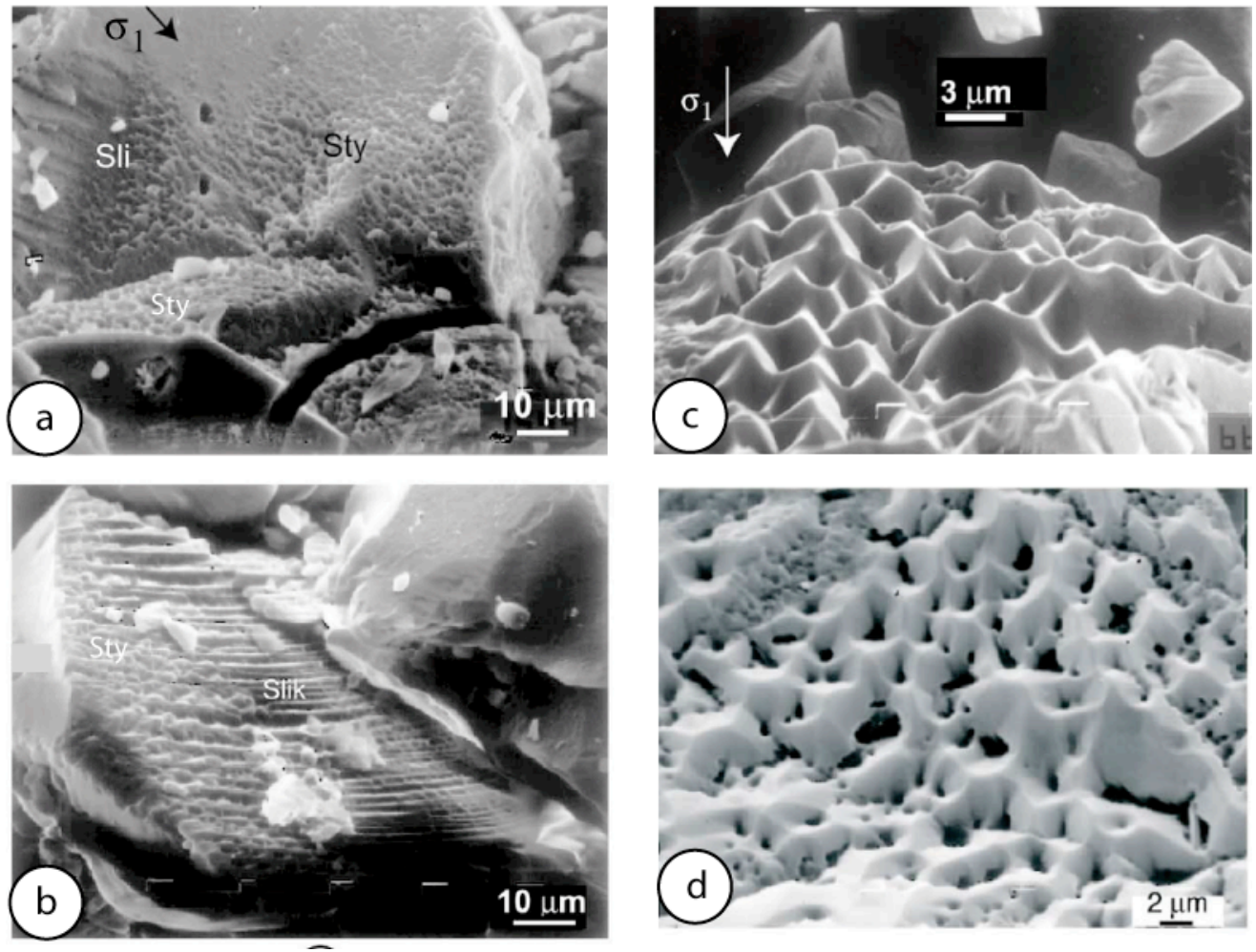

Figure 11: Experimental micro-stylolites on quartz grains: (a) microstylolites (Sty) and slickolites (Sli) with peaks and spikes parallel to the maximum compressive stress; (b) microstylolites changing to solution striation (Slik) due to grain rotation; (c) microstylolite peaks in quartz; (d) evidence of dissolution pits developed in front of each microstylolite peak, see also Fig. 30g; adapted from (Gratier et al., 2005).

( $\mathrm{L}_{\mathrm{c}}$ on Fig. 12c) is well characterized and depends on the stress magnitude (Schmittbuhl et al., 2004). These measurements are consistent with a stochastic differential equation model that describes the growth of a stylolite surface as a competition between stabilizing long-range elastic interactions at large scales or local surface tension effects at small scales and a destabilizing quenched material disorder due to the presence of heterogeneities in the rock. Consequently, (Renard et al., 2004b; Schmittbuhl et al., 2004) proposed a model postulating that the complex interface morphology is the result of competition between the long-range elastic redistribution of local stress fluctuations, which roughen the surface, and surface tension forces along the interface, which smooth it. This model was also applied, using discrete element modelling, to show how the roughness of the stylolites could be related to the amount of heterogeneities in the rock and the state of stress (Ebner et al., 2009; Koehn et al., 2007). Experimental stylolites show that, at small scale, the quenched material disorder could be the presence of dislocations, see Fig. 11d (Gratier et al., 2005). The model also predicts the dependence of the crossover length scale on the mechanical behaviour of the rock. According to this idea, the stylolite morphology contains a signature of the stress field during formation and could thus 



Figure 12: Analysis of stylolite roughness: (a) open stylolite surface in a limestone from the Vercors mountains, France; (b) cross-section of stylolites showing roughness at all scales, adapted from (Renard et al., 2004b); (c) average wavelet spectral decomposition of stylolite roughness showing two fractal regimes and a crossover length scale $L_{c}$. The data for 4 stylolites (S12A, S12B, S15A, SJura) are represented, adapted from (Schmittbuhl et al., 2004).

be used as a paleo-stress gauge of deformation processes in the upper crust (Ebner et al., 2010a; Ebner et al., 2010b). This is a crucial parameter of creep laws. Alternatively, it has also been suggested that the roughening could emerge from stress induced instability (Bonnetier et al., 2009).

A statistical method based on a non-stationary Gaussian model, to estimate the roughness of the profiles and quantify the heterogeneity of stylolites, could also lead to classification of the stylolites in two families: those for which the morphology is homogeneous everywhere, and those with alternating regular and irregular portions (Brouste et al., 2007).

\subsubsection{Effect of fracturing on stylolite dissolution}

This effect is observed especially for tectonic stylolites that occur in low porosity rocks where 
fractures may guide the inter-digitation boundary (Fig. 9d). Stylolites associated with intense fracturing were found in damaged zones of active faults (Labaume et al., 2004). An example is given from the San Andreas damaged zone (Fig. 10a), (Gratier et al., 2003). In this case, as already discussed for impressed pebbles and grains, the mass transfer distance along the stylolite seams $(d)$, which appears in creep laws, is the distance between the fractures. This is because there is a large difference in the possible flux of matter (product of diffusion coefficient by thickness of the diffusive path) between the part that is under maximum compressive stress (the dissolution seams), which is very thin (just a few nanometres), and the part that is in the free fluid of the fracture, several microns wide. Note that the complexity of the stylolite roughness renders the evaluation of this distance rather difficult. In terms of geometry the behaviour of the pressure solution deposition process can be summarized as in Fig. 10c where it is shown that pressure solution may accommodate any finite deformation: flattening, rotating or shearing by changing the shape of small elements by dissolution or precipitation at their boundaries.

\subsubsection{Role of clays and phyllosilicates}

Another intriguing feature of stylolites not commonly integrated in the creep law is the catalytic role of clay or phyllosilicates (Heald, 1955; Meyer et al., 2006; Renard et al., 1997). From experiments using an atomic force microscope (Greene et al., 2009; Meyer et al., 2006) proposed new feedback that couples clays and pressure-solution and localizing dissolution along a flat interface (Aharonov and Katsman, 2009). This is discussed in more details in Section $3 \& 4$.

\subsubsection{Model of stylolite development}

Finally, many studies have tried to model the development of dissolution interfaces either by means of a kinematic approach (Guzzetta, 1984) or a quasi-static mechanical approach, stylolites being viewed as "anticracks" (Fletcher and Pollard, 1981). The idea is that a solution seam, considered as weak material due to passive clay concentration, propagates in its own plane along the direction of maximum mean compressive stress (see spaced solution cleavage below). Complementary models show that mode 1 veins, normal to stylolites with large width-to-length ratio, may be induced by selfsimilar dissolution (Katsman, 2010).

\section{5 - Spaced solution cleavage with associated veins}

Similarly to stylolites, spaced solution cleavages are surfaces of localized dissolution the only difference is that they are almost flat instead of being rough. The reason for the difference may be related to the composition and structure of the rocks (Railsback, 1993). Contrarily to stylolites that develop mainly in heterogeneous granular rocks, solution cleavages develop in homogeneous 

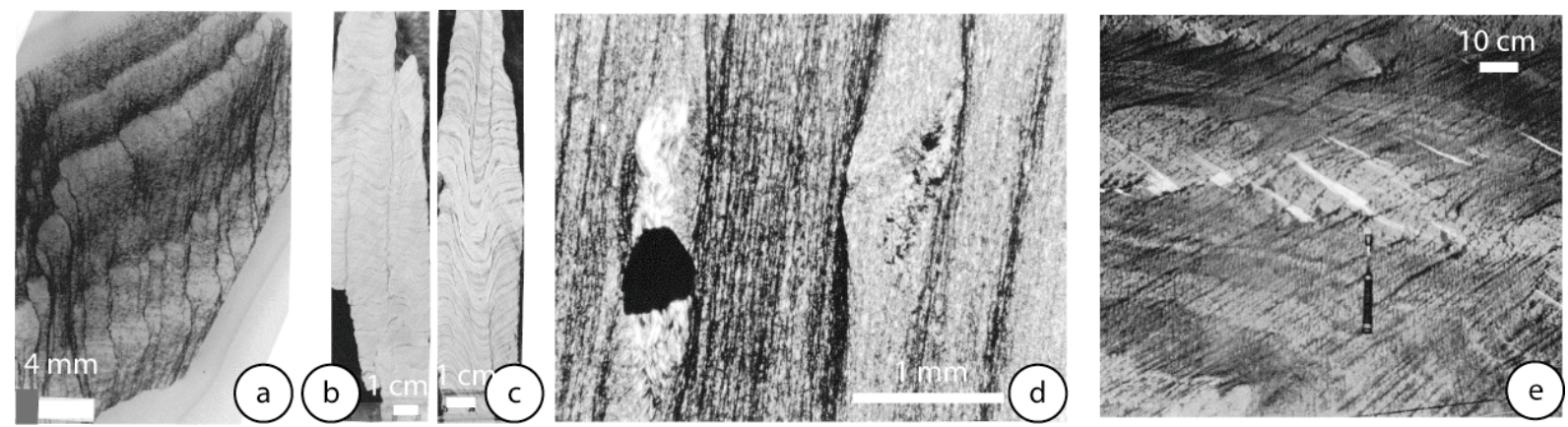

Figure 13: (a) Solution cleavage patterns showing change from competent to incompetent layer; (b) $\&$ (c) change from stylolite to solution cleavage within fold; (d) various solution cleavage spacings and various behaviours of rigid objects with or without precipitation in pressure shadow; (e) solution cleavage and associated veins. The samples are marls and limestones from the sedimentary cover of the Belledonne and Pelvoux massifs (Fig. 1).

polymineralic fine-grained rocks (Hobbs et al., 1976; Nicolas and Poirier, 1976; Ramsay, 1967; Siddans, 1972; Wood, 1974). This induces several differences: (i) fractures perpendicular to stylolites that often bound the stylolite peaks in limestones, do not develop so easily in marls; (ii) heterogeneities (initial or induced by the deformation as local porosity changes) are larger in limestones or in other monomineralic aggregates than in marls; (iii) when the insoluble mineral content is high enough, their passive concentration in the solution seams acts as a "smoothing" process as deformation increases. Moreover, lateral development from stylolites to solution seams can be seen depending on heterogeneity and progressive finite deformation (Fig.13a - b) so there is no gap between the two types of structure but rather a continuous change. Another important feature is that spaced cleavages and stylolites do not need any minimum depth to develop. They can develop very near the surface (less than $1 \mathrm{~km}$ ) as soon as sediments are sufficiently consolidated. So, the old idea of a "cleavage front" at depth must be discarded.

\subsubsection{Model of solution seam development}

Fig. 14 displays how the development of solution seams is induced by heterogeneities in the rock. The distribution of various elements is shown around a piece of fossil of about $1 \mathrm{~mm}$ size, parallel to the stratification. A solution cleavage seam is marked by the zone of high content of elements such as $\mathrm{Al}$, $\mathrm{Fe}$ and $\mathrm{K}$ belonging to insoluble minerals (such as illite, and chlorite minerals), associated with a depletion of other elements such as $\mathrm{Ca}$ and $\mathrm{Si}$ belonging to soluble minerals (such as calcite and quartz). The maximum compressive stress is parallel to the stratification. The piece of fossil acts as a rigid object despite its $100 \%$ calcite content. This illustrates the observation, already mentioned for 

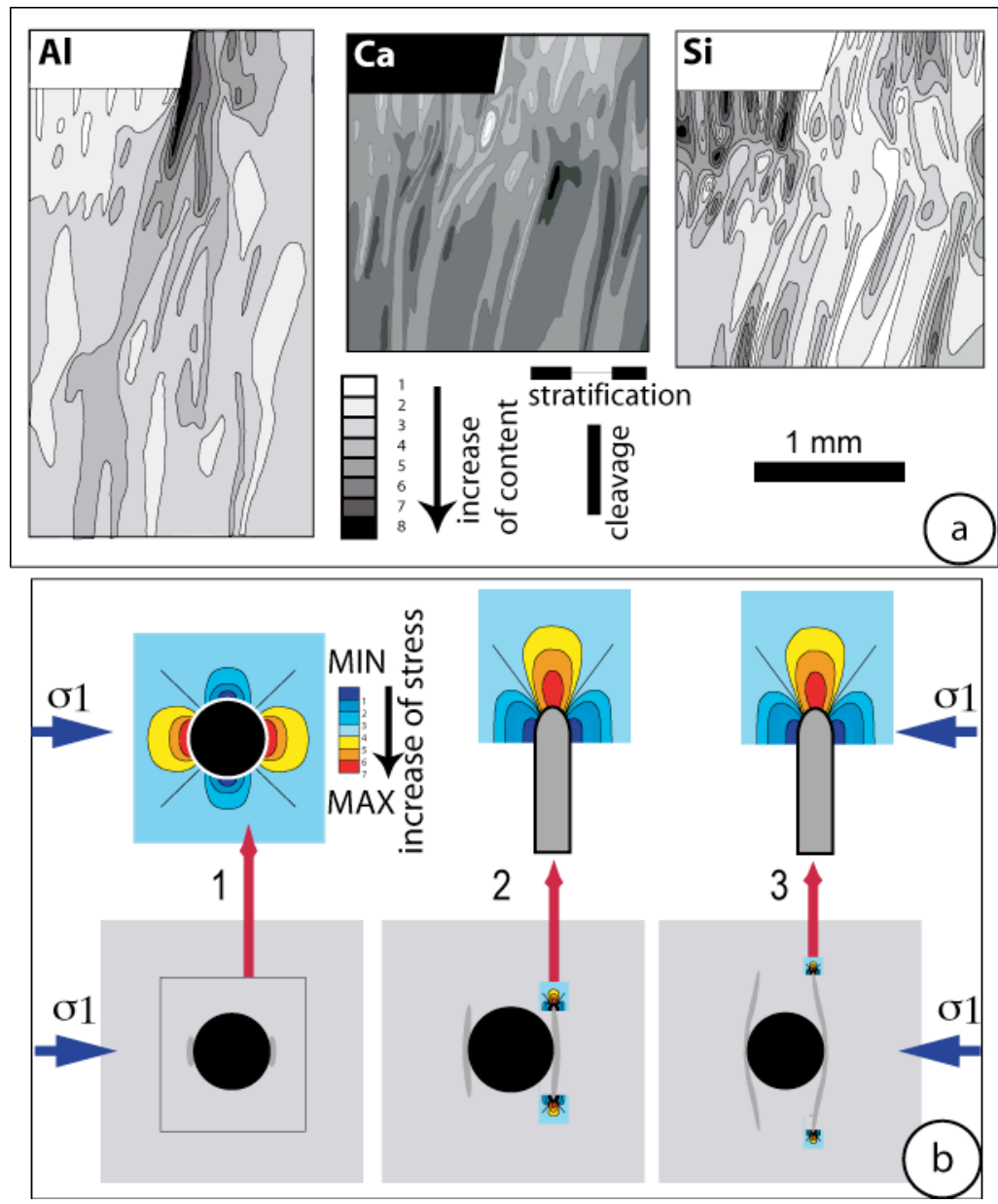

Figure 14: (a) Concentration of various chemical elements around a rigid object (piece of fossil 100\% Ca), marls in the sedimentary cover of the Belledonne massif, adapted from (Gratier, 1987); (b) model of solution seam propagation: step 1) local dissolution induced in the maximum stress zone near the rigid object; step 2-3) propagation of the solution seams away from the rigid object due to stress concentration at the tip, adapted from (Cosgrove, 1976).

stylolites, that the presence of clays or phyllosilicates activates the dissolution rate of the rocks and a polymineralic matrix dissolves more easily than a monomineralic element such as fossils (Fig. 14). Here, the zone of maximum dissolution is localized in the sector of the matrix subjected to the maximum compressive stress. However, the parenthesis shape of the curve of equal insoluble content, with a very narrow seam extending far away from the rigid indenter, does not fit the shape of the stress distribution near a rigid object, which is theoretically about the size of this indenter (Fig. 14b, step 1 (Stromgard, 1973)). Pressure solution initiates in the maximum stress zone but the propagation of the solution seams perpendicularly to the maximum compressive stress and away from the indenter has to be explained (Fig. 14b, steps 2-3). The most common explanation is to consider that the removal of soluble minerals constituting the skeleton of the rock disorganizes the rock and leads to a passive 


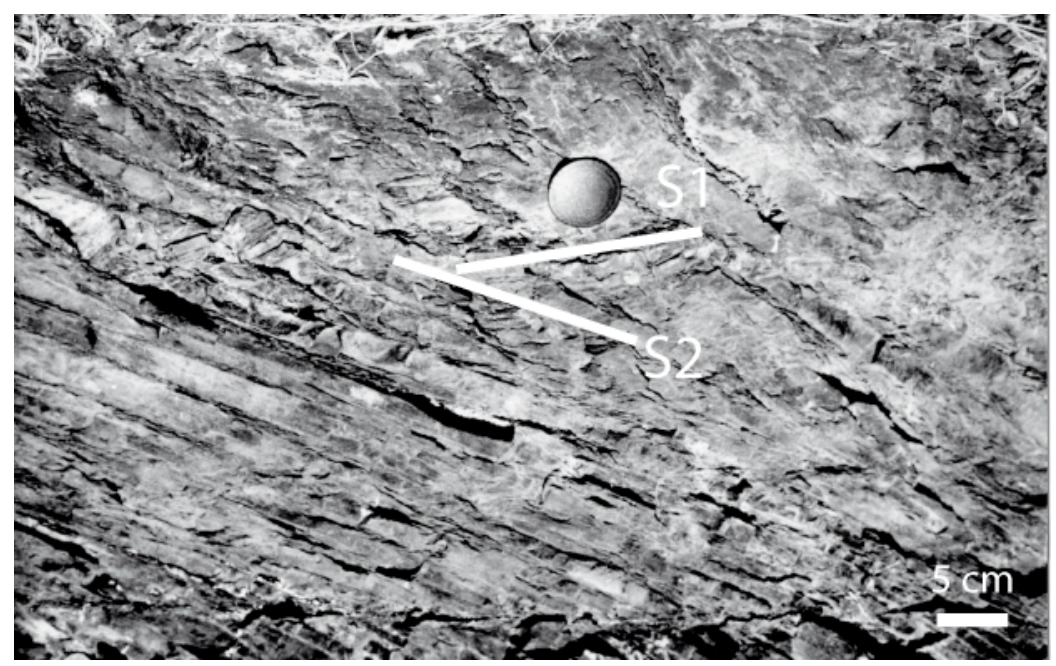

Figure 15: Crossing of successive cleavage planes: S1 was the first generation of cleavage planes, followed by a second generation S2, schist from the sedimentary cover of the Pelvoux massif (Fig. 1).

concentration of clays and phyllosilicates. Consequently, the dissolution zone becomes relatively less rigid than the initial rock. By comparison with the theoretical distribution of the stress values in a viscous matrix around an elliptical soft inclusion (Cosgrove, 1976), two zones of maximum compressive stress appear in the matrix near the tip of the inclusion (Fig. 14b, step 2). Consequently, the dissolution is concentrated in these two zones with progressive propagation of the dissolution zone in its own plane. Fletcher and Pollard (1981) used the term "anti-crack propagation" to describe the development of such solution seams perpendicular to the maximum compressive stress. It must be noted that, in this case, the driving force is the difference in mean normal stresses between the stress concentration zone and the deposition site. Observations of Carrio-Schaffhauser et al. (1990) revealing high porosity within the dissolution seam propagation zone suggest that it could be associated with high fluid pressure.

\subsubsection{Relation between spaced solution cleavage and stress magnitude}

Most of the time solution cleavage is considered to be oriented perpendicular to the maximum compressive stress. However, as already mentioned for stylolites, surface dissolution may develop on surfaces oblique to the maximum compressive stress direction. This can especially occur when the dissolution zone develops on preexisting surfaces (bedding, cleavage, faults) that are oblique to the maximum compressive stress. This is also attested by the observation that when two solution cleavages cross each other at various angles in heterogeneous deformation, there is a minimum value for the angle of crossing, for example $30^{\circ}$ in the Bourg d'Oisans massif (Gratier and Vialon, 1980), Fig. 15. This means that during the development of a second cleavage the dissolution has locally continued on the first one without any slip along this plane. An approximate value of the differential 
stress during pressure solution can thus be evaluated: mechanical experiments on the rocks studied (anisotropic slates) show that a low differential stress value of about 10-25 MPa is required to avoid slipping on the cleavage when the angle between the normal to the cleavage plane and the maximum compressive stress varies from 0 to $30^{\circ}$.

\subsubsection{Spacing of solution cleavage}

This is another crucial parameter of the creep laws as it imposes the geometry of the dissolution surface. Natural examples show that the heterogeneity of the rocks imposes the initial location of the dissolution zone at all scales (Fig. 13). Note, for example, that the spacing between solution cleavage decreases from competent to incompetent layer (Fig. 13a,e). Heterogeneity could be due to sedimentary or tectonic processes. The effect of fossils (Fig. 14) or veins (Fig. 16) acting as a rigid indenter has already been mentioned. Also worthy of note is the possible effect of folding with preferential dissolution along or within the limb of the fold leading to crenulation cleavage with spacing related to the wavelength of the fold (Fig. 16d). The mean grain size of the rock can also impose the cleavage spacing, for example in sandstones (Fig. 17a \& b) or in granite (Fig. 1a). However, the problem is even more complex since the dissolution/ precipitation process itself is a layering process (Fig. 14). It has already been seen that a dissolution zone becomes weaker than the initial rock thereby helping cleavage propagation and amplifying the effect of initial heterogeneity. A more complex effect is the precipitation that can strengthen part of the system. This is well illustrated by the development of a bamboo-like structure (Fig. 16c) (Gratier and Vialon, 1980) where, during a boudinage process, the boudins become progressively thinner than the interboudin sealed fractures. It is the same for deposition sites in the pyrite pressure shadow that are finally wider than the pyrite in rotational deformation (Fig. 16b). The reason is that, when pressure solution is the deformation mechanism, it is easier to dissolve a polycrystalline rock that contains both soluble and insoluble species (the boudin) than to dissolve a monomineralic rock composed of only one soluble species (the interboudin sealed fractures). An explanation is that the diffusion at the contact between soluble and insoluble minerals (such as phyllosilicates) is much faster than the diffusion at the contact between two soluble minerals. This is probably due to a more efficient healing process of the grain boundary of the same minerals. This effect is also demonstrated in laboratory experiments (Hickman and Evans, 1991; van Noort et al., 2007; Zubtsov et al., 2004). So, in natural processes, the process of fracture sealing strengthens the rocks, which become harder than before the fracturing process (at least when pressure solution is the main mechanism of deformation) (Gratier, 2011a). This has important consequences if precipitation occurs near the dissolution seams because it will consolidate the immediate environment of the dissolution seams and strengthen a layer that will become more difficult to dissolve. This also commonly happens near stylolites. Starting from a spacing imposed by the initial 

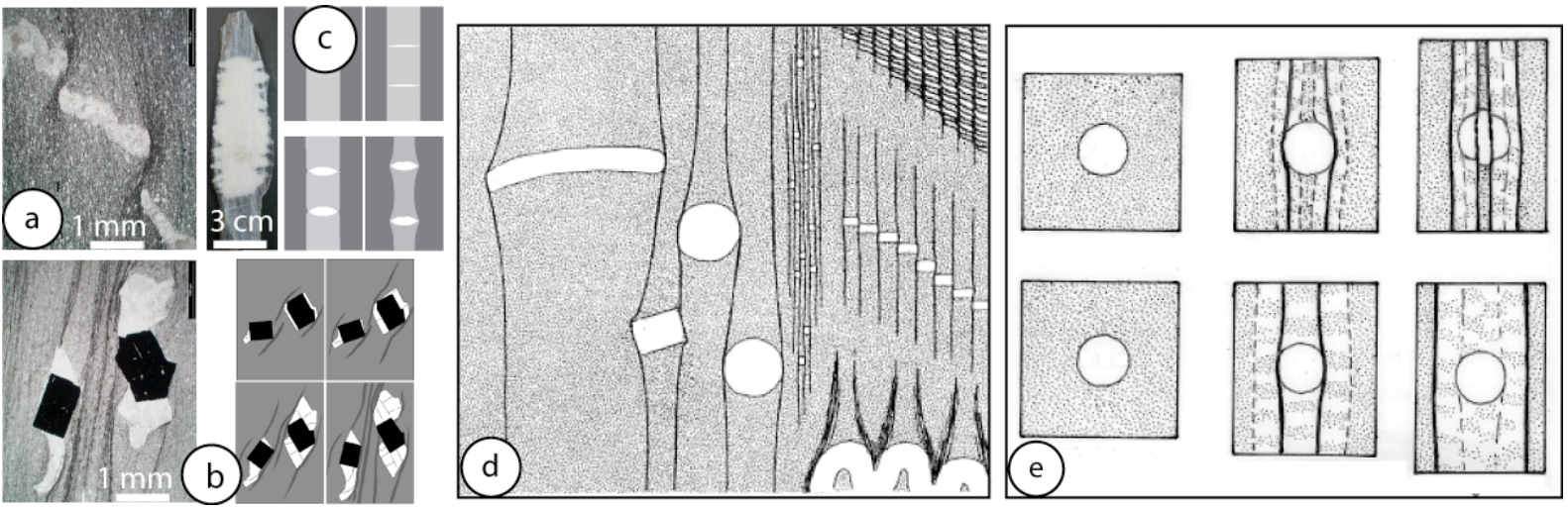

Figure 16: Relationship between solution cleavage spacing and heterogeneity: (a) dissolution parenthesis around a vein; (b) mineral fibre growth in a pressure shadow and schematic evolution; (c) bamboo-like structure showing how deposited minerals in interboudins become more rigid than the boudin itself; (d) effect of initial heterogeneity on solution spacing; $(\boldsymbol{e})$ effect of induced heterogeneity linked to redeposition near the solution seams on solution spacing, adapted from (Gratier, 1987).

heterogeneity, a new spacing (Fig. 16e) may develop, imposed by the thickness of the zone that has been consolidated by deposition. This new spacing is either smaller or larger than the initial one, depending on the efficiency of the diffusion - precipitation process away from the dissolution seams. Consequently, when applying a differential stress (with $\sigma_{1}$ representing the maximum compressive stress) on any initial state: (i) layers perpendicular to $\sigma_{1}$ (Fig. 14), (ii) scattered heterogeneities (Fig. 16b) or (iii) layers parallel to $\sigma_{1}$ (diagenetic stylolites, Fig. 9), the process of pressure solution deposition naturally leads to the development of a new tectonic layering perpendicular to the compressive stress. The path of the transformation and the final composition and size of the tectonic layers depends both on the deformation conditions: possibilities of mass transfer, nature of the solid/fluid phase, state of stress, temperature, and pressure) and on the initial or induced heterogeneities.

\subsubsection{Nature and amount of dissolved minerals}

Solution cleavage may or may not be associated with veins, depending on the possibility of mass transfer away from the solution seams. Consider for example a sample collected in the San Andreas Fault creeping zone from a drill hole (SAFOD facility): calcite, quartz and feldspars are depleted in the solution seams where chlorites and iron oxides are passively concentrated (Fig. 17). This leads to a foliation lying at low angle to the active creeping zone. Calcite minerals fill a network of vein fractures that are perpendicular to the solution seams and indicate extension parallel to the foliation. Finite deformation can be calculated from mineral distribution. Three zones are distinguished 


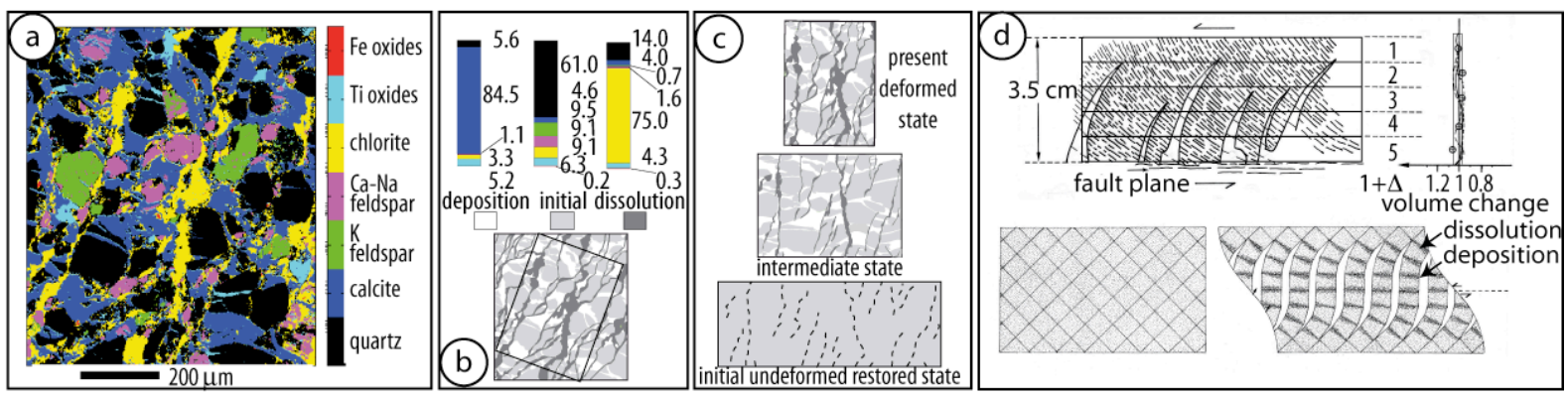

Figure 17: (a) Distribution map of mineral concentration in a sample from the San Andreas Fault creeping zone; (b) comparison of the mineral composition between initial, dissolution and redeposition sites; (c) restoration of the deformed area to its initial undeformed state, adapted from (Gratier et al., 2011); (d) mass balance of diffusive transfer from solution seams to tension gashes showing a system closed at centimetre scale (same composition of all the parallel strips), and schematic geometric model below, adapted from (Gratier and Gamond, 1990).

according to their mineral content: "dissolution" (with passively concentrated chlorites and iron oxides), "deposition" (with precipitated calcite and sometime titanium oxides) and "initial" zones (predeformation zone of quartz, feldspars, chlorites, etc.). Veins open and seal progressively (Mittempergher et al., 2011) and minerals from both initial (quartz and feldspar) and deposition (calcite) zones are dissolved during the pressure solution process (Fig. 17b). Minimum and maximum mass transfer amounts are obtained when comparing either initial and dissolution zones, or both initial and deposition zones with dissolution zones. The two calculations give roughly the same amount of relative mass decrease for the dissolution zones (-88\% to -90\%). By taking into account the areas of these dissolution zones, the mean value of contraction perpendicular to the foliation can be calculated, which is about $-60 \%$. The mean extension perpendicular to the veins is evaluated from the ratio of deposition to initial areas and is about $+50 \%$ (Fig. 17). Mineral segregation appears to be linked to pressure solution creep with an almost total disappearance of soluble minerals (quartz, K-feldspars, $\mathrm{Ca}-\mathrm{Na}$-feldspars and calcite) in the dissolution zones. Mass conservation calculations comparing the amounts of dissolved Ca-Na-feldspars and deposited minerals in veins show that a large part of calcite and titanium must come from outside the studied area, brought by episodic fluid flow. Therefore, the system is open in terms of the area studied.

Parentheses of dissolution may develop at scales much larger than the grain size (Fig. 16a), and the same mass transfer scheme is observed. For example, in the Bourg d'Oisans basin (France) affected by large deformation by solution cleavage, a local volume loss of $-71 \%$ is shown in parenthesis shaped solution seams around a $10 \mathrm{~cm}$ wide belemnite fossil and the decrease in soluble species is very high: $90 \%$ (quartz), $-93 \%$ (calcite), $-82 \%$ (dolomite). This means that, at all scales, almost all the soluble 
species can be removed from the dissolution zone (Richard, 2009). The question is then about the location of the deposition site associated with this mass transfer. It is sometimes possible to see deposition in a pressure shadow area (Fig. 16b). However, it is not a general case as, at the same place, rigid objects with or without deposition can also be found in the nearby pressure shadow areas (Fig. 13d). In this case, the efficiency of deposition depends on the possibility of opening the interface between the rigid object and the matrix.

\subsubsection{Size of the closed system}

It is sometimes possible to evaluate the size of the closed system. An example is given in Fig. 17d where shear deformation near a fault is accommodated by mass transfer from solution cleavage seams to tension gashes. Chemical analyses of strips of sandstone collected parallel to the shear zone were compared with the mineral composition of a reference zone away from the shear zone (strip 1). Using Eq. (1), the mass transfer is calculated and it is shown that no significant mass transfer occurs between the strips. So the maximum size of the closed system is here of the order of magnitude of the width of the strips. Filling of the tension gashes by quartz and calcite compensates almost completely for the dissolution of the same mineral along the solution seams. Such a closed system is confirmed by the geometric analysis of the angles between cleavage planes, veins, and the shear zone (see Fig. 7). A schematic model is given for such behaviour (Fig. 17d). In reality, the spacing of the solution cleavage, which is here of the order of magnitude of the grain size, is always smaller than the spacing of the tension gashes.

It should be noted that the size of the closed system may be kilometric when fluid flow is involved. For instance, in (Gratier and Gamond, 1990) an example is given of kilometre-length mass transfer between a compression bridge (with dissolution) and an extensive bridge (with precipitation) along segmented faults.

\subsubsection{Mass transfer in chevron folds}

Finally, another way of establishing quantitative relations between the amount of pressure solution and finite deformation is to analyze the chemical changes associated with solution cleavage in folds. One of the main problems in estimating the amount of mass transfer is to identify the insoluble species (Grant, 2005). The variation in ratio of element content in a hinge and limb pair versus the angle between hinge and limb can be plotted in order to visualize the behaviour of the various elements as a function of the increase in deformation values (Fig. 18). It is possible to distinguish the elements that remain insoluble during such an increase in deformation (the ratio remains constant) and the other elements for which this ratio varies, indicating a mobility that could possibly fluctuate with the increasing finite deformation. This can be applied to other types of deformation such as shear zones or 


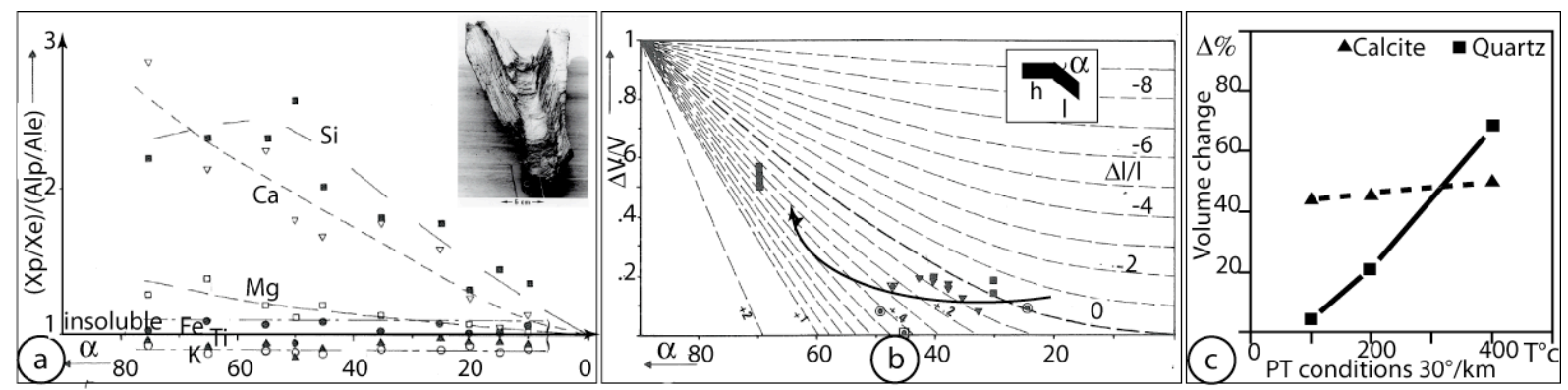

Figure 18: Mass transfer in a folded marl sample (sedimentary cover of the Belledonne massif): (a) variation in the ratio of concentration of each element in the hinge $\left(X_{p}\right)$ and the limb $\left(X_{e}\right)$ versus the angle between these two zones (normalized to Al concentrations), so as to separate soluble and insoluble species; (b) plot of the variation in mass transfer in a volume change versus hingellimb angle diagram with line of constant limb length change (bold line), adapted from (Gratier, 1983); (c) variation in the amount of dissolution of quartz and calcite versus temperature and depth in the sedimentary cover of the Alps.

any other heterogeneous deformation that associates protected and deformed zones with a finite deformation marker. Once these soluble and insoluble species are identified for the entire finite deformation, the relationship between volume change and finite deformation can be investigated. In this case, a simple diagram is used to compare this behaviour (Fig. 18). For example, chemical analyses were carried out on several limb-hinge pairs of straight-limbed folds of the same layer and, where possible, with various limb-hinge angles (Fig. 18). All the samples were taken from the Mesozoic cover of the external Alps (Gratier and Vialon, 1980). A crenulation cleavage parallel to the hinge-limb boundary may be seen in all these folds. In all cases, the hinge is taken as reference (as protected zone). Equation 1 is applied to calculate the relative volume change between hinge and limb. Assuming an open system where no deposition is seen at any place, the relationships between the elongation along the hinge, the angle between hinge and limb, and the volume change may be established in a diagram in order to follow the variation in these parameters with increasing deformation (increasing limb/hinge angle). The effect of shortening parallel to the hinge may be seen for low values of the angle $\alpha$ between hinge and limb. Few fold pairs show low or even no volume change. This does not mean that pressure solution is not active but it could simply be because mass transfer occurs at a lower distance than the fold wavelength. As the limb rotates, the extension is seen to be parallel to the limb and dissolution becomes partitioned between the crenulation cleavage and the stratification interface. The deformation path expresses the way pressure solution creep accommodates at least part of the folding process. The comparative behaviour of calcite and quartz, deduced from the study of various hinge and limb pairs with the same angle $\left(40^{\circ}\right)$, can be seen in Fig. 18c. It appears 

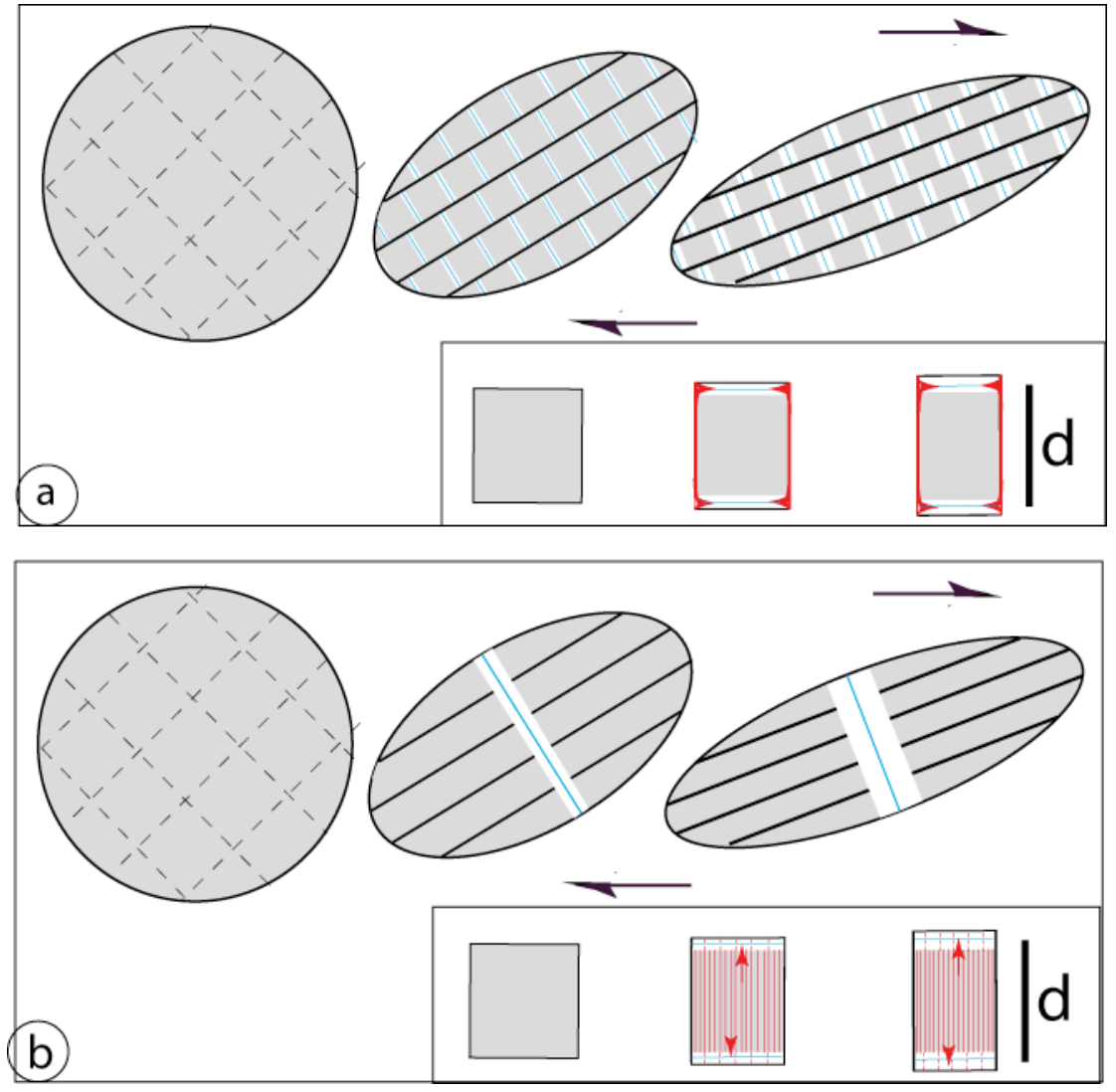

Figure 19: Geometric model of spaced solution cleavage: (a) diffusive mass transfer around each rigid element and precipitation in pervasive vein networks; (b) diffusive mass transfer through the element with dense array of dissolution seams and localization of precipitation in a single vein.

that calcite is more mobile than quartz at low temperature and less mobile at high temperature. This is due to the opposing variation in calcite and quartz solubility with temperature as solubility is a key parameter of the creep laws (see Section 3). It should be noted, however, that calcite mobility does not decrease with temperature, unlike its solubility. This is because other kinetic parameters of the creep laws (reaction rate or diffusion rate) remain activated by the temperature, which counteracts the change in solubility.

\subsubsection{Modelling of spaced solution cleavage in creep laws}

Two types of geometry (Fig. 19) summarize the observations of solution cleavage associated with veins when considering a difference in the path of diffusive mass transfer. Dissolution and deposition may occur around a rigid object, such as a grain or a rock fragment composed of several grains (Fig. 19a). In this case, mass transfer occurs by diffusion around the rigid element. Taking into account the presence of fluid that is a specific feature of pressure solution, the geometry of the mass transfer path is analogous to the Coble creep mechanism (Coble, 1963) where mass transport occurs at the grain 
boundaries. In this case, the strain rate of pressure solution is inversely proportional to the cube of the mass transfer distance along the trapped fluid phase $(d)$ when diffusion is rate-controlling (see Section $3)$.

Alternatively, dense arrays of solution cleavage may feed veins that are much larger than the spacing between the grains. In this case, dissolution occurs in the whole volume of the element (Fig. 19b). Always taking into account the presence of fluid, the geometry of the mass transfer path is in this case analogous to the Nabarro-Herring creep mechanism (Herring, 1950; Nabarro, 1948). The strain rate of pressure solution is then inversely proportional to the square of the mass transfer distance $(d)$ along the trapped fluid phase when diffusion is rate-controlling. It should be noted that, in all the cases, the size of the closed system (where the volume of the dissolved minerals equals the volume of the deposited minerals) is not necessarily the size of the element. For example if diffusion is rate-limiting, it is only the path along the trapped fluid phase that has to be taken into account as the distance $d$ in the creep laws since it is the slowest part of the path. Diffusion in open space or infiltration may evacuate the soluble species.

\section{6 - Aseismic sliding along a fault by pressure solution}

Competition and interaction between cataclastic and pressure solution creep deformation is well illustrated by considering the mechanisms of development of lineations in faults. Two different types of striations and corrugations need to be distinguished. One type has a mechanical origin, comparable to mechanical wear (Goguel, 1948), which may be associated with friction during slip. This type of striation is well known on natural fault surfaces that moved during earthquakes or in stable friction mode (Engelder, 1974). Other type of "striation", which is also very common on naturally formed faults (Durney and Ramsay, 1973; Means, 1987) consists of crystal fibres (Fig. 20a). The development of such fibres may be explained as follows (Gratier and Gamond, 1990). If two rock parts are separated by an irregular fault surface, a slow displacement of one part of the rock may be accommodated by the dissolution of the asperities that prevent the displacement. At the same time, deposition may occur in the cavities created by the displacement along the fault. The redeposited material is derived by pressure solution from the rock matrix, the crystals growing within these cavities sometimes have a typical fabric (fibre minerals), first described by Ramsay (1980a) and explained as linked to a succession of microcrack openings followed by their immediate sealing (crack-seal process). The mean width of each crack opening is commonly about 10 to 50 micrometres and, as each crack is limited to one or two crystals, several thousand crack-events would be required to achieve a displacement of $1 \mathrm{~cm}$. Note that the same mechanism of aseismic sliding by pressure solution is also very commonly observed accommodating layer-parallel sliding in folding process (Ramsay, 1967). 

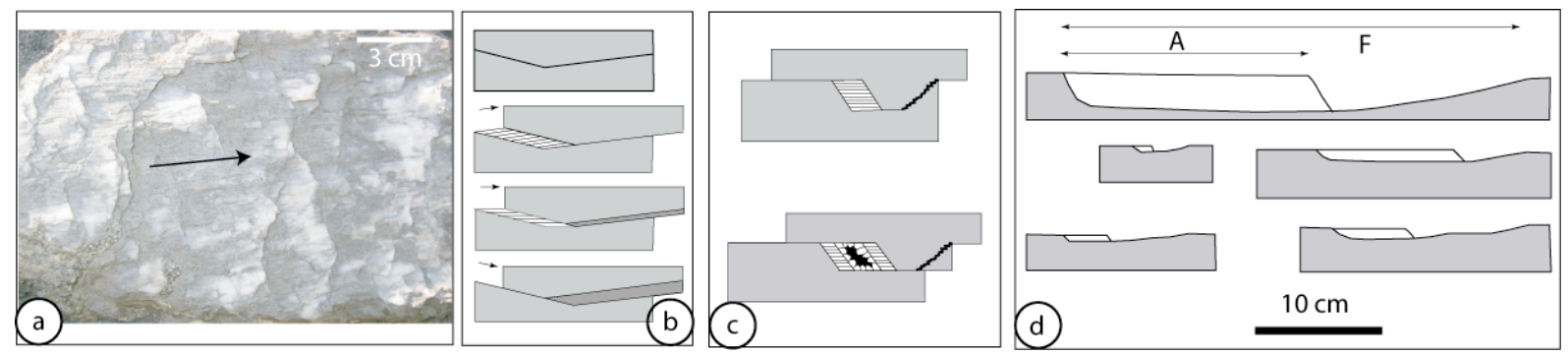

Figure 20: Pressure solution as mechanism of aseismic sliding on a fault: (a) crystallization of calcite fibres in open spaces along a fault in a limestone from the Chartreuse Mountains (Fig. 1); (b) crosssectional view of the various arrangements of dissolution precipitation patterns along a fault with either only precipitation (top), both dissolution and precipitation (middle) and only dissolution (bottom); (c) transition between aseismic sliding (top, crack seal) and seismic sliding (bottom, open void with euhedral crystals); (d) measured length of asperities along a fault $(F)$ versus fibre length $(A$ = displacement), adapted from (Gratier and Gamond, 1990).

\subsubsection{Brittle and creep deformation in fault zones}

Another feature that shows the interaction with brittle deformation is the observation whereby, in some cases, the fibres are kinked or broken and cut by cataclastic scratching faults with perfect polishing. This demonstrates that, on the same fault, brittle deformation may be associated with pressure solution creep. Evidence may even be found of voids opening in the redeposited material linked to large displacement on the fault and filled by euhedral crystals that indicate growth in free fluid (Fig. 20c). This attests to possible successive periods of brittle (fast) and creep (slow) events on the fault. An explanation is that the creep process could relax the stress only if the loading rate is not too high. When pressure solution cannot accommodate the imposed loading rate, the stress increases and a brittle rupture may nucleate. Since evidence can be found of fracturing events over more than ten orders of magnitude (from micrometre fibre rupture to the breaking of all the asperities at the plurikilometric scale), it is not easy to define a boundary between brittle and creep processes. It may simply be considered that if an event breaks several asperities, it is a cataclastic event for the fault. On the contrary, if an event only occurs at fibre (microns) scale within an asperity without significant associated displacement on the fault, this must be considered as linked to the pressure solution creeping process. Of course, some of these microcracks may be induced by regional seismicity but the brittle/creep transition must be defined for a given fault.

\subsubsection{Nature and amount of dissolved minerals}

Volume transfer balance along faults may be discussed through a simple geometrical plane-strain 
model with the volume dissolved along the dissolved part of the asperity being balanced by the volume redeposited in the gaps opened by sliding on the fault. On a section perpendicular to the fault surface, the change in area depends on the geometry of the asperity and on the angle between the displacement (indicated by the fibres, noted A in Fig. 20d) and the mean plane of the fault (F). All mechanisms are possible, between sliding with only deposition, with only dissolution or in a closed system (Fig. 20b). These values can be determined from measurements on natural faults, for example using a shape tracer (Fig. 20d). On various examples in limestone in the external Alps, the length of the asperities (A) is seen to vary from 5 to $30 \mathrm{~cm}$, as the length of the fibres (F) varies from 1.5 to 20 $\mathrm{cm}$. The F/A ratio, which expresses the portion of the asperity dissolved during aseismic slip, depends on the geological context and ranges here from 0.3 to 0.5 with extreme values of 0.25 to 0.7 . The spacing between the asperities is more difficult to estimate, but is most often of the same order of magnitude as the size of the asperities. The angle between dissolution surface and mean displacement on the fault remains low, with a narrow range (from $5^{\circ}$ to $15^{\circ}$ ). Conversely, the angle between the deposition surface and the fault varies more widely from $30^{\circ}$ to $80^{\circ}$. Note also that the lengths of the fibres along each fault surface are not necessarily constant due to various effects: in case of fault segmentation, cavities may develop within the bridge while others are already opened in the fault segments, some asperities may break during sliding, and a decrease in displacement along the fault often appears near the end of the fault associated with heterogeneous volume change around the fault. All the minerals that are dissolved in the other pressure solution markers can be dissolved along the fault in order to accommodate aseismic creep sliding.

\subsubsection{Seismic to aseismic sliding along faults}

The geometries of the fault displayed in Fig. 20b-d may be used to model aseismic creep sliding, with mass transfer from the part of the asperity that opposes the displacement to the part that opens during this displacement. Mass transfer can occur either along the fault contact or through the rocks, as shown in Fig. 17d. However, as the length of the asperities decreases with the progressive displacement, aseismic sliding is most often a transitory process since the strength of the asperities progressively decreases with decrease in asperity length. It is likely that, at one time during the sliding process, the energy required to break the remnant of the asperity becomes lower than the energy needed to promote pressure solution (Gratier and Gamond, 1990) and this may explain the shifting from one mechanism to the other. This is seen in nature (Fig. 20c) where it seems likely that seismic sliding can recreate asperities that are dissolved and so on. 

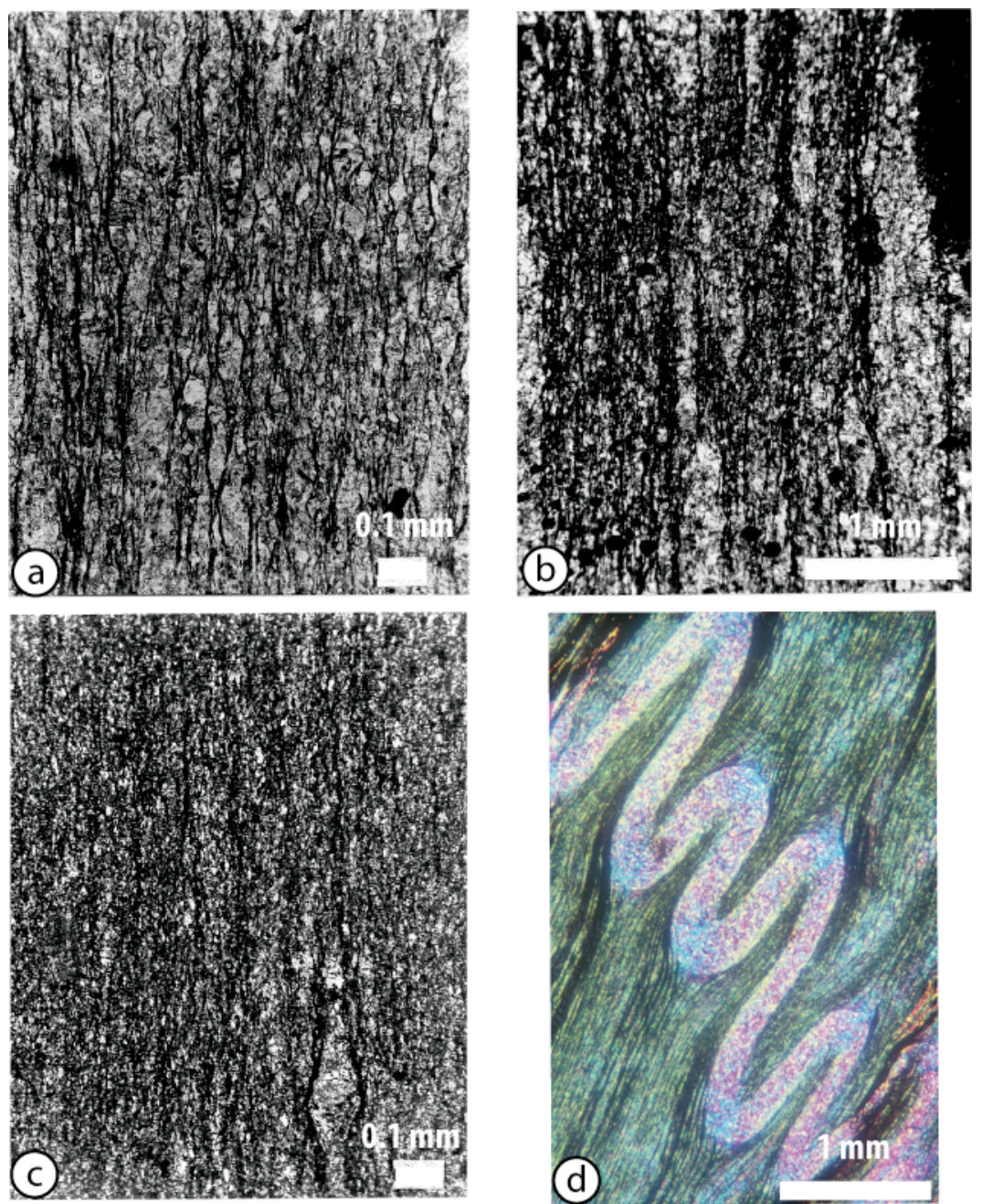

Figure 21: $(\boldsymbol{a}, \boldsymbol{b}, \boldsymbol{c})$ slaty cleavage in the sedimentary cover of the Pelvoux massif (Fig. 1); (d) ptygmatic fold in slaty cleavage, adapted image from (Ramsay and Huber, 1987).

\section{7 - Slaty cleavage with associated veins}

Slaty cleavage is a type of foliation that expresses the tendency of a rock to split along parallel planes (Hobbs et al., 1976; Nicolas and Poirier, 1976; Ramsay, 1967; Siddans, 1972; Wood, 1974). It results from the parallel orientation of phyllosilicate minerals. It is most often associated with large finite deformation values. This finite deformation may be evaluated using, for example, both fossil deformation, such as truncated belemnite fossils, and ptygmatic folds (see Fig. 1a \& 7b). Shortening values $\left(l_{z} / l_{0}\right)$ commonly range from 0.5 to 0.25 (Fig. 21 ), with associated values of the extension ranging from 2 to 4 depending on the volume change at the deca-kilometre scale of a massif. When the rock contains a certain amount of soluble minerals such as quartz, feldspar or calcite, the reorientation of the phyllosilicates requires ductile deformation of these other minerals. As shown in the diagram of the variation in deformation mechanism through the entire upper crust, three types of mechanism are 
possible (Fig. 1b): cataclasis is the first but most of the time is not seen as the main mechanism of deformation in slates. Dislocation glide is another possibility, which is relatively easy to identify because it leads to a preferred orientation of the minerals. This mechanism is highly sensitive to temperature and does not develop at less than $400^{\circ} \mathrm{C}$. Finally, pressure solution is the third mechanism that is the more likely to occur through the upper crust. In this case, the dissolution of soluble minerals leaves enough space for the passive concentration and rotation of the insoluble minerals such as phyllosilicates. It has been argued that preferred orientation of phyllosilicates developed by crystallization under stress may contribute to the development of slaty cleavage (Kamb, 1959). It may be a complementary process that occurs along passively rotated phyllosilicates, but it cannot explain the large deformation values associated with slaty cleavages. The transition from spaced solution cleavage to slaty solution cleavage occurs by a change in the spacing between solution seams that decreases ultimately toward the grain size. Slaty solution cleavage is not easy to identify directly as mass transfer occurs at the grain scale. In this case, as already mentioned, the dissolution of pure monomineralic grains leaves no evidence. The way to reveal pressure solution in this case is to study heterogeneously deformed areas such as indented, boudinaged, sheared or folded structures that could reveal the stress-driven chemical differentiation (Fig. 21-22).

\subsubsection{Nature and amount of dissolved minerals}

Fig. 22 presents an example derived from chemical analyses of samples cored within two slate layers adjacent to a folded competent layer (quartz and calcite) (Gratier, 1983). One of the layers is located just above the competent ptygmatic layer and, for this layer, the sample located near the ptygmatic fold extrados is considered as a (relatively) protected zone as it is the zone of minimum deformation. The other layer above is horizontal. The insoluble species are determined by plotting the ratio between protected and exposed zone versus the deformation value represented here by the increase in the layer dip (Fig. 18a): $\mathrm{Fe}, \mathrm{Ti}, \mathrm{Al}$ and $\mathrm{K}$ are insoluble while $\mathrm{Ca}, \mathrm{Mg}, \mathrm{Si}$ are mobile. The relative change in mineral composition may thus be evaluated (Fig. 22b) as the volume change (Fig. 22c) since densities have been measured to be constant. Of course, this volume change is at the scale of the samples. Measuring no chemical change along the horizontal layer does not mean that pressure solution does not occur. It just means that the size of the closed system is smaller than the size of the samples (close to $5 \mathrm{~cm}$ in the present case). Relative volume change is calculated according to Eq. (1) and displayed on Fig. 22c. A map view of the volume change is presented in Fig. 22d. As it stands however, it is difficult to say whether these values are relevant. To overcome this difficulty, the compatibility of these values can be tested by restoring the deformed area. This can be done using the technique developed by Cobbold (1979), whereby finite deformation is removed using strain trajectories. Strain trajectories are evaluated using both the volume change and the finite strain values. Strain values are 



Figure 22: Mass transfer during a folding process in schist of the sedimentary cover of the Pelvoux massif: (a) location of cored samples; (b) mineral content in protected (9) and exposed (5) samples of the same initial layer; (c) volume change along the same folded layer; (d) map distribution of the volume changes, adapted from (Gratier, 1983).

deduced both from the cleavage dip and from the strain values at the boundary of the studied area. The shortening is given by the unfolding of the ptygmatic fold assuming that it did not change thickness during the deformation $\left(l_{z} / l_{0}=0.4\right)$. The vertical extension is obtained from the measurement of elongated belemnites $\left(l_{x} / l_{0}=2.5\right)$. It can be seen that no significant deformation occurs along the third axis. The whole area is divided into small elements with homogeneous deformation. Each element is undeformed and restored to its initial state using a best fitting technique. It is clear here that volume changes calculated by comparing chemical analyses are entirely compatible with the studied strain pattern (Fig. 23a). Once the volume change is evaluated, it is possible to discuss the volume change associated with the slaty cleavage. It can be seen that a large amount of matter can be removed from decimetre sized sample and this can completely modify the chemical composition of the rock.

An important application is the change in fault gouge that always shows substantial depletion in mobile elements and such depletion may well be connected with pressure solution creep. When plotting the volume change $\Delta$ values along layers of the slaty matrix on a Flinn diagram (Fig. 7d), the variation in deformation path can be monitored by assuming that the spatial variation along each layer is equivalent to a time-dependent change (Gratier, 1987). Note that a linear relationship appears between volume change and internal deformation for the less deformed layer (blue path in Fig. 7d). However, for the most folded layers, there is a non-linear variation (red path in Fig. 7d) with a maximum value of the volume change of about $50 \%$ that expresses the fact that almost all the soluble species have been removed from the most deformed zone. 

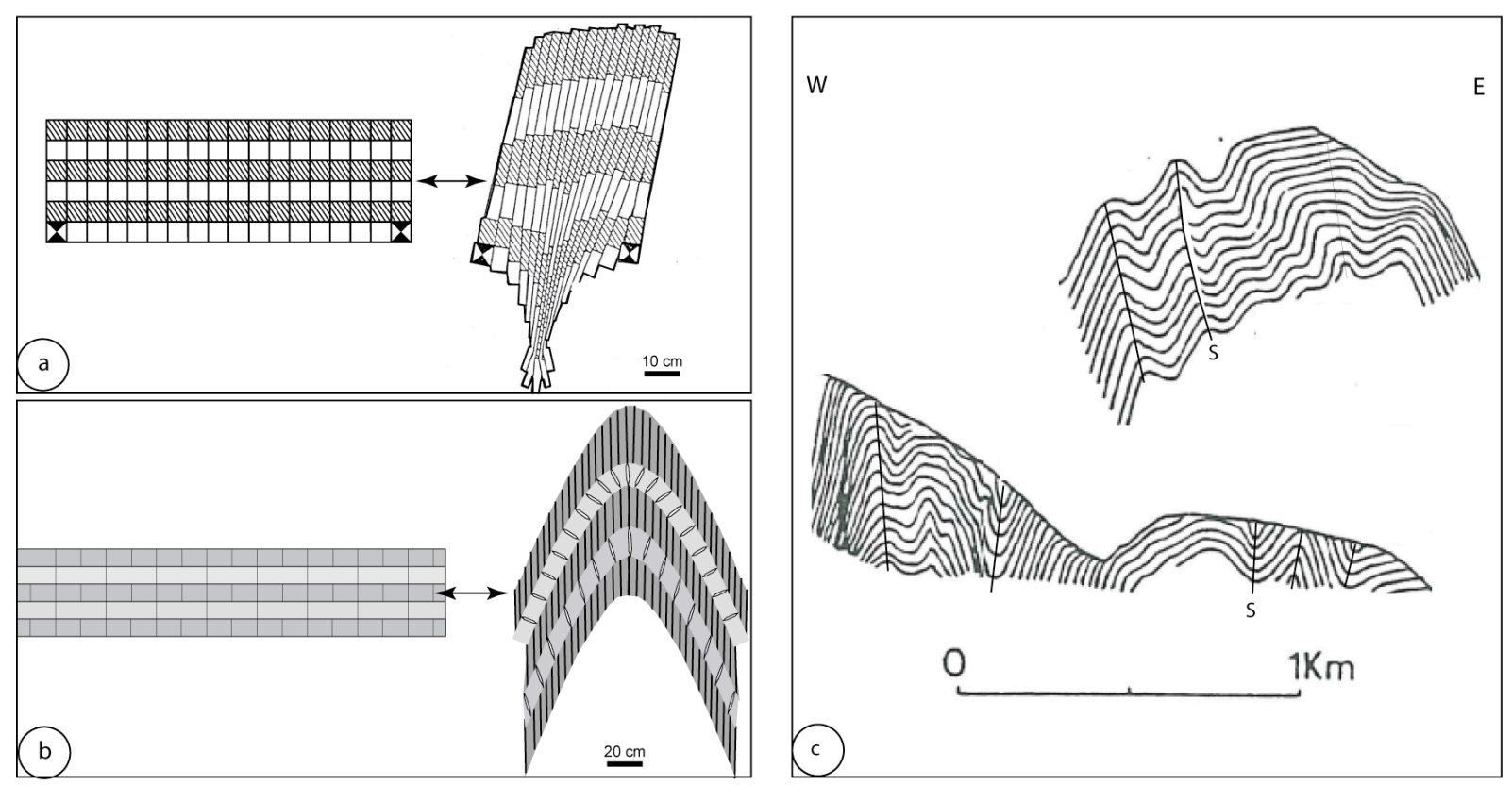

Figure 23: (a) Test of the compatibility of volume change value (Fig. 22d) by removal of finite deformation using strain trajectories; (b) Cleavage refraction during folding of layers with variable material properties; (c) Folding with axial plane cleavage (from photos) in schist of the sedimentary cover of the Pelvoux massif with large deformation: horizontal shortening $=50 \%$, vertical extension $=100 \%, S=$ axial plane slaty cleavage, adapted from (Gratier and Vialon, 1980).

\subsubsection{Slaty cleavage in a folding process}

Pressure solution slaty cleavage is also frequently associated with a folding process (Fig. 23c). The axial plane cleavage shows cleavage refraction that underlines the differential behaviour of competent and incompetent layers (Fig. 23b). The angle between the cleavage plane and the stratification is related to the variation in cleavage with progressive deformation. The most competent layer (i.e. the layer with the minimum content in clays and phyllosilicates) could show an angle up to $90^{\circ}$ between cleavage and stratification. This angle was acquired during the first stage of deformation when vertical cleavages developed in a formation with horizontal stratification. This angle did not change with the folding process; therefore the cleavages indicate here the first step of deformation. Conversely, the cleavages in the most incompetent layer are destroyed and reoriented at each step of the deformation in a shear process parallel to the stratification accommodating layer-parallel slip. Its final orientation is in agreement with the last orientation of the horizontal compressive stress. All intermediate cases are possible (Fig. 23b). Note that, frequently, cleavage planes in the most competent layers are filled with soluble minerals along veins. This intriguing behaviour may be explained by shear motion along the refracted cleavage surface producing dilatation of the competent layer and opening of mode I fractures 
(Ramsay, 1967). However, when this process occurs for cleavages in the hinge a fold, that always remained perpendicular to the horizontal stress, another explanation is needed that may rely on the hydraulic fracturing process of the anisotropic rocks: opening a surface perpendicular to the maximum compressive stress $\sigma_{1}$ is less energy consuming than opening a surface parallel to $\sigma_{1}$ when the differential stress value is lower than the difference between the tensional strength parallel and perpendicular to the cleavage. This is in agreement with the idea expressed above that solution cleavages develop under low differential stress and near lithostatic fluid pressure.

\subsubsection{Slaty cleavage and characteristic length of creep laws}

It will be shown in Section 3 that a key parameter to distinguish between the various creep laws is the functional relationship between the strain rate $\dot{\varepsilon}$ and the mass transfer distance $d$. The strain rate is inversely proportional to $d$ when the kinetics of reaction is rate limiting (Raj, 1982), or when it is the infiltration rate (Gratier, 1987), it is inversely proportional to $d^{2}$ when the rate-limiting step is the diffusion through the whole rock formation (Fig. 19b) and it is inversely proportional to $d^{3}$ when the rate-limiting step is the diffusion around the deforming element (Fig. 19a). Assuming that the deformation duration is the same for all the structures of a given area, it is possible to explore the relationships between the intensity of the deformation and the characteristic length of the structures. For example, Fig. 24a displays a linear relation between finite deformation associated with pressure shadows (the length of the fibres in the pressure shadow) and the size of the rigid object. In terms of mechanism, two interpretations are possible. (i) Either the amount of deposition is linked to the amount of dissolved species in the associated dissolution parentheses, so that the mass transfer distance is proportional to the size of the pressure shadow: closed system at the pressure shadows scale have been proposed and modelled by Berton et al. (2006). The result of Fig. 24a indicates that the strain-rate would not be sensitive to the mass transfer distance. (ii) Or the amount of deposition is only dependent on the possible void opening between the matrix and the rigid object. As seen in Fig. $13 \mathrm{~d}$, neighbouring rigid objects with dissolution parentheses may or may not show associated deposition within their pressure shadows. It seems that the second interpretation is more likely. In this case, this indicates that pressure solution develops at grain size scale by diffusion-accommodated grain sliding, whereas solutes are free to precipitate in any available void or vein. In this case, the relation of Fig. 24a cannot be used in terms of mechanism. However, since pressure shadow shape does depend on the deformation mechanism it may be assimilated to a strain ellipse and used as strain markers. In parallel, the variation in mineral fibres within pressure shadows (Fig. 16b) can indicate the change in deformation path (Beutner and Diegel, 1985; Etchecopar and Malavieille, 1987).

Another diagram concerns the boudinaged structures that develop at all scales in slate massifs. Contrary to pressure shadows, which remain almost undeformed, the boudins (the rock between 




Figure 24: Slaty cleavage and the characteristic length of creep laws: (a) linear relationship between fibre length in pressure shadows and the width of the rigid object; (b) log-log plot of finite extension (e) versus the width of deformed area $(d)$ showing the change in the power law exponent of $d$ from 2 to 1, sedimentary cover of the Pelvoux massif.

extension veins) deform differently according to their size. When plotting on a log-log diagram the width of the boudins $(d)$ versus the intensity of deformation (Fig. 24b), the slope varies from 1 to 2 when the distance $d$ decreases. Unfortunately, for this example, it is not possible to cover characteristic length scales smaller than several millimetres. However, this clear change in slope somewhere between decimetre and hectometre length scales could correspond to a change in mass transfer mechanism. Diffusion processes are not likely to be efficient above some decimetres. Above this length scale, advection is required and the deformation mechanism is probably different (see $\S 2.7 .5)$. In the present case, the exponent of 2 for $d$ is compatible with the geometric model of Fig. $19 \mathrm{~b}$, where numerous solution cleavage seams, with a spacing of the same order as the grain size, feed 
sparsely spaced veins. Finally, note also that, contrary to pressure shadows, the veins cannot be used as strain markers since the extension value given at one scale is not the same as that given at another scale as 3 orders of magnitude of strain difference could be measured.

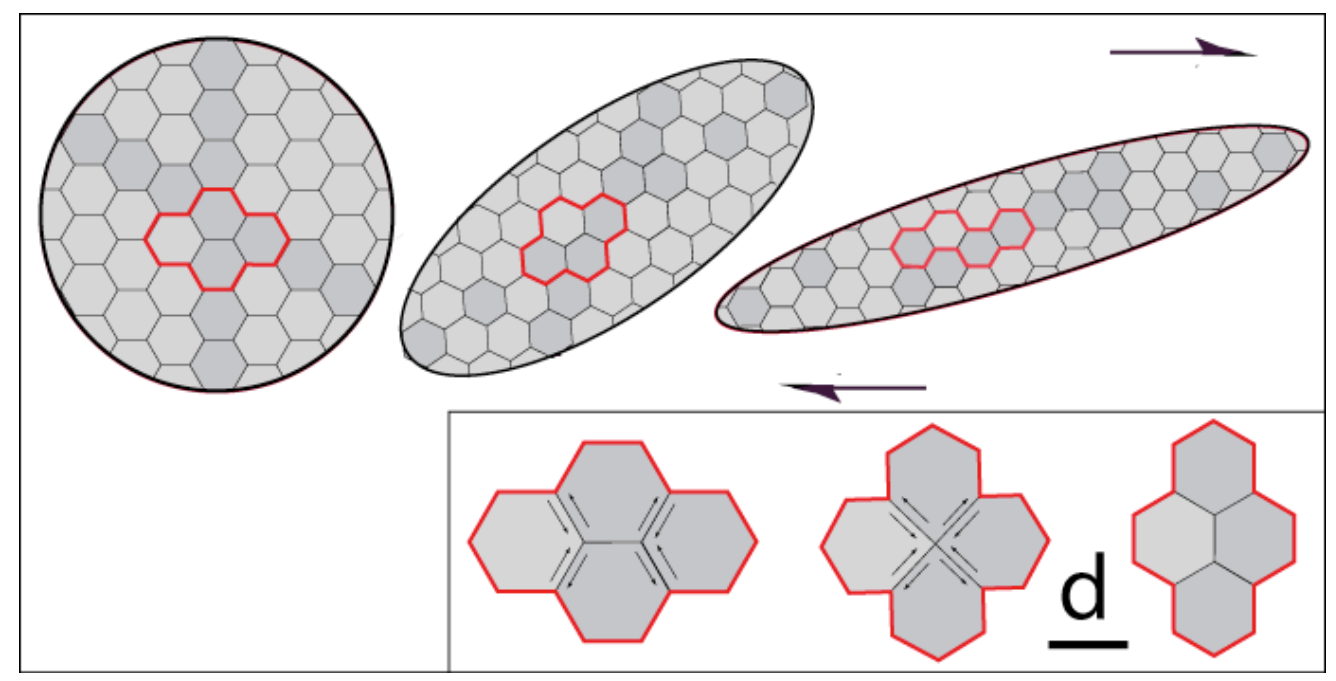

Figure 25: Geometric model of slaty cleavage deformation by grain-boundary sliding with diffusive accommodation by pressure solution. The mass transfer distance is noted (d), adapted from (Ashby and Verrall, 1973).

\subsubsection{Modelling of slaty cleavage in creep laws}

The models of spaced cleavage presented in Fig. 19 allow large finite deformation in the shortening direction. However, they are less efficient in the extension direction. It is very rare to see an extension of more than $50 \%$ accommodated by parallel veins of quartz or calcite. An example of a sample with $50 \%$ extension is presented in Fig. 17a. This sample was retrieved from the creeping zone of the San Andreas Fault, California, where much higher extension values are likely to occur. Moreover, when observing slaty cleavages no evidence can be seen of large elongation of grains that could fit the observed measured extension at the massif scale, which commonly ranges from 100 to $400 \%$. Ashby and Verrall (1973) proposed a flow mechanism for large finite deformation that differs fundamentally from other diffusion-accommodated plasticity mechanisms such as Nabarro-Herring and Coble creep (Poirier, 1985). In their model, polycrystalline matter can deform by grain-boundary sliding with the high strain levels being accommodated by a diffusion process along grain boundaries: grains switch neighbours and do not elongate significantly (Konstantinidis and Herrmann, 1998). Boullier and Guéguen (1975) explained the origin of some mylonites by such superplastic flow. As for pressure solution creep law, (Ashby and Verrall, 1973) suggested that the strain rate may be controlled either by diffusion or by interface reactions. When controlled by diffusion, the constitutive equation resembles the Nabarro-Herring-Coble equations but the model predicts strain rates, which are roughly 
one order of magnitude larger. This type of model may be extended to pressure solution if a fluid phase is trapped along the grain boundaries (Fig. 25). It should be noted that such a diffusionaccommodated process may be coupled with very local internal deformation such as "dislocation creep" and/or to mechanical sliding on some specific mineral such as clays in the case of polymineralic aggregates with both soluble and insoluble minerals. However, for the best efficiency of the pressure solution process accommodating grain sliding, the grain size must be as small as possible since the strain rate is inversely proportional to the cube of this grain size (see Section 3). Such pressure solution creep laws (Fig. $19 \& 25$ ) are used to model the viscous behaviour of folding processes: (Laubsher, 1975; Nino et al., 1998).

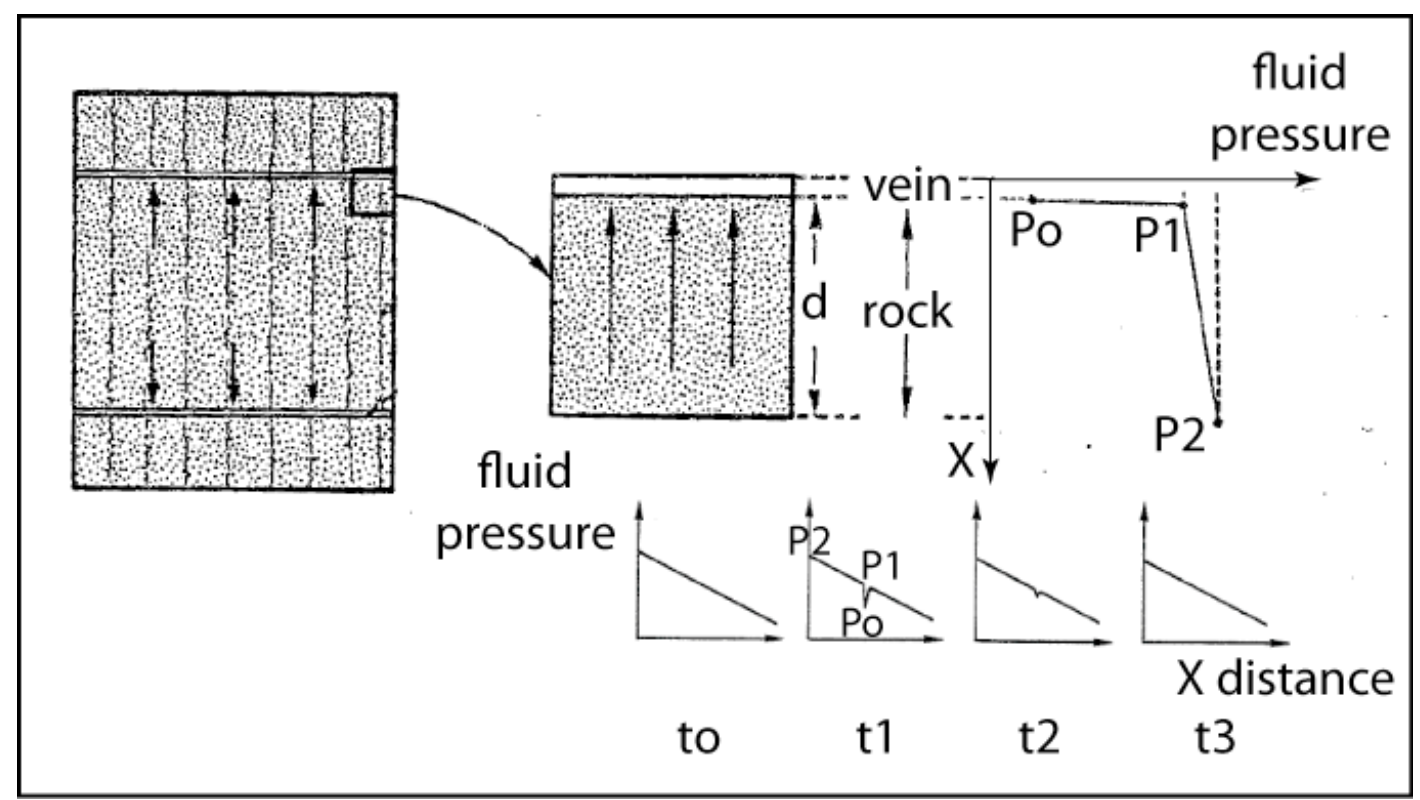

Figure 26: Geometric model of pressure solution deformation with large veins being sealed by fluid advection: change in fluid pressure with time: general head gradient and transient drop in fluid pressure in the veins.

\subsubsection{Modelling of veins filling with fluid advection in creep laws}

Another common observation in slate massifs is the presence of large veins, oriented perpendicular to the maximum extension direction, for example large horizontal veins, of hectometre size, associated with the vertically-extended sedimentary cover of the alpine crystalline massif (Fig. 24b \& 26). No significant change in composition of the slate rocks is seen near the veins and so mass transfer by diffusion from the matrix must be ruled out. It is more likely that the filling of veins is linked to a high degree of fluid advection (Cox and Etheridge, 1989). Evidence of such a high degree of advection is seen in mountain ranges (Marquer and Burkhard, 1992; McCaig, 1988) and associated with large crustal faults (Kennedy et al., 1997; Rice, 1992; Sibson, 1990). It should be noted that even in the case 
of fluid infiltration, a diffusion step along the fluid phase trapped under stress is required if dissolution occurs along solution cleavages. In this case, the limiting process is often diffusion. An alternative possibility is that dissolution occurs in the free fluid near the stressed contact. The difference can be seen easily from geological observation since free pore fluid dissolution must lead to an increase in porosity. In this case, the driving force may be either the difference in fluid pressure between dissolution and deposition sites or the difference in strain energy (Engelder, 1982). As already seen, when the path of diffusion from dissolution site to deposition site is in free fluid, diffusion is generally not the limiting process. Therefore, it is not easy to predict the limiting step in case of fluid advection but it is not excluded that it could be the infiltration rate and in this case the strain rate is inversely proportional to $d$.

Finally, a last problem with such a model is the way the veins open. Developing mode I fractures at 7 $10 \mathrm{~km}$ depth in the Alpine massifs (Gratier and Vialon, 1980), requires an elevated fluid pressure close to the lithostatic pressure. However, a drop in fluid pressure is required in order to precipitate minerals in the veins. Such a pressure drop at each incremental growth has been demonstrated by fluid inclusion studies (Mullis, 1975). It may result from sudden opening of the vein. However, a rather complex scenario is required to model the deformation associated with such large veins: (i) a general pressure gradient is required to move the fluid and (ii) transitory fluid pressure drop events must occur in the veins to precipitate the minerals sufficiently rapidly before the vein closes under the weight of the overlying rock (Fig. 26), so it could most often involve open self-supported cavities. Another possibility is that the minerals in the veins, growing in highly oversaturated fluid, may crystallize under stress (Gratier et al., 2012; Noiriel et al., 2010; Weyl, 1959). Moreover, precipitation in these large veins most often occurs by successive small opening and sealing (1 - 100 microns) (Ramsay, 1980a) and so may be connected with microseismic activity.

\section{3 - Thermodynamics and kinetics of the processes}

As mentioned in the introduction, many mechanisms may be active during ductile deformation in the upper crust: subcritical crack growth, grain sliding, crack healing and stress driven dissolutionprecipitation. In this section, we focus on the latter, three step process at work during pressure solution creep. Firstly, minerals dissolve at grain contacts because of a concentration of stress. Secondly, solutes diffuse along wet grain boundaries. The third and last step is precipitation of solutes at less stressed mineral faces ((Dewers and Ortoleva, 1990; Renard et al., 1999; Rutter, 1976; Weyl, 1959). The local mass transport at the grain scale induces deformation at grain boundaries and free surfaces, causing an overall deformation of the rock. If one of these three steps is slower than the two others, it will control the overall deformation rate. We start by the nature of the interface between two grains 
that is crucial because it is the medium of dissolution and diffusion of matter. The presence and structure of a fluid phase in the grain interface controls the kinetics of the process.

\subsection{Setting the scene: Thermodynamics and kinetics of the fluid phase trapped at grain contacts}

The most important site in pressure solution is the grain contact where stresses are transmitted, solid material is transferred to the fluid phase and subsequently transported to the pore space. Theory, experiments and molecular simulations have taught us a lot about the state of the grain contact (Bresme and Cámara, 2006; Dysthe et al., 2002b; Horn et al., 1988; Israelachvili, 2012; Pashley and Israelachvili, 1984; Renard and Ortoleva, 1997). We will first consider the properties of a small region of two solids where the two solid surfaces are atomically flat and parallel and where $\Delta$ is the separation of the two surfaces and also the thickness of the fluid film between the surfaces. When $\Delta$ is too large to form covalent bonds between the two solids the interactions between the solids shown in Fig. 27 are described by electrostatic interactions and van der Waals interactions (Israelachvili, 2012). The disjoining pressure, the disjoining pressure, $p_{d}$, must, at large separations $\Delta$, be considered as a fluid pressure in excess of the pore fluid pressure, $p_{f}$. Theory, experiments and simulations all show that the mean disjoining pressure increases with decreasing fluid film thickness. Solid surfaces have a different dielectric constant from that of water or brine. In addition, solid surfaces often have charged species; they may even have a net non-zero total charge. It is therefore clear that the environment of ions entering the confined "fluid" phase will in general experience more than just a change in the fluid pressure (French et al., 2010; Kjellander and Marcelja, 1984). The properties of the confined fluid phase are very variable and dependent on the exact nature of the surfaces and the fluids. Experiments (Horn and Israelachvili, 1981; Horn et al., 1989; Israelachvili, 1986; Israelachvili, 2012; Vigil et al., 1994) and molecular simulation (Frenkel and Smit, 2002; Magdar et al., 1985) have demonstrated that the confined fluid properties like pressure, ion concentration, and solubility are not simple, continuous functions of separation, $\Delta$. Care must therefore be taken when applying continuum models to processes at the grain contact scale.

As direct observations and measurements of the grain boundaries are difficult, the transport properties of grain boundaries are often characterized by the product between an effective thickness of the interface, $\Delta_{\mathrm{gb}}$, and an effective diffusion coefficient D. The fluid film thickness, $\Delta_{\mathrm{gb}}$, can vary from about $1 \mathrm{~nm}$ (four molecular water layers) to possibly $100 \mathrm{~nm}$ depending on the nature of the mineral, fluids and the normal stress (Dysthe et al., 2002b). The diffusion coefficient, D, of ions in water at room temperature is of the order $10^{-9} \mathrm{~m}^{2} \mathrm{~s}^{-1}$ and may be reduced by one to two orders of magnitude (Alcantar et al., 2003; Dysthe et al., 2002a) by the structure of a confined fluid film, depending on the 




Fluid film thickness, $\Delta$

Figure 27: Interaction energies between two closely spaced planar solid surfaces in a fluid. Two atomically flat, planar, parallel solid surfaces brought towards contact with a fluid in between will experience two main interactions resulting in three regions of attraction and repulsion. The electrostatic interaction of charged solid surfaces (black) with its diffuse liquid layer of water plus screening counterions will in general result in a positive interaction energy. The van der Waals interaction (blue) has negative interaction energy. The resulting total interaction energy (red) has both positive and negative regions, most notably there is an energy gain in expelling all fluid and bringing the two solids into contact. At intermediate distances $r$ the total interaction energy is positive and the so-called disjoining pressure between the two surfaces $p_{d}=-d U / d \Delta$ is positive. At larger distances there may be an attractive region as well.

film thickness. Consequently, the product of fluid film thickness and diffusion coefficient $\Delta_{\mathrm{gb}} \mathrm{D}$ is of the order $10^{-20}$ to $10^{-16} \mathrm{~m}^{3} \mathrm{~s}^{-1}$.

Using resistivity measurements, (van Noort et al., 2007) measured the product $\Delta_{\mathrm{gb}} \mathrm{D}$ for halite-halite and halite-glass contacts and found values in the range $10^{-19}$ to $10^{-17} \mathrm{~m}^{3} \cdot \mathrm{s}^{-1}$. They showed that this value decreased by one order of magnitude when increasing the normal load across the contact from 1 to $10 \mathrm{MPa}$. Using indenter experiments on quartz, (Gratier et al., 2009) found values $\Delta_{\mathrm{gb}} \mathrm{D}$ in the range 2.5 to $10^{*} 10^{-19} \mathrm{~m}^{3} \cdot \mathrm{s}^{-1}$ at $350^{\circ} \mathrm{C}$. On glass/silica interfaces, impedance spectroscopy measurements have revealed larger values of $\Delta_{\mathrm{gb}} \mathrm{D}$, close to $6^{*} 10^{-18} \mathrm{~m}^{3} \cdot \mathrm{s}^{-1}$ at $300-350^{\circ} \mathrm{C}$ (van Noort et al., 2011). Molecular dynamics simulations of water confined between calcite surfaces have proposed that the thickness of the water film decreases from $100 \mathrm{~nm}$ at $1 \mathrm{~km}$ burial depth to $0.95 \mathrm{~nm}$ at $10 \mathrm{~km}$ depth and that the 
product $\Delta_{\mathrm{gb}} \mathrm{D}$ decreases from $3.2 * 10^{-17}$ to $8.6^{*} 10^{-19} \mathrm{~m}^{3} \cdot \mathrm{s}^{-1}$ for the same depth range (Dysthe et al., 2002a). These values are consistent with the experimental results.

In the seminal work of Weyl (1959) on pressure solution and the force of crystallization, he used two models, one assuming an exponential relation between disjoining pressure $\mathrm{p}_{\mathrm{d}}$ and surface separation $\Delta$ and one with $\mathrm{p}_{\mathrm{d}}$ independent of $\Delta$. Weyl (1959) had some evidence of the existence of a fluid film, but at the time it was still considered hypothetical. He considered the fluid film to be continuous with the bulk fluid, with the same thermodynamic properties like the dependence of solubility on pressure. The fluid pressure inside the fluid film was taken to be the surface normal stress transmitted to the solid surfaces. Furthermore the assumption of continuity, i.e. no jump in pressure and mass conservation resulted in the solution of a continuously varying fluid film thickness in pressure solution (saturated bulk solution) and a growth rim of a certain width during crystallization (supersaturated bulk solution). This continuous stress distribution model of Weyl has recently been shown to be in contradiction with experimental results (Røyne and Dysthe, 2012).

To summarize so far, the fluid-like phase confined between the solid surfaces:

- transmits normal stress between the solid surfaces;

- does not transmit shear stress;

- allows molecular diffusion at rates comparable to a normal liquid;

- should only with the greatest care be treated as continuous with the fluid in the pore space and is perhaps better treated as a separate thermodynamic phase.

Actual grain contacts are not necessarily atomically flat and several conceptual models of rough grain contacts have been proposed. These models all consider the deformation of the solid surfaces: the grain contacts are formed by the non-equilibrium process of pressure solution itself. We will return to these models in due course.

\subsection{The protagonists: Thermodynamics of pressure solution}

In this section we will first develop a small example of the effect of pressure on the solubility of quartz. Then we consider the effect of non-hydrostatic stress and the driving force of pressure solution. There are many different approaches, both equilibrium and non-equilibrium, to deriving the driving forces of pressure solution. Luckily, they all end up with essentially the same driving forces. To increase the readability we have chosen to give a simple exposition of the thermodynamics and kinetics of the process first and present a historical overview of different contributions to the field in a separate section. Except for temperature, $T$, we will use capital letter symbols for extensive quantities and lower case symbols for intensive quantities. Specific quantities are molar quantities, for example the molar volume is $v=V / N$, where $N$ is the number of moles in volume $V$. We will use subscript s for solid and subscript 1 for liquid. 


\subsubsection{Effect of pressure on the chemical potential of dissolved quartz}

The state of pressure of a solid has a significant effect on its chemical potential. The effect is to increase the molar free energy of a solid pressurized at $p$ compared to that at a reference pressure state $p_{0}$ (Gibbs, 1877). At constant pressure and temperature, the state of energy of solids can be fully described by the solid chemical potential $\mu_{\mathrm{s}}$. If tangential stress on the solid surface is zero, the chemical potential can be written:

$$
\mu_{s}\left(T, p_{n}\right)=\mu_{0}\left(T, p_{0}\right)+\left(p-p_{0}\right) v_{s}
$$

where $\mu_{s}$ is the chemical potential of the solid component in contact with the solution, $\mu_{0}$ is the chemical potential for the solid at pressure $p_{0}$ and temperature $T, p$ is the hydrostatic pressure on the solid surface and $v_{s}=V / N$ is the molar volume of the solid at pressure $p$. The equilibrium of a solid with its solution depends on temperature and is described by an equilibrium constant $K_{e q}$. For a typical reaction such as quartz dissolution, the chemical equilibrium is described by

$$
\mathrm{SiO}_{2}+2 \mathrm{H}_{2} \mathrm{O} \Leftrightarrow \mathrm{H}_{4} \mathrm{SiO}_{4}
$$

where $\mathrm{SiO}_{2}$ is a solid and $\mathrm{H}_{4} \mathrm{SiO}_{4}$ is the silica in solution. The equilibrium constant of this reaction is calculated using the ratio of the activity coefficients of the products and the reactants:

$$
K_{e q}=\frac{a_{\mathrm{H}_{4} \mathrm{SiO}_{4}}}{a_{\mathrm{H}_{2} \mathrm{O}}{ }^{2} a_{\mathrm{SiO}_{2}}}
$$

where, for dilute aqueous solutions, the activity of water $a_{\mathrm{H}_{2} \mathrm{O}}$ is equal to 1 . The activity of dissolved silica $a_{\mathrm{H}_{4} \mathrm{SiO}_{4}}=\chi_{\mathrm{H}_{4} \mathrm{SiO}_{4}} c_{\mathrm{H}_{4} \mathrm{SiO}_{4}}$ is the product between the activity coefficient $\chi_{\mathrm{H}_{4} \mathrm{SiO}_{4}}$ that varies slightly around 1 , depending on salinity and solute concentration, and the concentration of silica in water $c_{\mathrm{H}_{4} \mathrm{SiO}_{4}}$. For the purpose of simplification, we will consider that $\chi_{\mathrm{H}_{4} \mathrm{SiO}_{4}}=1$ in the following; this is a reasonable assumption for aqueous solution with low solute concentration.

For the dissolution of quartz, it remains from Eq. (7) that the equilibrium constant is equal to the concentration of silica in a solution at a given pressure and temperature. The chemical potential is related to the equilibrium constant through $\mu_{q z}=R T \ln \left(K_{e q}\right)$. Thus, the equilibrium constant varies with pressure

$$
K_{e q}=c_{H_{4} \mathrm{SiO}_{4}, e q}=K_{0}\left(T, p_{0}\right) \cdot \exp \left(\frac{\left(p-p_{0}\right) v_{s}}{R T}\right)
$$

where $c_{\mathrm{H}_{4} \mathrm{SiO}_{4} \text {,eq }}$ is the equilibrium concentration of silica in solution, $K_{0}\left(T, p_{0}\right)$ is the equilibrium constant for the solid (quartz grain for example) at a pressure $p_{0}$, whose value depends mainly on 


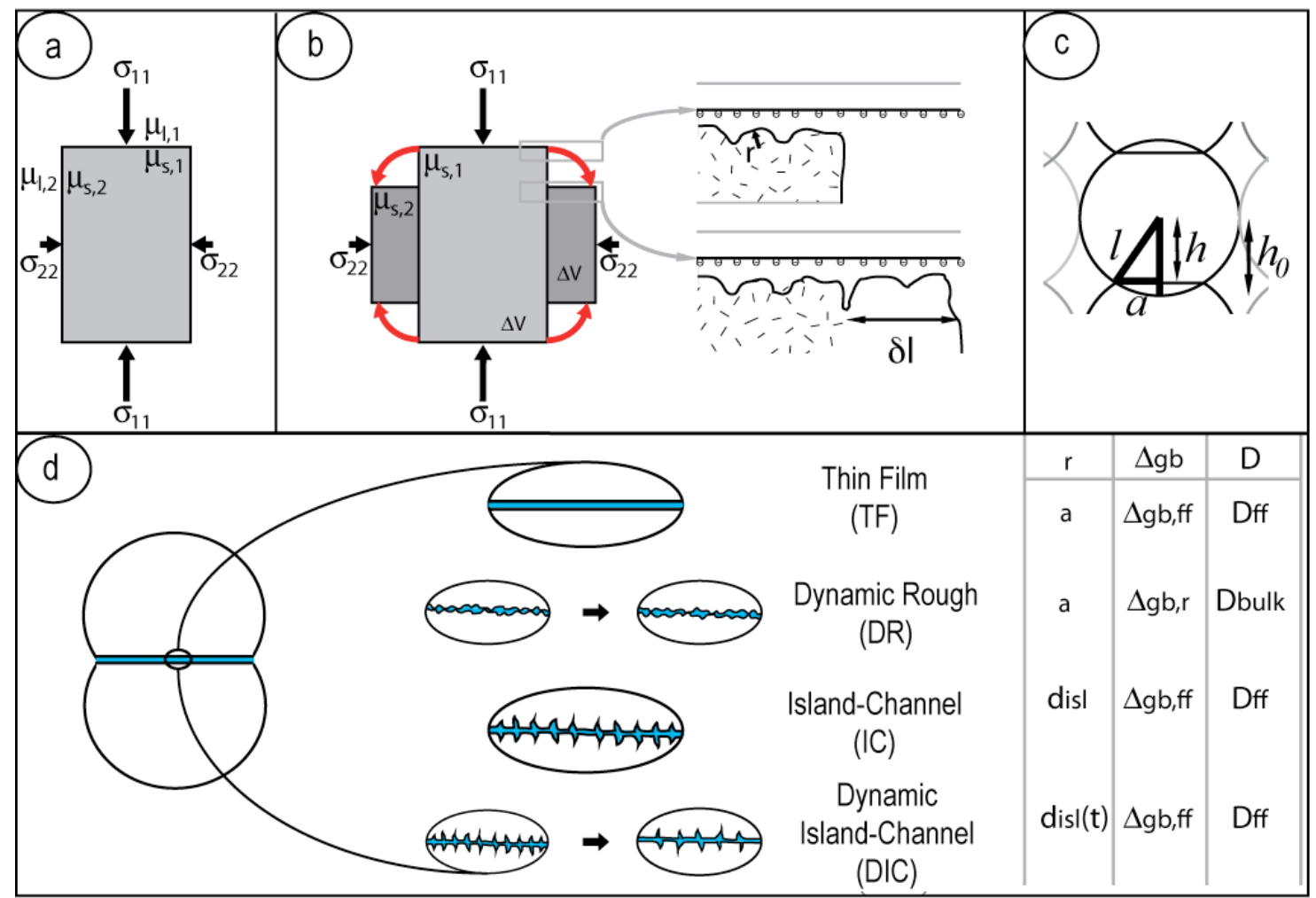

Figure 28: Driving force of pressure solution: (a) Surface normal stresses on a grain and the chemical potentials of the solid and liquid at the different interfaces; (b) Grain deformation by transfer of a volume $\Delta \mathrm{V}=1^{2} \delta 1$ under the same stresses resulting in the deformation work $W=\Delta V\left(\sigma_{11}-\sigma_{22}\right)$, enlargement on the right: contributions of surface curvature, $r$, to the Helmholtz energy, $f_{\gamma}$, the "electrochemical" contribution of the surface charges, $f_{s c}$, and the contribution of dislocations, $f_{d}$, in the original crystal. If a steady state deformation is reached, the typical surface curvatures and surface charges must be constant and the only energy change on deformation is proportional to the change in contact area $\Delta \mathrm{A}=l \delta l$ ( $l$ is the characteristic dimension of the crystal). If the precipitated material is without dislocations and unaffected by the stress component $\sigma_{11}$ these energy terms, $f_{d}$ and $f_{e l}$ are proportional to the displaced volume $\Delta \mathrm{V}$. (c) Geometry of uniaxial compaction of a simple cubic packing of spheres: grain radius, $l$, grain contact radius, $a$, and corresponding height in the packing $h(t)$, where $h(0)=h_{0}$. (d): Four cartoon models of the grain boundary during pressure solution and the parameter combinations that distinguish them. The rate limiting transport length, $r$, is either the entire grain boundary radius, $a$, or an average island size, $d_{i s l} \sim(0.1-10) \mu \mathrm{m}$, that is either a constant or that increases with time, $\mathrm{d}_{\text {isl }}(\mathrm{t}) \sim \mathrm{t}^{1 / 3}$. The grain boundary width, $\Delta_{\mathrm{g} b}$, is either the fluid film thickness $\Delta_{\mathrm{gb}, \mathrm{ff}} \sim$ 1-10 (possibly 1-100) $\mathrm{nm}$ or an effective width of a rough contact $\Delta_{\mathrm{gb}, \text { ff }} \sim 0.1-10 \mu \mathrm{m}$. The diffusion coefficient is either that of the bulk fluid, typically $\mathrm{D}_{\text {bulk }} \sim 10^{-9} \mathrm{~m}^{2} / \mathrm{s}$ at $25^{\circ} \mathrm{C}$, or that of a confined fluid film, $\mathrm{D}_{\mathrm{ff}} \sim\left(10^{-1}-10^{-2}\right) \mathrm{D}_{\text {bulk }}$. 
temperature. For quartz, taking $v_{s}=22.6810^{-6} \mathrm{~m}^{3} / \mathrm{mol}, T=298{ }^{\circ} \mathrm{K}, R=8.32 \mathrm{~J} \cdot \mathrm{mol}^{-1} .{ }^{\circ} \mathrm{K}^{-1}, p_{0}=0.1$ MPa, $p=100 \mathrm{MPa}$ (hydrostatic fluid pressure at $10 \mathrm{~km}$ depth) and the solubility of quartz $c_{\mathrm{H}_{4} \mathrm{SiO}_{4}}=0.1 \mathrm{~mol} . \mathrm{m}^{-3}$ at room temperature and pressure $\left(T_{0}=298^{\circ} \mathrm{K}, p_{0}=0.1 \mathrm{MPa}\right)$ given by Rimstidt and Barnes (1980), one obtains a concentration of quartz of $0.25 \mathrm{~mol} . \mathrm{m}^{-3}$, a 2.5 times increase compared to atmospheric pressure.

\subsubsection{Chemical potential of solids in contact with their solution}

We choose to start by the Gibbs, $G$, and Helmholtz, $F$, free energies of a solid of volume $V$ subject to a hydrostatic pressure $p$ :

$$
G=p V+F .
$$

Dividing by the number of moles, the chemical potential at surface $i$ of a solid (Fig. 28a) may be expressed as:

$$
\mu_{s, i}=\sigma_{i i} v_{s}+f_{s}, \quad f_{s}=f_{e l}+f_{d}+f_{\gamma}+f_{s c}
$$

where $f_{s}$ is the specific Helmholtz free energy of the solid and $\sigma_{i i}$ is the stress normal to surface $i$, defined as positive when pointing into the solid, thus $p=\frac{1}{3} \sum \delta_{i j} \sigma_{i j}$. The five terms contributing to the chemical potential are summarized in the following:

1. The work related to the change of volume under surface normal stress accounts for the largest contribution to the chemical potential of the solid adjacent to the surface: $\mu_{s p, i}=v_{s} \sigma_{i i}$, $\mu_{s p}=v_{s} p$

2. The elastic term of the specific Helmholtz free energy accounts for the non-hydrostatic strain energy:

$$
f_{e l}=\sum_{i j} v_{s}\left(\sigma_{i j}-p\right) d \varepsilon_{i j}=\sum_{i j} \frac{v_{s}\left(\sigma_{i j}-p\right) d \sigma_{i j}}{(1-v) E}
$$

where the latter equality is valid for isotropic solids with Young's modulus $E$ and Poisson's ratio $v$. The ratio between the energy due to hydrostatic pressure and energy due to elastic strain (for the same magnitude of hydrostatic pressure and non-hydrostatic stress) is $\frac{\mu_{s p}}{f_{e l}}=(1-v) \frac{E}{\sigma_{i i}} \leq 1000$ for quartz because the Young's modulus is typically 1000 times larger than the yield stress. Thus for most rock materials and stress conditions, the energy related to surface normal stress is much larger than the non-hydrostatic strain energy term.

3. The plastic strain energy, $f_{d}$, of a crystalline solid is stored in defects, such as dislocations. For a large enough density of dislocations, for example greater than $10^{10}$ dislocations per $\mathrm{cm}^{2}$ for quartz, the free energy of a crystal can be significantly increased (Table 1). The energy of a 
dislocation can be divided in two terms: the energy of the core of the dislocation itself, and the strain energy due to the deformation of the crystalline lattice (Wintsch and Dunning, 1985). This induces an increase of the solubility of quartz. For example, at $400^{\circ} \mathrm{C}$ and $300 \mathrm{MPa}$, a value of $10^{10}$ dislocation per $\mathrm{cm}^{2}$ in quartz may induce an increase of solubility close to $1 \%$. For non-deformed quartz crystals, the density of dislocation is usually smaller than $10^{9} \mathrm{~cm}^{-2}$ which is not sufficient to obtain a significant increase of the chemical potential of the solid.

4. The surface energy contribution, $f_{\gamma}=\frac{2 v_{s} \gamma}{r}$, to the Helmholtz energy may be viewed as an enhanced pressure contribution to the chemical potential (Kingery et al., 1976). The Laplace pressure difference over a curved interface is $\Delta p=\frac{2 \gamma}{r}$, thus for typical interfacial energies of mineral-water interfaces of $0.1-1 \mathrm{~J} / \mathrm{m}^{2}$ (Parks, 1984) a radius of curvature of $10^{-6} \mathrm{~m}$ corresponds to pressures in the range $0.2-2 \mathrm{MPa}$. This contribution to the Helmholtz energy affects a volume of typically the surface area $A$ times the typical radius of curvature, $r$, of surface roughness: $r A$, thus the effects can only be found on small length scales, like for the organization of the grain boundary.

5. The last term, $f_{s c}$, is also a surface contribution to the Helmholtz energy accounting for the effect of surface charges and ionic environment affecting the local solubility and strength of intermolecular bonds of the solid. The term $f_{s c}$ will only contribute to the change of energy of the system if the state of the interface (ion concentrations etc.) changes during the process or if the area of contact changes. The solid volume affected by this surface effect is the area times some small length scale, $\xi$, typically a few molecular layers thick, ie. $\sim 10^{-9} \mathrm{~m}$. This may be very important on a local grain boundary scale when the interface structure is modified, but during the deformation of whole grains the total change in surface energy is small compared to volume energies like $\mu_{s, p}, f_{e l}$ and $f_{d}$.

Although the four latter terms are much smaller than the first term (Table 2), they may be very important in determining the local shape and organization of the grain boundary and thereby the kinetics of the process.

\subsubsection{Driving force of pressure solution}

The classical way of considering the thermodynamic driving force of a process is to calculate changes to a well defined thermodynamic system. Fig. $28 \mathrm{~b}$ portrays the most important contribution in pressure solution, the work $W$ performed by the surroundings on a solid grain when a volume $\Delta V$ is moved from face 1 to face 2 :

$$
W=\Delta V\left(\sigma_{11}-\sigma_{22}\right)
$$




\begin{tabular}{lcccc}
\hline$\rho$ (dislocations. $\left.\mathrm{cm}^{-2}\right)$ & $10^{9}$ & $10^{10}$ & $10^{11}$ & $10^{12}$ \\
\hline$f_{d}($ Joule $/ \mathrm{mol}), \min$. & 2.24 & 19.70 & 169.76 & 1425.68 \\
$f_{d}($ Joule $/ \mathrm{mol}), \max$. & 3.03 & 29.06 & 290.62 & 2906.25 \\
\hline
\end{tabular}

Table 1: Effect of the density of dislocation $\rho$ inside a quartz crystal on the internal energy, at $400^{\circ} \mathrm{C}$ and $300 \mathrm{MPa}$ (Wintsch and Dunning, 1985). The range of minimum and maximum values is given.

\begin{tabular}{lcccc}
\hline $\begin{array}{l}\text { Energy } \\
\text { contribution }\end{array}$ & $\mu_{s p}$ & $f_{e l}$ & $f_{d}$ & $f_{\gamma}$ \\
\hline Work energy & $\begin{array}{c}\text { Elastic strain } \\
\text { energy }\end{array}$ & $\begin{array}{c}\text { Plastic strain } \\
\text { energy }\end{array}$ & $\begin{array}{c}\text { Surface } \\
\text { tension } \\
\text { energy }\end{array}$ \\
\hline Joule.mol $^{-1}$ & 6800 & 13 & 3 & 0.4 \\
\hline
\end{tabular}

Table 2: Order of magnitude of the different energy contributions given in Eq. (10) for a quartz grain, 100 micrometres radius, at $400^{\circ} \mathrm{C}, 300 \mathrm{MPa}$, with a concentration of dislocations of $10^{9} \mathrm{~cm}^{-2}$.

Identifying this work as the change in free energy of the grain and dividing by the mass of the volume $\Delta V$ displaced one obtains the "work term of the driving force" of pressure solution:

$$
\Delta \mu_{W}=\mu_{s p, 1}-\mu_{s p, 2}=v_{s}\left(\sigma_{11}-\sigma_{22}\right),
$$

which we may identify as originating from term 1 of the chemical potential of the solid in the list above. Considering Fig. 28b, the total change in free energy of the solid grain is

$$
v_{s} \Delta G=\Delta V\left(\mu_{s p, 1}+f_{e l, 1}+f_{d, 1}-\mu_{s p, 2}-f_{e l, 2}-f_{d, 2}\right)+\Delta A r\left(f_{\gamma, 1}-f_{\gamma, 2}\right)+\Delta A \xi\left(f_{s c, 1}-f_{s c, 2}\right)
$$

Dividing by the volume change $\Delta \mathrm{V}$ :

$$
\begin{aligned}
\Delta \mu_{t o t} & =\left(\mu_{s p, 1}+f_{e l, 1}+f_{d, 1}-\mu_{s p, 2}-f_{e l, 2}-f_{d, 2}\right)+\frac{r}{l}\left(f_{\gamma, 1}-f_{\gamma, 2}\right)+\frac{\xi}{l}\left(f_{s c, 1}-f_{s c, 2}\right) \\
& =\mu_{s, 1}-\mu_{s, 2}
\end{aligned}
$$

This demonstrates that the surface tension and surface charge effects are negligible as driving forces unless the grain size, $l$, is very small. The smaller terms (2-5 in the list above) of the chemical potential may, however contribute significantly to the organization of the interfaces and thereby to the kinetics of the process.

We have already mentioned that pressure solution is a three steps process. During the process the system is out of equilibrium and one must consider the chemical potential along the entire path of the process. The first step is the subdivision shown in Fig. 28a into the three steps and three driving forces.

- Dissolution $\Delta \mu_{D}=\mu_{s, 1}-\mu_{l, 1}$ 
- Transport $\Delta \mu_{T}=\mu_{l, 1}-\mu_{l, 2}$

- Precipitation $\Delta \mu_{\mathrm{P}}=\mu_{1,2}-\mu_{\mathrm{s}, 2}$

For a closed system, all three steps are necessary and one regains $\Delta \mu_{t o t}$ of Eq. (14) where the driving force is determined by the solid grain only. For an open system, $\mu_{l, 2}$ may be determined by long distance advection or diffusion of material and one may consider only the first two steps of the process. Alternatively one may choose to split the transport step as consisting of two parts, grain contact diffusion (short range) and long range transport.

\subsection{The action: Kinetics of pressure solution}

It is conceivable to perform a direct simulation of the whole three steps process and treat the chemical potential as a continuous variable from $\mu_{\mathrm{s}, 1}$ to $\mu_{\mathrm{s}, 2}$ (Dewers and Ortoleva, 1990; Gundersen et al., 2002a; Raj, 1982). There is however much insight to be gained in the traditional approach of assuming that one of the three steps is much slower than the other two processes. These assumptions may for closed systems be translated into conditions on the driving forces:

- Dissolution limited kinetics

$$
\begin{aligned}
& \mu_{l, 1}=\mu_{l, 2}=\mu_{s, 2} \Rightarrow \Delta \mu_{D}=\mu_{s, 1}-\mu_{s, 2} \\
& \mu_{s, 1}=\mu_{l, 1}, \mu_{l, 2}=\mu_{s, 2} \Rightarrow \Delta \mu_{T}=\mu_{s, 1}-\mu_{s, 2} \\
& \mu_{s, 1}=\mu_{l, 1}=\mu_{l, 2} \Rightarrow \Delta \mu_{P}=\mu_{s, 1}-\mu_{s, 2}
\end{aligned}
$$$$
\text { - Transport limited kinetics }
$$

- Precipitation limited kinetics

Using these assumptions, the driving force for pressure solution is identical for the three cases; however the rate at which this occurs will depend on the limiting step. Pressure solution of quartz is known to be dissolution limited at low temperature, below $150^{\circ} \mathrm{C}$ (Bjorkum et al., 1998) but is controlled by diffusion at higher temperature (Gratier et al., 2009), that of soluble salts like $\mathrm{NaCl}$ (Spiers and Brzesowsky, 1993) to be transport limited, however, special impurities that attach to the surfaces of calcite (Zhang et al., 2010) and quartz (Bjorkum et al., 1998; Bjorlykke and Hoeg, 1997) may render pressure solution of these minerals precipitation limited. We will consider the two first steps in the following sections. The kinetics of precipitation in this context does not distinguish itself from precipitation and crystal growth in other geological context and we will not discuss it any further.

\subsubsection{Geometry of aggregates, fluxes and strains}

The main processes we consider here relate to two grains with a single grain boundary. A sediment or a rock consists of an aggregate of grains and the deformation of the sediment or rock is the sum of discrete dissolution-transport-precipitation processes.

\subsubsection{Strain rate, fluxes and grain dimension}


Consider an aggregate of spherical grains of average radius $l$. Let the grain boundary radius be $a$ and let the grain boundary fluid thickness be $\Delta_{\mathrm{gb}}$. Then the average grain boundary region has an area of $\pi \mathrm{a}^{2}$ facing the grains and an area $2 \pi a \Delta_{g b}$ facing the surrounding fluid. The fluxes of dissolution, $j_{D}$, and transport, $j_{T}$, (moles per unit time per unit area) are related by conservation of mass, $j_{D} \pi \mathrm{a}^{2}=j_{T} 2 \pi \mathrm{a} \Delta_{\mathrm{gb}}$. The strain rate of the grain aggregate is then:

$$
\dot{\varepsilon}=\frac{1}{l} \frac{d l}{d t}=\frac{1}{l} \mathrm{v}_{\mathrm{s}} j_{D}=\frac{2 \Delta_{g b}}{l a} \mathrm{v}_{\mathrm{s}} j_{T}=\frac{2 v_{\mathrm{s}} j_{T} \Delta_{\mathrm{gb}}}{l^{2}(a / l)}
$$

We will see that for compaction by pressure solution it is practical to express the shape change of the grains as the ratio of grain boundary radius to grain radius $a / l$. Equation 18 will be the basis for rate laws for aggregates' deformation, whatever expression of fluxes we choose. For low porosity rocks $a / l$ $=1$ and this factor is of little interest.

\subsubsection{Simplest model: spherical grains}

In Figure 28c we show one spherical grain of radius $l$ in a simple cubic stack. The distance from the grain center to the grain boundary is $h(t)$ and $h_{0}=h(t=0)$. The uniaxial strain of the aggregate is

$$
\varepsilon=\frac{h_{0}-h}{l} \approx 1-\frac{h}{l}, \text { for } h_{0} \approx l .
$$

The grain boundary radius is $a=\sqrt{l^{2}-h^{2}}$ and we obtain a simple relation between the uniaxial strain and the ratio between grain boundary radius and grain radius:

$$
\frac{a}{l}=\sqrt{1-\left(\frac{h}{l}\right)^{2}}=\sqrt{\left(1-\frac{h}{l}\right)\left(1+\frac{h}{l}\right)}=\sqrt{\varepsilon(2-\varepsilon)} .
$$

Finally, this yields a simple relation between the stress imposed on the aggregate, $\sigma_{0}$, and the contact stress $\sigma_{11}(\varepsilon)$ as a function of strain:

$$
\sigma_{11}(\varepsilon)=\sigma_{0}\left(\frac{l}{a}\right)^{2}=\frac{\sigma_{0}}{\varepsilon(2-\varepsilon)} \propto \frac{\sigma_{0}}{\varepsilon} .
$$

The last proportionality signifies that to leading order the contact stress scales inversely with strain. Hexagonal packing, random packing or other packings of spherical grains have the same scaling of the contact stress with strain, only a multiplicative factor changes.

\subsubsection{Rate of dissolution}

\subsubsection{Non-equilibrium thermodynamics}


We have already established that the driving force of dissolution is $\Delta \mu_{D}=\mu_{s, 1}-\mu_{l, 1}$. There are several ways of treating the kinetics of dissolution. In non-equilibrium thermodynamics the dissolution flux $j_{D}$ (moles per unit time per unit area) is considered to be linear in the jump condition $\Delta \mu_{D}$ at the sharp interface (de Groot and Mazur, 1984):

$$
j_{D}=k_{\mu} \Delta \mu_{D}
$$

where $j_{D}$ is the dissolution flux and $k_{\mu}$ a dissolution rate constant. This relation is also inherent in diffuse interface (as opposed to sharp interface) models like the Cahn-Hilliard equation (Cahn and Hilliard, 1958) where transport in both bulk and through the interface is treated as diffusion. If one wants to model the process in a self-consistent manner the value of $\mu_{l, 1}$ will depend on $k$ (or the diffusion coefficient of the interface) and the other parameters of the model. For the dissolution limited case the work term of the driving force is $\Delta \mu_{D}=v_{s}\left(\sigma_{11}-\sigma_{22}\right)$ and the strain rate of the system is from Eq. (18):

$$
\dot{\varepsilon}=\frac{v_{s} j_{D}}{l}=\frac{k_{\mu}\left(\sigma_{11}-\sigma_{22}\right) v_{s}^{2}}{l}
$$

where $\sigma_{22}$ may be exchanged for the pore fluid pressure, $p_{f}$, in deformation of porous aggregates. The strain rate is linear in stress, that is, the dissolution limited strain rate is a Newtonian viscous rheology.

\subsubsection{Concentration-based jump conditions}

An alternative path to develop the dissolution rate is to consider the fluid chemical potential

$$
\mu_{l, 1}(p, T, c)=\mu_{0}(p, T)+R T \ln (a),
$$

where $R$ is the universal gas constant, a $=\chi \mathrm{c}$ is the activity of the solute $\chi$ is the activity coefficient $(\chi=1$ for an ideal solution) and $c$ the concentration of the dissolved solid material in the fluid, and subscript 0 signifies the reference state of $c=0$. Using the dissolution limited case as an example again:

$$
\Delta \mu_{D}=\mu_{s, 1}-\mu_{s, 2}=\left(\sigma_{11}-\sigma_{22}\right) v_{s}=R T \ln \frac{c\left(\sigma_{11}\right)}{c\left(\sigma_{22}\right)} .
$$

Here we have used the solid-fluid equilibrium condition, $\mu_{l, i}(p, T)=\mu_{s, i}(p, T)$ and we have assumed that the surface normal stress is equivalent to the fluid pressure of a "normal fluid" in this equilibrium condition. Then, the interface jump expressed in concentration is

$$
\Delta c=c\left(\sigma_{11}\right)-c\left(\sigma_{22}\right)=c\left(\sigma_{22}\right)\left[e^{\frac{\left(\sigma_{11}-\sigma_{22}\right) v_{s}}{R T}}-1\right] \text {. }
$$


If one assumes the dissolution rate to be proportional to the concentration jump, $j_{D}=-k_{c} \Delta c$, one may then conclude that the strain rate is

$$
\dot{\varepsilon}=\frac{\mathrm{v}_{\mathrm{s}} j_{D}}{l}=\frac{\mathrm{k}_{\mathrm{c}} \mathrm{v}_{\mathrm{s}} \mathrm{c}\left(\sigma_{22}\right)}{l}\left[\mathrm{e}^{\frac{\left(\sigma_{11}-\sigma_{22}\right) \mathrm{v}_{\mathrm{s}}}{\mathrm{RT}}}-1\right],
$$

that is, a non-linear viscous rheology. It is worth discussing in what range of stresses $\left(\sigma_{11}-\sigma_{22}\right)$ the strain rate above represents a non-linear rheology. The approximation $e^{x}-1 \approx x$ is wrong by a factor 2 for $x \approx 1.25$. Thus for quartz at $300 \mathrm{~K}$ we may calculate the reasonable range of stresses for the linear approximation to be

$$
\frac{\left(\sigma_{11}-\sigma_{22}\right) v_{s}}{R T}<1.25 \Rightarrow\left(\sigma_{11}-\sigma_{22}\right)<0.13 G P a .
$$

However, this is not a test of the assumption $j_{D}=-k_{c} \Delta c$ or the assumption of the state of the confined fluid.

\subsubsection{Activation barrier to dissolution}

We will now discuss dissolution kinetics based on the basic concept of rates of change limited by an activation barrier. This is the basis of many statistical mechanical models and of the Arrhenius equation, Eyring rate theory or transition state theory of chemical reactions. The following example is not rigorous and is included to illustrate a possible rationale of three aspects: non-linear rheology, electrochemical effects and confined fluid films.

Consider a liquid in a state where dissolved solid molecules are characterized by $\mu_{l}$ and a solid at chemical potential $\mu_{s}>\mu_{l}$. Assume that there is an interfacial phase or state between the solid and liquid where the solid molecules going from solid to dissolved state (or inverse) have to be "activated" to the molar energy $g_{A}>\mu_{\mathrm{s}}$. This assumption of an activated transition state differs from the nonequilibrium thermodynamic assumption of a sharp or diffuse interface with a linear transport coefficient. The probability $P_{\mathrm{s}-1}$ of some molecule in the solid to cross the activation barrier is

$$
P_{s-l}=\frac{N_{s}}{Z_{s}} e^{-\left(g_{A}-\mu_{s}\right) / R T},
$$

where $Z_{s}$ is the partition function of the solid and $N_{s}$ is the number of molecules in the solid adjacent to the interface. The probability of the opposite jump is

$$
P_{l-s}=\frac{N_{l}}{Z_{l}} e^{-\left(g_{A}-\mu_{l}\right) / R T},
$$

where $N_{l}$ is the number of molecules in the liquid adjacent to the interface. The dissolution rate is proportional to the difference in probabilities: 


$$
\begin{aligned}
& \mathrm{j}_{\mathrm{D}} \propto \frac{N_{l}}{\mathrm{Z}_{1}} \mathrm{e}^{-\left(\mathrm{g}_{\mathrm{A}}-\mu_{1}\right) / \mathrm{RT}}\left(\frac{N_{s}}{N_{l}} \frac{\mathrm{Z}_{l}}{\mathrm{Z}_{\mathrm{s}}} \mathrm{e}^{\left(\mu_{\mathrm{s}}-\mu_{1}\right) / \mathrm{RT}}-1\right) \\
& \dot{\varepsilon} \propto \mathrm{j}_{\mathrm{D}} \propto \mathrm{e}^{-\mathrm{g}_{\mathrm{A}} / \mathrm{RT}}\left(\mathrm{e}^{\left(\mu_{11}-\mu_{22}\right) \mathrm{v}_{\mathrm{s}} / \mathrm{RT}}-1\right)
\end{aligned}
$$

Here we have assumed that $N_{s} Z_{l} / N_{l} Z_{s} \sim 1$, that the system is dissolution limited and regained an expression of the dissolution rate of the same form as Eq. (27). Thus in cases where dissolution studies have shown that there is a significant activation barrier, one may have to consider dissolution controlled pressure solution as a non-Newtonian rheology. The apparent contradiction between Eqs. (23), (27) and (31) is equivalent to the result of de Groot and Mazur (1984) (p205) that "the linear relations of thermodynamics of irreversible processes hold for chemical reactions when the condition $\mathrm{A}<<\mathrm{RT}$ is satisfied". This is similar to the condition in Eq. (28). More recent work (Kjelstrup et al., 2010), (chapter 7) demonstrates that one may obtain non-linear flux-force relationships in the framework of irreversible thermodynamics if one integrates the entropy production along the reaction pathway (that includes the energy barrier). We hope this simple illustration will prompt research into a proper formulation of the transition state theory of pressure solution and how this relates to an irreversible thermodynamics formulation. This would clarify the question of pressure solution being a linear or non-linear rheology we have raised here. A proper treatment of transition state theory of dissolution in confined fluids and under stress will also be necessary to understand the electrochemical effects of ions in solution and surface charges.

Finally we will mention that for dissolution rate limitation the only strain hardening effect is through the grain contact stress (see Eq. 21):

$$
\begin{aligned}
& \dot{\varepsilon} \propto \frac{\sigma_{0}}{\varepsilon l} \text { from Eq. (23), or } \\
& \dot{\varepsilon} \propto \frac{\exp \left(\frac{\sigma_{0} v_{s}}{\varepsilon R T}\right)-1}{l} \text { from Eqs. (27) or (31). These scaling relations may be compared }
\end{aligned}
$$

to the expressions in Table 3 and experimental exponents in Table 5.

\subsubsection{Rate of transport}

The transport flux, $j_{T}$, by diffusion may be expressed as a diffusion coefficient, $D$, times the gradient in chemical potential:

$$
j_{T}=-D\left(\frac{\mathrm{dc}}{\mathrm{d} \mu}\right) \nabla \mu_{\mathrm{T}} \approx-D \frac{\mathrm{c}}{R T} \nabla \mu_{\mathrm{T}}=-D \frac{\mathrm{c}}{R T} \frac{\Delta \mu_{\mathrm{T}}}{r},
$$

where $r$ is the transport length. This expression for the transport flux may be inserted into Eq. (18), but there are still some parameters to be determined. It is worth noting that unlike dissolution, that is an activated process, diffusion in a liquid phase is truly linear in the chemical potential. We state this 


\begin{tabular}{|c|c|c|}
\hline mechanism of deformation & stress-strain rate relationship & reference \\
\hline $\begin{array}{l}\text { Pressure solution creep } \\
\text { (limited by diffusion) }\end{array}$ & $\dot{\varepsilon} \propto \frac{D_{a} \delta v_{s} c \sigma_{e}^{\lambda}}{\operatorname{RTd}^{3}}$ & Rutter (1976) \\
\hline $\begin{array}{l}\text { Pressure solution creep } \\
\text { (limited by surface kinetics) }\end{array}$ & $\dot{\varepsilon}_{1} \propto \frac{\overline{\mathrm{v}_{\mathrm{s}}} \mathrm{c} \sigma_{\mathrm{e}}^{\lambda}}{\mathrm{RTd}} \mathrm{k}_{\mathrm{cin}}$ & Raj and Chyung (1981) \\
\hline $\begin{array}{l}\text { Pressure solution creep } \\
\text { (limited by diffusion) }\end{array}$ & $\dot{\varepsilon}_{2} \propto \frac{\mathrm{v}_{\mathrm{s}} \mathrm{c \sigma _{ \textrm {e } } ^ { \lambda }}}{\eta \mathrm{d}^{3}}$ & Raj and Chyung (1981) \\
\hline $\begin{array}{l}\text { Pressure solution creep } \\
\text { (diffusion }+ \text { surface kinetics) }\end{array}$ & $\dot{\varepsilon}=\frac{\varepsilon_{1} \varepsilon_{2}}{\varepsilon_{1}+\varepsilon_{2}}$ & Raj and Chyung (1981) \\
\hline $\begin{array}{l}\text { Pressure solution creep } \\
\text { (limited by surface kinetics), exponential } \\
\text { dependence on stress }\end{array}$ & $\dot{\varepsilon} \propto \frac{\mathrm{k}_{\mathrm{c}} \mathrm{v}_{\mathrm{s}} \mathrm{c}}{\mathrm{d}}\left[\mathrm{e}^{\frac{\sigma_{\mathrm{e}} \mathrm{v}_{\mathrm{s}}}{\mathrm{RT}}}-1\right]$ & see Eq. (27) \\
\hline $\begin{array}{l}\text { Pressure solution creep } \\
\text { (limited by diffusion) exponential } \\
\text { dependence on stress }\end{array}$ & $\dot{\varepsilon} \propto \frac{\mathrm{D}_{\mathrm{a}} \delta \mathrm{v}_{\mathrm{s}} \mathrm{c}}{\mathrm{d}^{3}}\left[\mathrm{e}^{\frac{\sigma_{\mathrm{e}} \mathrm{v}_{\mathrm{s}}}{\mathrm{RT}}}-1\right]$ & see Eq. (35) \\
\hline $\begin{array}{l}\text { Pressure solution creep } \\
\text { (limited by diffusion) taking into account } \\
\text { grain deformation }\end{array}$ & $\dot{\varepsilon} \propto \frac{\mathrm{D}_{\mathrm{a}} \delta \mathrm{v}_{\mathrm{s}} \mathrm{c} \sigma_{\mathrm{e}}}{\mathrm{RTd}^{3}}\left[\frac{(1-\varepsilon)^{1 / 3}}{\varepsilon^{2}}\right]$ & $\begin{array}{l}\text { Equation } 8 \text { in Spiers and } \\
\text { Brzesowsky (1993) and Eqs. } \\
(21) \&(33) \text { here }\end{array}$ \\
\hline
\end{tabular}

Table 3: Flow laws of deformation by pressure resolution, depending on the limiting rate for deformation. Notations: $\sigma_{e}$ : effective stress (load stress minus pore pressure or difference of normal stress between two faces of a grain) (Pa); T: temperature (K); $k_{\text {cin }}$ : kinetics constant for dissolution (mole. $\left.m^{-2} . s^{-1}\right)$; $c$ : solubility of the mineral (mole. $\left.m^{-3}\right) ; d$ : grain size $(m) ; \Delta_{g b}$ : water film thickness (m); $\lambda$ : stress exponent: usually close to 1 at low stress (Rutter, 1976) up to 1.75, or exponential dependance, see Eq. (27 \& 35); $\eta$ : viscosity of the interface (Pa.s); D: diffusion coefficient along the interface $\left(\mathrm{m}^{2} \cdot \mathrm{s}^{-1}\right) ; \mathrm{v}_{\mathrm{s}}:$ molar volume of the solid $\left(m^{3}\right.$. mole $\left.^{-1}\right) ; R:$ gas constant $\left(J \cdot\right.$ mole $\left.^{-1} \cdot K^{-1}\right) ; \varepsilon:$ strain. 
although many authors like for example Dewers \& Ortoleva (1990) used an exponential form for the strain rate vs. stress relation for both dissolution and diffusion limited kinetics. Since the work term (Eq. 13) dominates $\Delta \mu_{\mathrm{T}}$ the transport rate (Eq. 32) must be linear in stress $\left(\sigma_{11}-\sigma_{22}\right)$. The factor $\delta c / \delta \mu=$ c/RT (for activity coefficient $\chi=1$, see Eq. 32) may be said to represent a non-linearity, but it remains to work more to quantify this.

\subsubsection{Grain boundary models}

When material dissolves into the grain boundary region it has to be transported through this grain boundary region to a less stressed region. The important phenomenological parameters for this transport are the diffusion coefficient of the material in the grain boundary region, $D$, the effective grain boundary fluid thickness $\Delta_{g b}$ and the limiting transport length, $r$. Figure 28d summarizes the four main models of the grain boundary and the "realizations" of the transport parameters associated with each model. The model names have varied somewhat through time and our naming scheme is specific to the parameter realizations tabulated in Fig. 28d. The oldest model, the thin film (F) model of Weyl (1959) assumes that the entire grain boundary is smooth and kept apart by a fluid film as described in section 3.1. The limiting transport length, $r$, is therefore the grain boundary radius $a$ (as in section 3.3.1), the thickness of the grain boundary fluid is $\Delta_{g b}=\Delta_{g b, f f} \sim 1-10(-100) \mathrm{nm}$ and the diffusion coefficient $D=D_{f f}=\left(10^{-1}-10^{-2}\right) D_{b u l k}$, where $D_{b u l k}$ is the bulk fluid diffusion coefficient. The next model we will mention, which is a cartoon model of the formal treatment of dynamic grain boundary structure proposed by Lehner and Bataille (1985), assumes a dynamic roughness (DR) of the grain boundary. The real contacts supporting stress are small and change from place to place as old contacts dissolve and new contacts form. These points of contact do not limit the transport, the limiting transport length is the grain boundary radius and the fluid that limits the transport is not under stress, thus $\Delta_{g b}=\Delta_{g b, r} \sim 0.1-10 \mu \mathrm{m}$ and $D=D_{b u l k}$. The third model, the Island-Channel (IC) model, that has been ascribed to Gratz (den Brok, 1998; Gratz, 1991) and assumes that transport is limited by diffusion in thin fluid films between contacting islands, thus $r=d_{i s l}, D=D_{f f}$ and $\Delta_{g b}=\Delta_{g b, f f}$. The island size $d_{i s l}$ is some constant, presumably in the range $0.1-10 \mu \mathrm{m}$. The fourth model, the Dynamic Island Channel (DIC) model, based on quantitative experimental data for $\mathrm{NaCl}$ (Dysthe et al., 2003) is much like the IC model except that the island size increases with time $t$ since the last stress change (be it an earthquake or a local grain rearrangement) as $d_{i s l}(t)=t^{1 / 3}$, which results in a dramatic strain hardening. We may summarize all four models using the fundamental parameters $D, \Delta_{g b}$ and $r$ and rewrite Eq. (18) using $r$ and using Eq. (32): 


$$
\begin{aligned}
& \dot{\varepsilon}=\frac{2 \mathrm{v}_{\mathrm{s}} j_{T} \Delta_{\mathrm{gb}}}{l^{2}(r / l)} \approx \frac{2 c v_{s} \Delta_{g b} D \Delta \mu}{R T l^{3}\left(\frac{r}{l}\right)^{2}} \propto \frac{\Delta \mu \Delta_{g b} D}{l^{3}\left(\frac{r}{l}\right)^{2}} \propto \frac{\sigma_{0} \Delta_{g b} D}{\varepsilon l^{3}\left(\frac{r}{l}\right)^{2}} \\
& \dot{\varepsilon} \propto \frac{\sigma_{0} \Delta_{g b} D}{\varepsilon^{2} l^{3}}, \text { for TF and } D R \\
& \dot{\varepsilon} \propto \frac{\sigma_{0} \Delta_{g b} D}{\varepsilon l d_{i s l}{ }^{2}(t)}, \text { for IC and DIC }
\end{aligned}
$$

We have used the work term of the driving force of pressure solution (Eq. 13) for $\Delta \mu$. Once again it is worth noting that the nonlinear relations between strain rate and stress arise only for dissolution limited kinetics with large stresses (see Eq. 28). These relations may be compared to the expressions in Table 3 and experimental exponents in Table 5.

The last 15 years much theoretical work has focused on the stability of the grain boundary in order to give a rational basis for the cartoon models presented here. We choose to review the theoretical development together with the experimental advances presented in section 4.1.

\section{4 - Historical developments and further reading}

\subsubsection{Thermodynamics and kinetics}

Since the mention of a correlation between chemical and mechanical forces in rocks (Sorby, 1863; Thomson, 1861) and the Gibbs'thermodynamic theory of phase equilibrium (Gibbs, 1877), which proposed that both interfacial tension and pressure variations could be responsible for chemical potential gradients, the driving force and kinetics for pressure solution creep have been debated. Weyl (1959) developed analytical solutions for the dissolution and diffusion of solutes along grain contacts because of higher stress there, assuming an isothermal system and a diffusion limited process along a thin film. Almost at the same time, (Kamb, 1959; 1961) treated non-hydrostatically stressed systems, taking into account the local equilibrium between the fluid and the solid and the fact that a given solid in contact with its fluid can display various state of stress along its surface. In this approach, the chemical potentials are assigned to the components of solid dissolved into the fluid (i.e. the solutes) and not the solid itself, Kamb stating that "it is not possible to usefully associate a chemical potential or Gibbs free energy with a non-hydrostatically stressed solid, even though it is possible [...] to discuss the equilibrium between the solid and the adjacent fluids" (Kamb, 1961) p. 267).

The full elastic parameter tensor was also incorporated in the calculation of the effect of elastic strain on the Helmholz free energy (Kamb, 1959), and the fact that this tensor is anisotropic was used to explain preferred crytallographic orientation in some metamorphic rocks. For this situation, even an isotropic state of stress would lead to non-isotropic strain because of non-isotropic elastic moduli. 
Paterson (1973) wrote a review article on the thermodynamics of non-hydrostatically stressed solid and proposed an approach where, starting from hydrostatic thermodynamics, the non-hydrostatic effects were derived as perturbation of the hydrostatic situation. For this, he considered a thought experiment where a solid is surrounded by a porous belt, which applies a force on its surface. The solid deforms by dissolution-precipitation processes along its surface that tend to decrease the whole internal energy of the system, providing a physical basis for the deformation process (Green 1984). A local equilibrium at the interface between the solid and the belt is considered and a chemical potential for the recrystallization process, similar to that of Kamb's but with another physical interpretation, is proposed. This hydrostatic approach (Paterson, 1973) was used to interpret the first experiments of salt pressure solution creep (Rutter, 1976) and to calculate the rate of pressure solution at quartz graingrain contacts (de Boer, 1977; Robin, 1978).

In the framework of non-equilibrium thermodynamics, (Lehner and Bataille, 1985) derived a dissipation jump condition along a non-coherent grain-thin film interface, generalizing the Gibbs' condition of equilibrium between a solid under stress and a fluid and proposing a treatment of microscale variations in equilibrium chemical potential along an interface. They also cast the basis for solving the deformation along a rough grain-grain contact whose geometry evolves continuously. The driving force for pressure solution, in addition to the so-called work term, may also contain contributions due to elastic strain, plastic strain and interfacial tension (Heidug, 1995; Heidug and Leroy, 1994; Shimizu, 1992). Finally, the contribution of the fluid composition (i.e. undersaturated or supersaturated) can also be included into the driving force for pressure solution creep (Lehner, 1995).

\subsubsection{The dynamic grain boundary: undercutting, rough interface and the Asaro Tiller Grinfeld instability}

Several studies (Pharr and Ashby, 1983; Rutter, 1983; Spiers and Brzesowsky, 1993; Tada and Siever, 1986) have discussed the possibility of grain contacts deforming plastically. Due to the large dislocation density, the Helmholtz energy contribution in Eq. (10) becomes larger than the other terms and deformation occurs by undercutting (i.e. strain enhanced dissolution) at the contact margins until the actual contact surface area becomes so small that a yield limit is reached and the contact collapses on itself by a plastic or brittle process. The whole process of dissolution at the margin and collapse continues over and over, leading to increments of deformation. In such a process, the strain rate is assumed to be controlled by the kinetics of dissolution at the margin (Spiers and Brzesowsky, 1993). Conversely, (Weyl, 1959) assumed a continuous fluid film along which dissolution occurs, leading to the convergence between grains and deformation (Fig. 28d). Later, a more complex model of graingrain interface was proposed (Raj, 1982), where dissolution occurs inside the contact, along a rough grain-grain contact that contains a fluid phase that could be discontinuous (Fig. 28d). Lehner and 
Bataille (1985) developed a theoretical framework for such the grain-grain boundary with a dynamic interface in terms of irreversible thermodynamics. In such system, the diffusive transport of solutes along the grain-grain boundary can become the limiting step for deformation and the diffusion distance can be either the grain contact radius (Robin, 1978; Weyl, 1959) or the size of the actual contacts (den Brok, 1998; Gratz, 1991) in the island-and-channel model of grain boundary. Such an approach of dynamic grain contact was used to model pressure solution creep rate for complex contacts (Renard et al., 1999; van Noort et al., 2008a).

A set of thought provoking experiments by Schutjens and Spiers (1999) imaging the grain boundary contact during pressure solution showed that the grain boundary roughened upon a stress increase and the roughness then coarsened with time. Both theoretical and experimental studies followed. A dynamic grain boundary could be argued to correspond to the so-called Asaro-Tiller-Grinfeld instability (ATG instability) (Asaro and Tiller, 1972; Grinfeld, 1986) that was originally formulated for a solid stressed along its surface in equilibrium with its melt and was experimentally observed on a free surface of a stressed sodium chlorate crystal (den Brok and Morel, 2001). Gal and Nur (1998) and Gal et al. (1998) and later Angheluta et al. (2008) and Angheluta et al. (2010), have shown how this may be applied to two solids under normal stress. Numerical models of this instability (Kassner et al., 2001; Koehn et al., 2003) have predicted that the ATG instability may develop into dissolution cracks. However, there is no experimental evidence under controlled load conditions that demonstrates such a change. Well controlled experiments in confinement (Dysthe et al., 2003; Dysthe et al., 2002b) and for free surfaces (Bisschop and Dysthe, 2006; Jettestuen et al., 2009) clearly suggest that the incorporation of dislocations during growth and the anisotropic surface tension of facet-forming crystals bring other mechanisms into play that override the ATG and cause the roughness length scale to coarsen and the surface to smoothen. The most ambitious theoretical and numerical investigation into the dynamic behaviour of the grain boundary (Ghoussoub and Leroy, 2001) performed a finite size domain stability analysis of the same instability as ATG and used numerical simulations to study stabilizing and destabilizing factors leading island-channel-like geometries to the extreme cases of a thin fluid film or a dry contact. Ghoussoub and Leroy (2001) performed a finite size domain instability analysis to study numerically destabilizing and stabilizing factors to probe the possibilities going from a stable thin fluid film to a dry contact. More recently, van Noort et al., 2008b proposed a comprehensive study of the grain-grain contact by taking into account a large number of microscopic processes, including grain boundary healing.

\subsubsection{Rate laws for aggregate deformation: the linear case}

We have introduced the rate laws for dissolution and diffusion control. Historically, two kinds of approaches have been proposed. On the one hand, analytical rheological laws were proposed for 
diffusion (Raj and Chyung, 1981; Rutter, 1976), dissolution or precipitation (Raj and Chyung, 1981) as the limiting step (Table 3). On the other hand, analytical or numerical laws were derived that take into account the three steps, and select automatically the limiting step depending on the initial values of the thermodynamic and kinetics parameters. Raj and Chyung (1981) proposed to combine the effects of diffusion and dissolution in a single law (Table 3), while other studies involved the numerical combination of dissolution, diffusion and precipitation steps as well as grain deformation (Dewers and Ortoleva, 1990; Niemeijer et al., 2002; Renard et al., 1999) and the coupling with fluid flow (Gundersen et al., 2002b) or the enhanced kinetics of dissolution due to the effect of clay particles (Gundersen et al., 2002a).

Conceptually these laws are very similar to the Cobble and Herring Nabarro creep laws (Coble, 1963; Herring, 1950; Nabarro, 1948) with grain boundary or intragranular diffusion, respectively. The difference is that, due to the lower activation energy of diffusion in water than in solids or at grain boundaries, pressure solution creep develops at lower temperature than these two other mechanisms. The existence of several mechanisms of irreversible deformation allows defining the field of each of these mechanisms in a diagram where the axes are the control parameters of deformation: stress, temperature and grain size. Phase diagrams for pressure solution creep were then proposed to account for the possibility of deforming rocks by different mechanisms in the lithosphere (Farver and Yund, 2000; Rutter, 1976; Rutter, 1983; Urai et al., 1986).

\subsubsection{Rate laws for aggregate deformation: the non-linear case}

Pressure solution creep flow laws, derived theoretically, are used to fit experimental data of either contact indentation or aggregate compaction. Note, however, that empirical laws have also been experimentally measured and showed another category of strain-stress relationship where 1) a dependence of the strain rate on the total strain was observed (Niemeijer et al., 2002; van Noort et al., $2008 \mathrm{a})$; 2) the strain rate displays a power law dependence on time during deformation along a single contact (Dysthe et al., 2002a; Dysthe et al., 2003) or during compaction of aggregates (Chester et al., 2007; Croize et al., 2010b; Renard et al., 2001). Such power law behaviour in time was related either to some dynamics of grain boundary roughness, or the presence of another mechanism of deformation, for example subcritical crack growth or fracturing processes (Gratier, 2011b; Gratier et al., 1999), that acted concomitantly with pressure solution creep. Finally, the fact that individual grains deform and that their shape changes (see Fig. 29) is also responsible for a non-linear relationship between strain and strain rate (Dewers and Ortoleva, 1990; Lehner, 1995; Lemée and Gueguen, 1996; Niemeijer et al., 2002; Renard et al., 1999; Spiers and Brzesowsky, 1993). To summarize, the non-linearity in time 


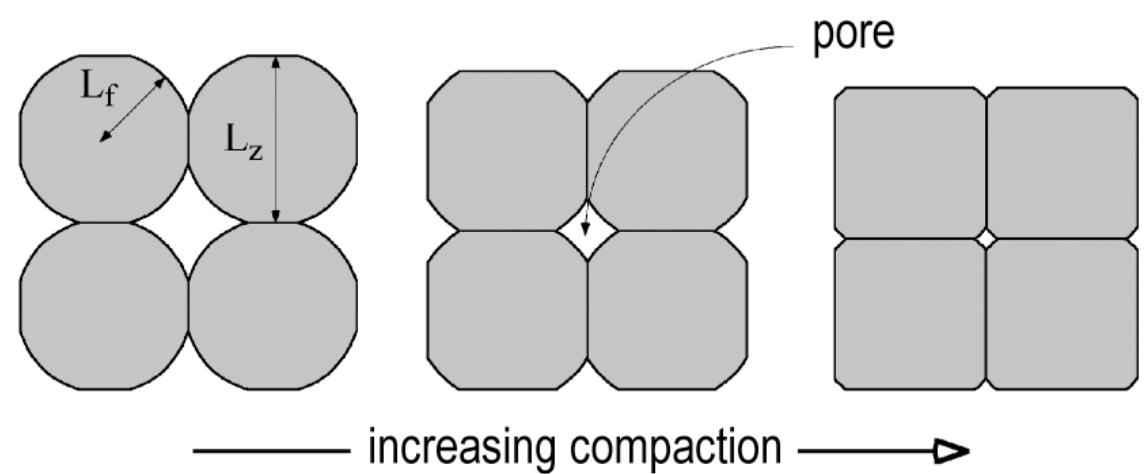

Figure 29: A cross-sectional view of a cubic-packed network of truncated spheres used to model pressure solution at the grain scale. The grain shapes vary due to pressure solution as shown: the grain radius $L_{f}$ increases while the grain flattens ( $L_{z}$ decreases) resulting in a decrease in porosity and pore surface, adapted from (Renard et al., 1999).

may come from 1) the action of several deformation mechanisms at the same time; 2) the variation of grain geometry during dissolution precipitation (i.e. increase of contact surface area during deformation); and 3) some other processes responsible for the roughening of grain boundaries.

\section{4 - Pressure solution creep experiments}

Experiments have three main roles in science: testing theoretical models, measuring coefficients that models cannot predict, and producing evidence of new phenomena that may lead to the development of new models. We will show how experiments have provided evidence of the main theoretical framework of pressure solution but at the same time have cast some doubts on our understanding of the governing processes. We will also try to summarize some of the data that may be used in pressure solution modelling.

There are two types of experiments probing the nature of the pressure solution process. On one hand, experiments on single interfaces attempt to isolate the basic mechanisms of dissolution - transport precipitation. On the other hand, experiments on aggregates or rock core samples test how stressdriven dissolution and precipitation processes contribute to a larger scale deformation. Examples of the former are grain indentation and precipitation in open pores and veins, examples of the latter are compaction, fault gouge creep and strengthening, friction and stylolite formation. In an attempt to illustrate the various kinds of experimental studies done in the past 40 years, Table 4 displays a selection of experiments performed on various materials, under various thermodynamic conditions, where slow creep has been measured under the influence of the coupling between mechanical and chemical forces. 
Table 4 Selected expérimental studies on pressure solution and solution transfer creep

\begin{tabular}{|c|c|c|c|c|c|c|c|c|c|c|}
\hline reference & material composition & $\begin{array}{c}\text { load } \\
\text { conditions }\end{array}$ & $\sigma_{\text {eff }}(\mathrm{MPa})$ & $\mathbf{T}\left({ }^{\circ} \mathbf{C}\right)$ & $\begin{array}{l}\text { grain } \\
\text { size } \\
(\mu \mathrm{m})\end{array}$ & $\begin{array}{l}\text { duration } \\
\text { maximum } \\
\text { (h) }\end{array}$ & fluid composition & $\begin{array}{c}\text { initial } \\
\text { porosity }\end{array}$ & $\begin{array}{c}\text { maximum } \\
\text { compaction } \\
\text { strain } \\
\text { achieved } \\
\end{array}$ & $\begin{array}{l}\text { strain mechanism / } \\
\text { observations }\end{array}$ \\
\hline $\begin{array}{l}\text { [Renton et } \\
\text { al., 1969] }\end{array}$ & $\begin{array}{l}\text { Aggregate: quartz crystals or chert } \\
\text { pieces + zircon grains }\end{array}$ & $\begin{array}{l}\text { hydrostatic } \\
\text { loading }\end{array}$ & $\begin{array}{l}69 \text { to } 117 \\
\text { (hydrostatic } \\
\text { pressure) }\end{array}$ & 272 to 560 & $\begin{array}{c}180 \text { to } \\
1000\end{array}$ & 12 to 325 & $\begin{array}{l}\text { air or distilled water }+ \text { various } \\
\text { aqueous solutions } \mathrm{NaOH}, \mathrm{Na}_{2} \mathrm{CO}_{3} \text {, } \\
\mathrm{NaCl}\end{array}$ & $\begin{array}{l}40 \text { to } \\
55 \%\end{array}$ & $\begin{array}{l}\text { reduction of } \\
\text { porosity by } \\
45 \text { to } 70 \%\end{array}$ & $\begin{array}{l}\text { pressure solution creep with } \\
\text { grain indentation }\end{array}$ \\
\hline $\begin{array}{l}\text { [Rutter, } \\
\text { 1972] }\end{array}$ & Rock: limestone, marble & $\begin{array}{l}\text { triaxial } \\
\text { loading }\end{array}$ & 150 & 200 to 500 & $\begin{array}{l}5 \text { to } 20 \\
200\end{array}$ & - & water or air & $\begin{array}{c}5 \% \\
0.1 \%\end{array}$ & - & $\begin{array}{l}\text { no effect of pressure solution } \\
\text { creep observed in these } \\
\text { experiments, weakening } \\
\text { effect of water due to its } \\
\text { action at grain boundaries } \\
\end{array}$ \\
\hline $\begin{array}{l}\text { [Sprunt and } \\
\text { Nur, 1976] }\end{array}$ & $\begin{array}{l}\text { Rock: sandstone core sample (hollow } \\
\text { cylinder) }\end{array}$ & $\begin{array}{l}\text { hydrostatic } \\
\text { loading }\end{array}$ & 50 & 270 to 280 & $\begin{array}{c}250 \text { to } \\
300\end{array}$ & 336 & distilled water & $13 \%$ & $\begin{array}{l}\text { reduction of } \\
\text { porosity by } \\
50 \%\end{array}$ & $\begin{array}{l}\text { pressure solution creep rate } \\
\text { measured when varying pore } \\
\text { pressure and confining } \\
\text { pressure }\end{array}$ \\
\hline $\begin{array}{l}\text { [Rutter, } \\
1976]\end{array}$ & $\begin{array}{l}\text { Salt slab made of a compacted } \\
\text { aggregate: } \mathrm{Na}_{2} \mathrm{CO}_{3}, \mathrm{~K}_{2} \mathrm{CO}_{3}, \mathrm{SrSO}_{4}\end{array}$ & $\begin{array}{l}\text { uniaxial } \\
\text { compaction }\end{array}$ & 880 & 22 & - & $\sim 240$ & water & - & - & $\begin{array}{l}\text { observed strain partly due to } \\
\text { pressure } \\
\text { solution creep }\end{array}$ \\
\hline $\begin{array}{l}\text { [Sprunt and } \\
\text { Nur, 1977] }\end{array}$ & $\begin{array}{l}\text { Rock slabs or single crystals: } \\
\text { novaculite/granite/carbonates/halite } \\
\text { slabs drilled with a hole }\end{array}$ & $\begin{array}{l}\text { uniaxial } \\
\text { loading }\end{array}$ & $\begin{array}{l}\text { up to } 45 \\
\text { Mpa }\end{array}$ & $\begin{array}{c}22 \\
\text { (carbonate) } \\
-260 \\
\text { (granite) }\end{array}$ & - & 170 to 840 & $\begin{array}{l}\text { air or } \\
\text { saturated/undersaturated/dilute } \mathrm{HCl} \\
\text { or acetic acid aqueous solution }(< \\
0.1 \mathrm{M})\end{array}$ & - & $\begin{array}{l}10 \% \text { (salt), to } \\
30 \% \\
\text { (limestone) }\end{array}$ & $\begin{array}{l}\text { free face dissolution and } \\
\text { deformation of an initially } \\
\text { circular hole due to elastic } \\
\text { strain energy }\end{array}$ \\
\hline $\begin{array}{l}\text { [de Boer et } \\
\text { al., 1977] }\end{array}$ & $\begin{array}{l}\text { Aggregate: quartz }+ \\
\text { kaolinite/bentonite/illite }+ \text { organic } \\
\text { matter }\end{array}$ & $\begin{array}{l}\text { uniaxial } \\
\text { compaction }\end{array}$ & 55 & 340 & 170 & 6100 & water $+1 \mathrm{M} \mathrm{NaCl}$ & $42 \%$ & $\sim 10 \%$ & $\begin{array}{l}\text { compaction of quartz sand by } \\
\text { pressure solution creep (grain } \\
\text { indentation and cementation), } \\
\text { clay should increase the strain } \\
\text { rate }\end{array}$ \\
\hline $\begin{array}{l}\text { [Rutter and } \\
\text { Mainprice, } \\
\text { 1978] }\end{array}$ & Rock: sandstone core sample & $\begin{array}{l}\text { isotropic } \\
\text { loading }\end{array}$ & 150 & 20 to 400 & 150 & 1700 & water or air & - & - & $\begin{array}{l}\text { significant water weakening } \\
\text { effect interpreted as due to } \\
\text { stress corrosion (subcritical } \\
\text { microcracking), pressure } \\
\text { solution may have occurred } \\
\end{array}$ \\
\hline $\begin{array}{l}\text { [Baker et al., } \\
\text { 1980] }\end{array}$ & $\begin{array}{l}\text { Aggregates: carbonate sediments, } \\
\text { calcite, clastic sediments, basaltic glass }\end{array}$ & $\begin{array}{l}\text { triaxial } \\
\text { compaction }\end{array}$ & 45 to 100 & 200 & $\begin{array}{l}62 \text { to } \\
300\end{array}$ & 21 to 240 & $\begin{array}{l}\text { sulfate-free sea water, with } \\
\text { monitored oxygen isotope } \\
\text { composition }\end{array}$ & $\begin{array}{l}10 \text { to } \\
49 \%\end{array}$ & - & $\begin{array}{l}\text { precipitation of carbonate } \\
\text { driven by surface energy and } \\
\text { strain energy }\end{array}$ \\
\hline $\begin{array}{l}\text { [Raj and } \\
\text { Chyung, } \\
1981]\end{array}$ & Aggregate: glass ceramics & $\begin{array}{l}\text { three point } \\
\text { bending }\end{array}$ & 7 to 21 & 950 & $\begin{array}{l}500 \text { to } \\
2000\end{array}$ & 80 & melt at the grain boundaries & - & - & $\begin{array}{l}\text { interface-controlled } \\
\text { dissolution-precipitation } \\
\text { creep with island model of } \\
\text { grain boundary } \\
\end{array}$ \\
\hline
\end{tabular}




\begin{tabular}{|c|c|c|c|c|c|c|c|c|c|c|}
\hline [Raj, 1982] & Aggregate: salt & $\begin{array}{l}\text { uniaxial } \\
\text { compaction }\end{array}$ & 1.5 to 2.85 & 35 to 45 & $\begin{array}{c}200 \text { to } \\
3000\end{array}$ & 40 & saturated brine & - & $10 \%$ & $\begin{array}{l}\text { pressure solution creep may } \\
\text { be controlled } \\
\text { by interface reaction }\end{array}$ \\
\hline $\begin{array}{l}\text { [Rutter, } \\
1983]\end{array}$ & Aggregate: $\mathrm{K}_{2} \mathrm{CO}_{3}+$ kaolinite & $\begin{array}{l}\text { uniaxial } \\
\text { compaction }\end{array}$ & 2.5 to 5 & 20 to 41 & $\sim 2$ & 3 & unsaturated brine & - & - & \\
\hline $\begin{array}{l}{[\text { Tada and }} \\
\text { Siever, 1986] }\end{array}$ & Single crystal: halite & $\begin{array}{l}\text { single } \\
\text { contact }\end{array}$ & 4.5 to 15 & 50 & 260 & 48 to 408 & saturated brine or air or nitrogen & - & - & $\begin{array}{l}\text { undercutting below the } \\
\text { indenter, pressure solution by } \\
\text { free-face dissolution } \\
\text { enhanced by strain energy } \\
\text { and microcracking } \\
\end{array}$ \\
\hline $\begin{array}{l}\text { [Gratier and } \\
\text { Guiguet, } \\
\text { 1986] } \\
\end{array}$ & Aggregate: quartz & $\begin{array}{l}\text { uniaxial } \\
\text { loading }\end{array}$ & 50 & 360 & $\begin{array}{c}80 \text { to } \\
125\end{array}$ & $\begin{array}{l}1200 \text { (up to } \\
27600 \text { ) }\end{array}$ & $\begin{array}{l}\text { saturated aqueous solution }+0.1 \mathrm{M} \\
\mathrm{NaOH}\end{array}$ & - & - & $\begin{array}{l}\text { diffusion-limited pressure } \\
\text { solution on quartz at low- } \\
\text { crust conditions } \\
\end{array}$ \\
\hline $\begin{array}{l}\text { [Rutter et al., } \\
\text { 1986] }\end{array}$ & Aggregate: quartz + kaolinite & $\begin{array}{l}\text { triaxial shear } \\
\text { loading }\end{array}$ & 175 & up to 600 & $\begin{array}{l}\text { up to } \\
200\end{array}$ & 3600 & water or air & - & - & $\begin{array}{l}\text { creep in the presence of } \\
\text { water, importance of } \\
\text { compositional heterogeneity } \\
\text { (quartz vs. clay), } \\
\text { microstructure similar to what } \\
\text { is observed in fault gouge }\end{array}$ \\
\hline $\begin{array}{l}\text { [Lockner et } \\
\text { al. 1986] }\end{array}$ & Aggregate: crushed granite & $\begin{array}{l}\text { triaxial shear } \\
\text { loading }\end{array}$ & 140 to 210 & 22 to 845 & 90 & - & distilled water or air & - & - & $\begin{array}{l}\text { strength of a gouge increases } \\
\text { with heal time, calculation of } \\
\text { parameters of the rate-and- } \\
\text { state friction law }\end{array}$ \\
\hline $\begin{array}{l}\text { [Spiers et al., } \\
\text { 1990a] }\end{array}$ & Aggregate: halite & $\begin{array}{l}\text { uniaxial } \\
\text { compaction }\end{array}$ & 0.5 to 2.2 & 20 to 90 & $\begin{array}{l}100, \\
200, \\
275\end{array}$ & 240 & saturated brine & $42 \%$ & up to $35 \%$ & $\begin{array}{l}\text { grain boundary diffusion } \\
\text { controlled pressure } \\
\text { solution creep }\end{array}$ \\
\hline $\begin{array}{l}\text { [Schutjens, } \\
1991]\end{array}$ & Aggregate: quartz sand & $\begin{array}{l}\text { uniaxial } \\
\text { compaction }\end{array}$ & 9.0 to 20.7 & 150 to 350 & $\begin{array}{l}20 \text { to } \\
100\end{array}$ & $\begin{array}{l}340 \text { to } \\
2200\end{array}$ & saturated aqueous solution or air & $\begin{array}{l}45 \text { to } \\
52 \%\end{array}$ & 8 to $16 \%$ & $\begin{array}{l}\text { compaction by micro- } \\
\text { cracking at } 250^{\circ} \mathrm{C} \text { and } \\
\text { reaction-controlled pressure } \\
\text { solution creep above } 300^{\circ} \mathrm{C} \\
\end{array}$ \\
\hline \begin{tabular}{|l} 
[Cox and \\
Paterson, \\
$1991]$ \\
\end{tabular} & Aggregate: quartz & $\begin{array}{l}\text { triaxial } \\
\text { compaction }\end{array}$ & 100 & 925 & 3.7 & 4 to 8 & purified water & $16 \%$ & $\begin{array}{c}\text { porosity } \\
\text { decrease up to } \\
50 \%\end{array}$ & $\begin{array}{l}\text { compaction creep by } \\
\text { dissolution at grain-grain } \\
\text { contacts with island-channel } \\
\text { grain contact microstructure }\end{array}$ \\
\hline $\begin{array}{l}\text { [Hickman } \\
\text { and Evans, } \\
\text { 1991] }\end{array}$ & $\begin{array}{l}\text { Single crystal: halite against halite or } \\
\text { lens of fused silica }\end{array}$ & $\begin{array}{l}\text { single } \\
\text { contact }\end{array}$ & 1 to 14 & 50 & $\begin{array}{c}500 \text { to } \\
1000\end{array}$ & 71 to 572 & saturated brine & - & - & $\begin{array}{l}\text { no deformation observed for } \\
\text { halite-halite contacts, } \\
\text { pressure solution creep when } \\
\text { using halite-silica contacts, } \\
\text { competition between contact } \\
\text { healing and pressure solution } \\
\text { creep }\end{array}$ \\
\hline $\begin{array}{l}\text { [Elias and } \\
\text { Hajash, } \\
\text { 1992] } \\
\end{array}$ & Aggregate: quartz & $\begin{array}{l}\text { uniaxial } \\
\text { compaction }\end{array}$ & 0 to 69 & 150 & $\begin{array}{l}180 \text { to } \\
250\end{array}$ & 7000 & $\begin{array}{l}\text { saturated aqueous solution (static or } \\
\text { flow through) }\end{array}$ & $35 \%$ & $4 \%$ & $\begin{array}{l}\text { compaction creep increases } \\
\text { with effective pressure and is } \\
\text { controlled by pore fluid } \\
\text { chemical composition }\end{array}$ \\
\hline $\begin{array}{l}\text { [Chester and } \\
\text { Higgs, 1992] }\end{array}$ & Aggregate: quartz & \begin{tabular}{|l} 
triaxial shear \\
loading
\end{tabular} & 150 & 600 & $\begin{array}{c}<1 \text { to } \\
100\end{array}$ & $\sim 28$ & water or air & - & - & $\begin{array}{l}\text { creep by a solution } \\
\text { precipitation mechanism may } \\
\text { explain fault healing during } \\
\text { the interseismic period }\end{array}$ \\
\hline
\end{tabular}




\begin{tabular}{|c|c|c|c|c|c|c|c|c|c|c|}
\hline $\begin{array}{l}\text { [Gratier, } \\
\text { 1993] }\end{array}$ & Single crystal: halite & $\begin{array}{l}\text { single } \\
\text { contact }\end{array}$ & 1 or 65 & 30 to 40 & $\begin{array}{c}0.2 \text { to } \\
1.6\end{array}$ & $\begin{array}{l}720 \text { to } \\
6430\end{array}$ & $\begin{array}{l}\text { saturated (or slightly undersaturated) } \\
\text { brine }\end{array}$ & - & - & $\begin{array}{l}\text { diffusion controlled pressure } \\
\text { solution creep with saturated } \\
\text { brine, elastic strain } \\
\text { undercutting with slightly } \\
\text { undersaturated brine } \\
\end{array}$ \\
\hline $\begin{array}{l}\text { [Hickman } \\
\text { and Evans, } \\
1995]\end{array}$ & $\begin{array}{l}\text { Single crystal: halite against halite or } \\
\text { fused silica (+ layer of } \\
\text { montmorillonite) }\end{array}$ & $\begin{array}{l}\text { single } \\
\text { contact }\end{array}$ & 0.5 to 13.5 & 8.3 to 90.2 & $\begin{array}{l}300 \text { to } \\
700\end{array}$ & 100 to 572 & saturated brine or air or nitrogen & - & - & $\begin{array}{l}\text { diffusion-controlled pressure } \\
\text { solution creep; clay minerals } \\
\text { increase the rate of pressure } \\
\text { solution creep by a factor } 5\end{array}$ \\
\hline $\begin{array}{l}\text { [Dewers and } \\
\text { Hajash, } \\
\text { 1995] }\end{array}$ & Aggregate: quartz sand & $\begin{array}{l}\text { triaxial } \\
\text { compaction }\end{array}$ & 0 to 55 & 150 to 200 & $\begin{array}{l}10 \text { to } \\
300\end{array}$ & 13800 & saturated fluid & - & $10 \%$ & $\begin{array}{l}\text { exponential dependence of } \\
\text { pressure solution creep rate } \\
\text { on effective stress, } \\
\text { competition between pressure } \\
\text { solution and } \\
\text { micro-cracking } \\
\end{array}$ \\
\hline $\begin{array}{l}\text { [de Meer et } \\
\text { al., 1997] }\end{array}$ & Aggregate: gypsum & $\begin{array}{l}\text { uniaxial } \\
\text { compaction }\end{array}$ & 0.5 to 2.5 & 22 & $\begin{array}{l}30 \text { to } \\
280\end{array}$ & 120 & $\begin{array}{l}\text { saturated } \mathrm{CaSO}_{4} \text { aqueous solution, } \\
\text { open system (fluid flow) or closed } \\
\text { system }\end{array}$ & - & $\sim 4 \%$ & $\begin{array}{l}\text { precipitation controlled } \\
\text { pressure solution } \\
\text { creep }\end{array}$ \\
\hline $\begin{array}{l}\text { [de Meer and } \\
\text { Spiers, 1997] }\end{array}$ & Aggregate: gypsum & $\begin{array}{l}\text { uniaxial } \\
\text { compaction }\end{array}$ & 0.5 to 2.5 & 22 & $\begin{array}{l}32 \text { to } \\
282\end{array}$ & 168 to 840 & $\begin{array}{l}\text { saturated } \mathrm{CaSO}_{4} \text { aqueous solution, } \\
\text { open system (fluid flow) or closed } \\
\text { system }\end{array}$ & $\sim 45 \%$ & 4 to $16 \%$ & $\begin{array}{l}\text { precipitation controlled } \\
\text { (closed system), diffusion or } \\
\text { dissolution controlled (open } \\
\text { system) pressure solution } \\
\text { creep } \\
\end{array}$ \\
\hline $\begin{array}{l}{[\text { Karner et al. }} \\
\text { 1997] }\end{array}$ & Aggregate: quartz & $\begin{array}{l}\text { triaxial shear } \\
\text { loading }\end{array}$ & 175 & 230 to 636 & 2 to 3 & 28 & distilled water & - & - & $\begin{array}{l}\text { strength of a gouge increases } \\
\text { with heal time and } \\
\text { temperature, calculation of } \\
\text { parameters of the rate-and- } \\
\text { state friction law } \\
\end{array}$ \\
\hline $\begin{array}{l}\text { [den Brok et } \\
\text { al., 1999a] }\end{array}$ & Aggregate: sodium chlorate & $\begin{array}{l}\text { uniaxial } \\
\text { compaction }\end{array}$ & 2.4 or 5 & 22 & $\begin{array}{l}75 \text { to } \\
500\end{array}$ & 14 to 83 & $\begin{array}{l}\text { air or saturated } \mathrm{NaClO}_{3} \text { aqueous } \\
\text { solution }\end{array}$ & - & up to $27 \%$ & $\begin{array}{l}\text { grain indentation, pressure } \\
\text { solution creep } \\
\text { limited by diffusion }\end{array}$ \\
\hline $\begin{array}{l}\text { [Martin et } \\
\text { al., 1999] }\end{array}$ & Single crystal: halite (+sheet of mica) & $\begin{array}{l}\text { single } \\
\text { contact }\end{array}$ & 0.1 to 2 & 30 to 50 & $\begin{array}{c}3000 \text { to } \\
9000\end{array}$ & 1000 & saturated brine & - & - & $\begin{array}{l}\text { no effect of stress on strain } \\
\text { rate, observation of sudden } \\
\text { fast creep events without any } \\
\text { clear trigger }\end{array}$ \\
\hline $\begin{array}{l}\text { [Gratier et } \\
\text { al., 1999] }\end{array}$ & Single crystal: halite & $\begin{array}{l}\text { single } \\
\text { contact }\end{array}$ & 0 to 80 & 25 & $\begin{array}{c}200 \text { to } \\
600\end{array}$ & 700 & saturated brine & - & - & $\begin{array}{l}\text { the formation of microcracks } \\
\text { enhances } \\
\text { pressure solution creep }\end{array}$ \\
\hline $\begin{array}{l}\text { [Bos et al., } \\
\text { 2000a] }\end{array}$ & $\begin{array}{l}\text { Aggregate: halite+kaolinite or } \\
\text { quartz+kaolinite }\end{array}$ & $\begin{array}{l}\text { rotary shear } \\
\text { loading }\end{array}$ & $\begin{array}{l}5 \text { to } 9 \\
\text { (normal } \\
\text { load) }\end{array}$ & 22 & $\begin{array}{c}100 \\
(\mathrm{NaCl})\end{array}$ & up to 6 & air or oil or saturated brine & - & - & $\begin{array}{l}\text { pressure solution creep may } \\
\text { control frictional-viscous } \\
\text { flow of fault gouge }\end{array}$ \\
\hline $\begin{array}{l}{[\text { Bos and }} \\
\text { Spiers, 2000] }\end{array}$ & Aggregate: halite + kaolinite & $\begin{array}{l}\text { rotary shear } \\
\text { loading }\end{array}$ & $\begin{array}{l}2.5 \text { (normal } \\
\text { load) }\end{array}$ & 22 & 100 & 1.7 & saturated brine & - & $<8 \%$ & $\begin{array}{l}\text { pressure solution creep may } \\
\text { control fault } \\
\text { healing, effect of clays }\end{array}$ \\
\hline $\begin{array}{l}\text { [Bos et al., } \\
\text { 2000b] }\end{array}$ & Aggregate: halite & $\begin{array}{l}\text { rotary shear } \\
\text { loading }\end{array}$ & $\begin{array}{l}0.5 \text { to } 3 \\
\text { (normal } \\
\text { load) }\end{array}$ & 22 & $\begin{array}{l}50 \text { to } \\
200\end{array}$ & - & $\begin{array}{l}\text { mixture of saturated brine }+ \\
\text { methanol or air or silicone oil }\end{array}$ & - & - & $\begin{array}{l}\text { strain of the sheared } \\
\text { aggregate is controlled by } \\
\text { both pressure solution and } \\
\text { cataclasis }\end{array}$ \\
\hline
\end{tabular}




\begin{tabular}{|c|c|c|c|c|c|c|c|c|c|c|}
\hline $\begin{array}{l}\text { [Renard et } \\
\text { al., 2001] }\end{array}$ & Aggregate: halite + clays & $\begin{array}{l}\text { uniaxial } \\
\text { compaction }\end{array}$ & 0.1 to 4.7 & 22 & $\begin{array}{l}106 \text { to } \\
250\end{array}$ & 360 & saturated brine or air & - & $8 \%$ & $\begin{array}{l}\text { clay promote pressure } \\
\text { solution creep, strain follows } \\
\text { a power law in time }\end{array}$ \\
\hline $\begin{array}{l}\text { [Zhang et al., } \\
\text { 2002] }\end{array}$ & Aggregate: calcite & $\begin{array}{l}\text { uniaxial } \\
\text { compaction }\end{array}$ & 1 to 4 & 22 & $\begin{array}{l}15 \text { to } \\
70\end{array}$ & 600 & $\begin{array}{l}\text { saturated aqueous solution or decane } \\
\text { or air }\end{array}$ & $50 \%$ & $1 \%$ & $\begin{array}{l}\text { pressure solution creep in } \\
\text { calcite controlled } \\
\text { by precipitation kinetics }\end{array}$ \\
\hline $\begin{array}{l}\text { [de Meer et } \\
\text { al., 2002] }\end{array}$ & Single crystal: halite & $\begin{array}{l}\text { single } \\
\text { contact }\end{array}$ & 1.5 to 20 & 28 & $\begin{array}{c}50 \text { to } \\
180\end{array}$ & 288 & saturated brine & - & - & $\begin{array}{l}\text { in-situ measurement of the } \\
\text { diffusivity of the grain } \\
\text { boundary during pressure } \\
\text { solution creep }\end{array}$ \\
\hline $\begin{array}{l}\text { [Dysthe et } \\
\text { al., 2002a, } \\
\text { 2003] }\end{array}$ & Single crystal: halite & $\begin{array}{l}\text { single } \\
\text { contact }\end{array}$ & 1 to 20 & 23 to 90 & $\begin{array}{l}30 \text { to } \\
200\end{array}$ & $\begin{array}{c}\sim 10 \text { to } \\
1000\end{array}$ & saturated brine & - & - & $\begin{array}{l}\text { no steady state during } \\
\text { pressure solution creep, } \\
\text { power-law time dependence } \\
\text { of both strain and grain } \\
\text { boundary geometry, } \\
\text { observation of precipitated } \\
\text { material, stress cycling } \\
\text { variations increases the strain } \\
\text { rate } \\
\end{array}$ \\
\hline $\begin{array}{l}\text { [Hellmann et } \\
\text { al., 2002a, } \\
\text { 2002b] }\end{array}$ & Aggregate: chalk rock core samples & $\begin{array}{l}\text { triaxial } \\
\text { loading }\end{array}$ & 4 to 8 & 25 to 80 & $\sim 1$ & 16800 & $\begin{array}{l}\text { saturated aqueous solution }(+\mathrm{NaCl}) \\
\text { or dry or propanol }\end{array}$ & $40 \%$ & 1.6 to $2.8 \%$ & $\begin{array}{l}\text { fluid composition controls the } \\
\text { compaction rate of chalk, } \\
\text { nonlinear compaction with } \\
\text { time }\end{array}$ \\
\hline $\begin{array}{l}\text { [Niemeijer et } \\
\text { al., 2002] }\end{array}$ & Aggregate: quartz & $\begin{array}{l}\text { isotropic } \\
\text { loading }\end{array}$ & 50 to 150 & 20 to 600 & $\begin{array}{c}28 \text { to } \\
125\end{array}$ & 250 & saturated aqueous solution or dry & $\begin{array}{l}25 \text { to } \\
31 \%\end{array}$ & up to $24 \%$ & $\begin{array}{l}\text { compaction by intergranular } \\
\text { pressure solution creep, some } \\
\text { evidence of subcritical } \\
\text { microcracking }\end{array}$ \\
\hline $\begin{array}{l}\text { [Alcantar et } \\
\text { al., 2003] }\end{array}$ & Single crystal: quartz against mica & $\begin{array}{l}\text { single } \\
\text { contact }\end{array}$ & $\begin{array}{l}\text { up to } 50 \\
\text { Mpa }\end{array}$ & 22 & $\begin{array}{l}\text { up to } \\
25\end{array}$ & - & distilled water $+\mathrm{NaCl} / \mathrm{CaCl}_{2}$ & - & - & $\begin{array}{l}\text { measurement of the thickness } \\
\text { and transport properties of the } \\
\text { water film trapped at grain } \\
\text { boundaries by a surface-force } \\
\text { apparatus. }\end{array}$ \\
\hline $\begin{array}{l}\text { [He et al., } \\
2003]\end{array}$ & Aggregate: quartz or novaculite & $\begin{array}{l}\text { uniaxial } \\
\text { compaction }\end{array}$ & 34,5 & 150 & $\begin{array}{l}10 \text { to } \\
350\end{array}$ & 5900 & $\begin{array}{l}\text { distilled water (static or flow } \\
\text { through) or air }\end{array}$ & $\begin{array}{l}35 \text { to } \\
44 \%\end{array}$ & up to $5 \%$ & $\begin{array}{l}\text { compaction creep is enhanced } \\
\text { by the flow of undersaturated } \\
\text { fluid }\end{array}$ \\
\hline $\begin{array}{l}\text { [Skvortsova } \\
\text { et al., 2003] }\end{array}$ & Single crystal: halite & $\begin{array}{l}\text { single } \\
\text { contact }\end{array}$ & 20 to 30 & 22 & 2000 & 1700 & saturated brine or heptane & - & - & $\begin{array}{l}\text { diffusion-limited pressure } \\
\text { solution creep efficient below } \\
\text { 30MPa, dislocation glide } \\
\text { mechanism above }\end{array}$ \\
\hline $\begin{array}{l}\text { [Renard et } \\
\text { al., 2004a] }\end{array}$ & Aggregate: halite & $\begin{array}{l}\text { uniaxial } \\
\text { compaction }\end{array}$ & 0.1 to 0.6 & 22 & $\begin{array}{l}100 \text { to } \\
150\end{array}$ & 72 to 168 & saturated brine & - & $18 \%$ & $\begin{array}{l}\text { 3D X-ray tomography } \\
\text { imaging during pressure } \\
\text { solution creep, permeability } \\
\text { variation due to compaction } \\
\text { and precipitation, observation } \\
\text { of precipitated material }\end{array}$ \\
\hline $\begin{array}{l}\text { [Zubtsov et } \\
\text { al., 2004] }\end{array}$ & Aggregate: halite + calcite & $\begin{array}{l}\text { uniaxial } \\
\text { compaction }\end{array}$ & 2.3 & 33 & $\begin{array}{c}80 \text { to } \\
100\end{array}$ & 120 & saturated brine or brine or paraffine & $47 \%$ & $27 \%$ & $\begin{array}{l}\text { competition between } \\
\text { diffusion-limited pressure } \\
\text { solution creep and grain } \\
\text { boundary healing that } \\
\text { decreases the strain rate }\end{array}$ \\
\hline
\end{tabular}




\begin{tabular}{|c|c|c|c|c|c|c|c|c|c|c|}
\hline $\begin{array}{l}\text { [Zhang and } \\
\text { Spiers, } \\
\text { 2005b] }\end{array}$ & Aggregate: calcite & $\begin{array}{l}\text { uniaxial } \\
\text { compaction }\end{array}$ & 1 to 4 & 22 & 6 to 14 & 480 & $\begin{array}{l}\text { saturated aqueous solution }+ \\
\text { addition of } 10^{-6} \text { to } 10^{-3} \mathrm{M} \text { phosphates }\end{array}$ & $\begin{array}{l}46 \text { to } \\
56 \%\end{array}$ & $2.6 \%$ & $\begin{array}{l}\text { pressure solution creep } \\
\text { controlled by interface- } \\
\text { reaction kinetics, phosphate } \\
\text { ions decrease the strain rate } \\
\text { by two orders of magnitude } \\
\end{array}$ \\
\hline $\begin{array}{l}\text { [Zhang and } \\
\text { Spiers, } \\
\text { 2005a] }\end{array}$ & Aggregate: calcite & $\begin{array}{l}\text { uniaxial } \\
\text { compaction }\end{array}$ & 1 to 4 & 22 & 2 to 68 & 288 & $\begin{array}{l}\text { saturated aqueous solution }+ \\
\text { addition of various salts }(\mathrm{NaCl} \text {, } \\
\mathrm{MgCl}_{2} \text {, phosphate) or silicon oil or } \\
\text { air or alcohol or decane }\end{array}$ & $\begin{array}{l}39 \text { to } \\
52 \%\end{array}$ & $2 \%$ & $\begin{array}{l}\text { diffusion-controlled pressure } \\
\text { solution, salinity (up to } 0.5 \\
\text { M) increases the rate of } \\
\text { pressure solution creep for } \\
\text { calcite. The presence of some } \\
\text { inhibiting ions or oil reduces } \\
\text { the strain rate }\end{array}$ \\
\hline $\begin{array}{l}\text { [de Meer et } \\
\text { al., 2005] }\end{array}$ & Single crystal: halite against $\mathrm{CaF}_{2}$ & \begin{tabular}{|l|} 
single \\
contact
\end{tabular} & 1 to 5 & 22 & $\begin{array}{l}180 \text { to } \\
460\end{array}$ & 360 & saturated brine & - & - & $\begin{array}{l}\text { in-situ infra-red spectroscopy } \\
\text { measurement of the thickness } \\
\text { of the grain boundary during } \\
\text { pressure solution creep, } \\
\text { observation of dynamic grain } \\
\text { boundary }\end{array}$ \\
\hline $\begin{array}{l}\text { [Jordan et al., } \\
\text { 2005] }\end{array}$ & Single crystal: halite against $\mathrm{SiO}_{2}$ & \begin{tabular}{|l|} 
single \\
contact
\end{tabular} & 5 to 15 & 30 & $\begin{array}{c}200 \text { to } \\
1000\end{array}$ & 720 & saturated aqueous solution or air & - & - & $\begin{array}{l}\text { local plastic deformation in } \\
\text { the loaded interface enhances } \\
\text { dissolution, which controls } \\
\text { the overall fluid-assisted } \\
\text { strain, observation of } \\
\text { precipitated material }\end{array}$ \\
\hline $\begin{array}{l}\text { [Zubtsov et } \\
\text { al., 2005] }\end{array}$ & Single crystal: calcite & $\begin{array}{l}\text { single } \\
\text { contact }\end{array}$ & 50 to 200 & 40 & $\begin{array}{l}50 \text { to } \\
300\end{array}$ & 1000 & $\begin{array}{l}\text { saturated aqueous solution or } 5 \% \\
\mathrm{NH}_{4} \mathrm{Cl} \text { or air }\end{array}$ & - & - & $\begin{array}{l}\text { diffusion-controlled pressure } \\
\text { solution, microcracks } \\
\text { increase the strain rate for one } \\
\text { order of magnitude at least }\end{array}$ \\
\hline $\begin{array}{l}\text { [Gratier et } \\
\text { al., 2005] }\end{array}$ & Aggregate: quartz & $\begin{array}{l}\text { uniaxial } \\
\text { loading }\end{array}$ & 50 & 350 & $\begin{array}{l}100 \text { to } \\
125\end{array}$ & 1200 & $\begin{array}{l}\text { saturated aqueous solution }+0.1 \mathrm{M} \\
\mathrm{NaOH}\end{array}$ & - & - & $\begin{array}{l}\text { observation of corrugated } \\
\text { grain contacts during pressure } \\
\text { solution creep, interpreted as } \\
\text { micro-stylolites }\end{array}$ \\
\hline $\begin{array}{l}\text { [Kay et al., } \\
2006]\end{array}$ & $\begin{array}{l}\text { Aggregate: quartz from crushed } \\
\text { sandstone }\end{array}$ & $\begin{array}{l}\text { isotropic } \\
\text { loading }\end{array}$ & 13.8 & 120 & $\begin{array}{l}75 \text { to } \\
425\end{array}$ & 800 & distilled water & - & - & $\begin{array}{l}\text { compaction creep by Ostwald } \\
\text { ripening }+ \\
\text { precipitation of quartz }\end{array}$ \\
\hline $\begin{array}{l}\text { [Karcz et al., } \\
2006]\end{array}$ & Single crystal: halite & $\begin{array}{l}\text { single } \\
\text { contact }\end{array}$ & 20 to 69 & 50 & $\begin{array}{l}170 \text { to } \\
275\end{array}$ & 100 & saturated brine & - & - & $\begin{array}{l}\text { observation of a dynamic } \\
\text { grain interface with channels } \\
\text { and islands using confocal } \\
\text { microscopy }\end{array}$ \\
\hline $\begin{array}{l}\text { [Anzalone et } \\
\text { al., 2006] }\end{array}$ & $\begin{array}{l}\text { Single crystal: quartz against mica or } \\
\text { mica against mica }\end{array}$ & $\begin{array}{l}\text { single } \\
\text { contact }\end{array}$ & 1 to 50 & 21 & $\begin{array}{l}250 \text { to } \\
350\end{array}$ & 110 & $\begin{array}{l}\text { distilled water }+\mathrm{CaCl}_{2}(0.03 \text { to } \\
0.06 \mathrm{M}) \text { or } \mathrm{NaCl}(0.6 \mathrm{M})\end{array}$ & - & - & $\begin{array}{l}\text { evidence of electrochemical } \\
\text { process driven dissolution } \\
\text { using surface force apparatus, } \\
\text { interface reaction rate } \\
\text { controlling dissolution }\end{array}$ \\
\hline $\begin{array}{l}\text { [He et al., } \\
2007]\end{array}$ & Aggregate: quartz & $\begin{array}{l}\text { triaxial } \\
\text { loading }+ \\
\text { fluid flow }\end{array}$ & 54.5 & 150 & $\begin{array}{l}10 \text { to } \\
1000\end{array}$ & 5900 & $\begin{array}{l}\text { supersaturated to saturated aqueous } \\
\text { solution }\end{array}$ & $\begin{array}{l}34 \text { to } \\
45 \%\end{array}$ & $4.3 \%$ & $\begin{array}{l}\text { quartz compaction under } \\
\text { diagenetic conditions, } \\
\text { microgranulation at grain } \\
\text { contact, resulting in ultra-fine }\end{array}$ \\
\hline
\end{tabular}




\begin{tabular}{|c|c|c|c|c|c|c|c|c|c|c|}
\hline & & & & & & & & & & $\begin{array}{l}\text { particules, may drive } \\
\text { dissolution }\end{array}$ \\
\hline $\begin{array}{l}\text { [Chester et } \\
\text { al., 2007] }\end{array}$ & Aggregate: quartz & $\begin{array}{l}\text { uniaxial } \\
\text { compaction }\end{array}$ & 34.5 & 150 & $\begin{array}{l}35 \text { to } \\
255\end{array}$ & 4300 & distilled water & $\begin{array}{l}33 \text { to } \\
46 \%\end{array}$ & $4.4 \%$ & $\begin{array}{l}\text { creep deformation by } \\
\text { microcracking (subcritical } \\
\text { crack growth), no observation } \\
\text { of pressure solution creep, }\end{array}$ \\
\hline \begin{tabular}{|l} 
[Le Guen et \\
al., 2007]
\end{tabular} & Rock: limestone, sandstone & \begin{tabular}{|l|} 
triaxial \\
loading + \\
fluid flow
\end{tabular} & 2.2 to 8 & 25 to 80 & - & 11800 & $\begin{array}{l}\text { saturated aqueous solution }+ \\
\text { dissolved } \mathrm{CO}_{2}\end{array}$ & $\begin{array}{l}16 \text { to } \\
30 \%\end{array}$ & $1 \%$ & $\begin{array}{l}\text { enhancement of creep in } \\
\text { limestone by injection of } \\
\text { dissolved } \mathrm{CO}_{2}\end{array}$ \\
\hline \begin{tabular}{|l|} 
[van Noort et \\
al., 2008a]
\end{tabular} & Aggregate: quartz & $\begin{array}{l}\text { uniaxial } \\
\text { compaction }\end{array}$ & 25 to 100 & 300 to 600 & $\begin{array}{l}3 \text { to } \\
129\end{array}$ & 310 & saturated aqueous solution & $\begin{array}{l}30 \text { to } \\
41 \%\end{array}$ & $\sim 30 \%$ & $\begin{array}{l}\text { interface-reaction controlled } \\
\text { pressure solution is the main } \\
\text { compaction mechanism, ESD } \\
\text { imaging of grain boundaries } \\
\text { after deformation }\end{array}$ \\
\hline $\begin{array}{l}\text { [Niemeijer et } \\
\text { al., 2008a] }\end{array}$ & $\begin{array}{l}\text { Aggregate: halite, halite+muscovite, } \\
\text { quartz }\end{array}$ & shear loading & 5 to 10 & 65 & $\begin{array}{l}106 \text { to } \\
212\end{array}$ & 3 & saturated aqueous solution or air & $\sim 40 \%$ & - & \begin{tabular}{|l|} 
restrengthening of an \\
analogue fault gouge by \\
pressure solution creep and \\
grain boundary \\
healing/welding \\
\end{tabular} \\
\hline $\begin{array}{l}\text { [Liteanu et } \\
\text { al., 2009] }\end{array}$ & Aggregate: limestone & $\begin{array}{l}\text { uniaxial } \\
\text { compaction }\end{array}$ & 30 & 80 & $\begin{array}{c}28 \text { to } \\
106\end{array}$ & 58 & $\begin{array}{l}\text { saturated aqueous solution }+ \\
\text { supercritical } \mathrm{CO}_{2}+\text { salts }(0 \text { to } 3 \mathrm{M} \\
\mathrm{NaCl} \text { or } \mathrm{MgCl}_{2} \text { ) }\end{array}$ & $25 \%$ & $2 \%$ & $\begin{array}{l}\text { supercritical } \mathrm{CO}_{2} \text { or high salt } \\
\text { content increases the } \\
\text { compaction rate of calcite }\end{array}$ \\
\hline $\begin{array}{l}\text { [Greene et } \\
\text { al., 2009] }\end{array}$ & Single crystal: quartz against mica & $\begin{array}{l}\text { single } \\
\text { contact }\end{array}$ & 0.2 to 0.3 & 25 & - & 30 & distilled water $+0.03 \mathrm{M} \mathrm{CaCl}_{2}$ & - & - & $\begin{array}{l}\text { the electric potential } \\
\text { difference drives quartz } \\
\text { dissolution, as measured } \\
\text { using a surface force } \\
\text { apparatus }\end{array}$ \\
\hline $\begin{array}{l}\text { [Gratier et } \\
\text { al., 2009] }\end{array}$ & Single crystals: quartz & $\begin{array}{l}\text { single } \\
\text { contact }\end{array}$ & 25 to 350 & 350 to 360 & 200 & 6200 & $\begin{array}{l}\text { saturated aqueous solution or } \mathrm{NaOH} \\
1 \mathrm{M} \text { saturated aqueous solution or air }\end{array}$ & - & - & $\begin{array}{l}\text { diffusion-limited pressure } \\
\text { solution creep with } \\
\text { exponential stress } \\
\text { dependence, grain surface } \\
\text { roughness controls the strain } \\
\text { rate }\end{array}$ \\
\hline $\begin{array}{l}\text { [Traskin et } \\
\text { al., 2009] }\end{array}$ & $\begin{array}{l}\text { Single crystals or aggregates: halite, } \\
\text { calcite, ammonium nitrate }\end{array}$ & \begin{tabular}{|l} 
single \\
contact and \\
uniaxial \\
compaction \\
\end{tabular} & 0.6 to 1 & 22 & $\begin{array}{l}20 \text { to } \\
350\end{array}$ & 30 & $\begin{array}{l}\text { saturated aqueous solution or } \\
\text { paraffin or heptane }\end{array}$ & - & - & $\begin{array}{l}\text { cyclic stress variations } \\
\text { increases the strain rate }\end{array}$ \\
\hline $\begin{array}{l}\text { [Niemeijer et } \\
\text { al., 2010] }\end{array}$ & $\begin{array}{l}\text { Aggregate: halite or halite }+ \text { muscivite } \\
\text { mixtures }\end{array}$ & shear loading & 5 & 22 & $\begin{array}{l}106 \text { to } \\
212\end{array}$ & 3 & saturated brine or air & $\begin{array}{l}10 \text { to } \\
20 \%\end{array}$ & - & $\begin{array}{l}\text { restrengthening of an } \\
\text { analogue fault gouge by } \\
\text { pressure solution creep and } \\
\text { grain boundary } \\
\text { healing/welding }\end{array}$ \\
\hline $\begin{array}{l}\text { [Croizé et al., } \\
\text { 2010a] }\end{array}$ & Aggregate: carbonate & $\begin{array}{l}\text { uniaxial } \\
\text { compaction }\end{array}$ & 10 to 30 & 22 & $\begin{array}{c}63 \text { to } \\
500\end{array}$ & 250 & $\begin{array}{l}\text { saturated aqueous solution }+5 \% \\
\mathrm{NH}_{4} \mathrm{Cl} \text { or decane }\end{array}$ & $\begin{array}{l}28 \text { to } \\
48 \%\end{array}$ & $47 \%$ & $\begin{array}{l}\text { pressure solution creep has } \\
\text { power-law time dependence }\end{array}$ \\
\hline
\end{tabular}




\begin{tabular}{|c|c|c|c|c|c|c|c|c|c|c|}
\hline $\begin{array}{l}\text { [Croizé et al., } \\
\text { 2010b] }\end{array}$ & $\begin{array}{l}\text { Single crystals: calcite against glass or } \\
\text { sapphire }\end{array}$ & $\begin{array}{l}\text { single } \\
\text { contact }\end{array}$ & 430 to 830 & 22 & $\begin{array}{c}40 \text { to } \\
80\end{array}$ & 25 & saturated aqueous solution & - & - & $\begin{array}{l}\text { nanometer resolution } \\
\text { roughness measurements } \\
\text { indicate that the rate of } \\
\text { pressure solution creep in } \\
\text { calcite is controlled by } \\
\text { interface roughness and } \\
\text { formation of cracks } \\
\end{array}$ \\
\hline $\begin{array}{l}\text { [Hangx et al., } \\
\text { 2010] }\end{array}$ & Aggregate: quartz or feldspar & $\begin{array}{l}\text { uniaxial } \\
\text { compaction }\end{array}$ & 35 to 100 & 20 to 100 & $\begin{array}{c}25 \text { to } \\
425\end{array}$ & 60 & $\begin{array}{l}\text { saturated solution }+\mathrm{CO}_{2}+\mathrm{NaOH}, \\
\mathrm{Ca}(\mathrm{OH})_{2} \text { or air }\end{array}$ & $\begin{array}{l}39 \text { to } \\
44 \%\end{array}$ & up to $3 \%$ & $\begin{array}{l}\text { creep observed by subcritical } \\
\text { cracking inducing corrosion } \\
\text { damage, no pressure solution } \\
\text { creep }\end{array}$ \\
\hline $\begin{array}{l}\text { [Zhang et al., } \\
2010]\end{array}$ & $\begin{array}{l}\text { Aggregate: calcite or crushed } \\
\text { limestone }\end{array}$ & $\begin{array}{l}\text { uniaxial } \\
\text { compaction }\end{array}$ & 20 to 47 & 28 to 150 & $\begin{array}{c}12 \text { to } \\
86\end{array}$ & 960 & $\begin{array}{l}\text { saturated solution or air or oil, } \\
\text { intermittent flow }\end{array}$ & $\begin{array}{l}25 \text { to } \\
34 \%\end{array}$ & up to $10 \%$ & $\begin{array}{l}\text { diffusion-controlled pressure } \\
\text { solution creep at low strains; } \\
\text { for high strains, the strain rate } \\
\text { decreases (interface- } \\
\text { controlled process) }\end{array}$ \\
\hline $\begin{array}{l}\text { [Pachon- } \\
\text { Rodriguez et } \\
\text { al., 2011] }\end{array}$ & Single crystal: gypsum & $\begin{array}{l}\text { single } \\
\text { contact }\end{array}$ & - & 22 & 0,04 & - & undersaturated solution & - & - & $\begin{array}{l}\text { stress-enhanced dissolution } \\
\text { measured under the tip of an } \\
\text { atomic force microscope and } \\
\text { interpreted as pressure } \\
\text { solution creep }\end{array}$ \\
\hline $\begin{array}{l}\text { [Zhang et al., } \\
\text { 2011] }\end{array}$ & $\begin{array}{l}\text { Aggregate: calcite or crushed } \\
\text { limestone }\end{array}$ & $\begin{array}{l}\text { uniaxial } \\
\text { compaction }\end{array}$ & 30 to 40 & 150 & $\begin{array}{c}14 \text { to } \\
37\end{array}$ & 460 & $\begin{array}{l}\text { saturated solution }+\mathrm{NaCl}, \mathrm{Mg}^{2+} \text {, } \\
\mathrm{HPO}_{4}^{2-} \text {, intermittent flow }\end{array}$ & $\begin{array}{l}27 \text { to } \\
36 \%\end{array}$ & up to $10 \%$ & $\begin{array}{l}\text { flow of fluid may modify the } \\
\text { strain rate and may induce a } \\
\text { switch from diffusion- to } \\
\text { interface-controlled pressure } \\
\text { solution creep } \\
\end{array}$ \\
\hline $\begin{array}{l}\text { [Kristiansen } \\
\text { et al., 2011] }\end{array}$ & Silica glass against gold & $\begin{array}{l}\text { single } \\
\text { contact }\end{array}$ & 0.2 to 0.5 & 23 & & 2 & distilled water $+\mathrm{Ca}\left(\mathrm{NO}_{3}\right)_{2}$ solution & - & - & $\begin{array}{l}\text { evidence of electrochemical } \\
\text { process driven dissolution } \\
\text { using surface force apparatus } \\
\text { with electrochemical cell } \\
\end{array}$ \\
\hline $\begin{array}{l}\text { [van Noort et } \\
\text { al., 2011] }\end{array}$ & Single crystal: quartz or lense of glass & $\begin{array}{l}\text { single } \\
\text { contact }\end{array}$ & 12 to 15 & 301 to 353 & $\sim 60$ & 648 & saturated aqueous solution & - & - & $\begin{array}{l}\text { impedance spectroscopy } \\
\text { allows calculating the } \\
\text { diffusivity of the interface } \\
\text { during pressure solution } \\
\text { creep, observation of a rough } \\
\text { interface }\end{array}$ \\
\hline
\end{tabular}


Earlier experiments (Baker et al., 1980; de Boer et al., 1977; Raj, 1982; Renton et al., 1969; Rutter, 1972; Rutter, 1976; Sprunt and Nur, 1976; Sprunt and Nur, 1977) attempted to identify the stress conditions under which dissolution and precipitation of matter could induce a measurable strain. To this end, either core samples or aggregates produced by crushing rocks or sand particles were used. Such experiments were extended to various kinds of minerals (quartz, calcite, feldspar, gypsum and clays), various conditions of stress, temperature and fluid composition relevant to geological creep processes occurring in the Earth's upper crust. These experiments show a collective strain behaviour of a sample made of a large number of deforming particles, and the end-result is an average strainstress relationship. They are also useful for testing how the variations in control parameters modify the creep rate and its rate-limiting step. However, it is sometimes difficult to identify the underlying deformation processes: for example pressure solution creep may compete or interact with other deformation mechanisms such as stress corrosion creep (Chester et al., 2007; He et al., 2003; He et al., 2007) or dynamic fracturing (Gratier et al., 1999). For this reason, (Tada and Siever, 1986) designed an experiment where dissolution under a knife-edge was monitored, thus proposing, to the authors's knowledge, the first study of a single contact undergoing pressure solution creep. This was following later by the development of experimental techniques where a single grain-grain contact could be imaged optically during pressure solution creep (Gratier, 1993; Hickman and Evans, 1991; Hickman and Evans, 1995). In such kind of experiments, it is also possible to measure in-situ the strain (Croize et al., 2010b; Dysthe et al., 2002a; Dysthe et al., 2003; Hickman and Evans, 1991; Karcz et al., 2006; Zubtsov et al., 2005), and the transport properties of the interface under stress using infra-red spectroscopy (de Meer et al., 2005; de Meer et al., 2002), impedance spectroscopy (van Noort et al., 2011) or surface force apparatus (Greene et al., 2009; Kristiansen et al., 2011). The two families of experiments - deformation of aggregate or single contact studies - are described in more detail in the following sections.

\section{1 - Single interface experiments}

The last 20 years has seen a range of experiments (Table 4) demonstrating that, even in the simplest possible case of a single solid interface under pressure immersed in a saturated solution, the behaviour is always complex mainly due to the coupling of pressure solution with other processes such as plasticity, fracturing and electrochemistry. The experiments have revealed the key problem in our understanding of the pressure solution process: the stability of the pressure solution interface, and more specifically the conditions under which a pressure solution interface will be smooth with a fluid film as described in the seminal work of Weyl (1959). And when the fluid film model breaks down, how does the interface evolve towards an island-and-channel structure? Experiments have been 
performed on four different materials, ionic salts (de Meer et al., 2002; Dysthe et al., 2002a; Dysthe et al., 2003; Gratier, 1993; Gratier et al., 1999; Hickman and Evans, 1991; Hickman and Evans, 1995; Jordan et al., 2005; Karcz et al., 2006; Martin et al., 1999; Skvortsova et al., 2003; Tada and Siever, 1986; Traskine et al., 2009), calcite (Croize et al., 2010a; Zubtsov et al., 2005), gypsum (PachonRodriguez et al., 2011) and quartz (Alcantar et al., 2003; Anzalone et al., 2006; Gratier et al., 2009; Greene et al., 2009; Kristiansen et al., 2011; van Noort et al., 2011) with a wide range of solubilities, interface kinetics and elastic/plastic properties.

\subsubsection{Coupling with other processes: plasticity, fracturing and electrochemistry}

Most single interface experiments have been performed on sodium chloride ( $\mathrm{NaCl}$, halite) monocrystals. The main reason for this is its high solubility: 26 weight \% (Pinho and Macedo, 2005) and rapid interface kinetics at room temperature. However, few rock-forming minerals are as plastically deforming as $\mathrm{NaCl}$.

\section{4-1-1-1 Plasticity: $\mathrm{NaCl}$}

Tada and Siever (1986) designed a single interface experiment pressing a knife edge onto polished (001) surfaces of halite single crystals in the presence of 0.151 of $\mathrm{NaCl}$ saturated brine at a temperature of $50+/-0.5^{\circ} \mathrm{C}$. They reported that the knife edge indented into the halite crystal with a typical rate of $4 \mu \mathrm{m}$ per day. However, the dissolution was even greater in the grooves that formed next to the contact between the knife edge and the crystal. Their interpretation was that pressure solution is not a process of dissolution and transport in a thin fluid film, but plastic deformation under the knife edge and rapid dissolution at free surfaces of the plastically deforming material. This socalled "undercutting" model of pressure solution has been highly influential.

There are two main concerns with the generality of their results. First, $\mathrm{NaCl}$, like all halides, easily deforms plastically at room temperature unlike other major rock-forming minerals. Secondly, the bulk dissolution and precipitation of $\mathrm{NaCl}$ due to the temperature variations in such a large volume of brine relative to the surface area of the crystal amounts to about $40 \mu \mathrm{m}$ height change of the entire crystal per temperature cycle, i.e. ten times more than the daily indentation. In fact, the $+/-1 \%$ weight change of their samples corresponds to an overall height change of $+/-30 \mu \mathrm{m}$. Thus, the most important lesson learned from this experiment is perhaps to use small fluid volumes.

Both earlier (Sprunt and Nur, 1977) and later (den Brok and Morel, 2001; Koehn et al., 2004; Morel and den Brok, 2001) studies have shown the effect of strain energy on dissolution and precipitation. If there is a bulk dissolution-precipitation cycle due to temperature changes this would tend to dissolve preferentially at free surfaces with high strain energy, i.e. next to the knife edge. 
Later studies by Hickman and Evans (1991) and (Gratier, 1993), where the brine volume to crystal surface area ratio was at least 100 times smaller than in the experiments of Tada and Siever (1986), showed that the indentation was directly underneath the piston. It was also demonstrated that the indentation rate depended on the piston diameter and the normal stress under the indenter and, thus semi-quantitatively supporting the diffusion limited dissolution in a trapped fluid phase.

Different suggestions for the interplay of water with plasticity have been proposed. In siliceous minerals and glasses water is known to split the strong Si-O bonds and replace them by much weaker hydrogen bonds. In high temperature plasticity of siliceous minerals this "hydrolytic weakening" has been studied extensively since the first observation by Griggs (1967). The same water weakening mechanism is known to be responsible for high rates of subcritical crack growth in siliceous minerals and glasses (Lawn, 1993). Recent studies suggest that even in the brittle, subcritical fracture of siliceous glass at room temperature there is a plastic process zone affected by water (Bonamy et al., 2006). A suggested mechanism applicable to salts (Skvortsova, 2004) and other minerals (Traskin, 2009; Traskin et al., 1998) is the so-called Rehbinder effect (Rehbinder and Shchukin, 1972). The original work of Rehbinder in the 1930s was refuted by Andrade et al. (1950) and has since not been mentioned outside Russian scientific literature. The current use of the term "Rehbinder effect" seems to be generalized to all effects of a surrounding medium on the mechanical properties of the crystal. This non-specific definition implies that several mechanisms may be at work. The Joffe (or Ioffe) effect is more specific: ionic crystals fracture when dry, but deform plastically when wet (Joffe et al., 1924 ). Joffe explained this as a pure surface phenomenon: water blunts cracks and removes stress concentrators on the crystal surface. Fractures do not therefore grow in the ionic crystals (which have high dislocation mobility at room temperature) and plastic deformation becomes the most efficient response to the exerted stress. For some time, the explanation was challenged by theory and observation of water inside wet ionic crystals (Barnes, 1933), but more careful experiments later refuted this idea and firmly supported Joffe's explanation (Kellogg and Pohl, 1964). Rock salt has been shown to be "weakened" by water (Carter et al., 1993; Urai et al., 1986) by aiding recrystallization. This recrystallization is not an intracrystalline creep process, but a process where grains with higher energy (due to higher dislocation density and higher surface energy, i.e. smaller grains) are dissolved and lower energy grains are precipitated. This process is also known as Ostwald ripening. In conclusion, to the authors' knowledge there is only evidence of direct interplay between plasticity and water in point defects for high temperature siliceous minerals and possibly for siliceous glasses at low temperatures. The undercutting mechanism of pressure solution can therefore be viewed as a dissolution-recrystallization process where the increased strain energy (with or without defects) drives dissolution (Spiers and Brzesowsky, 1993). 


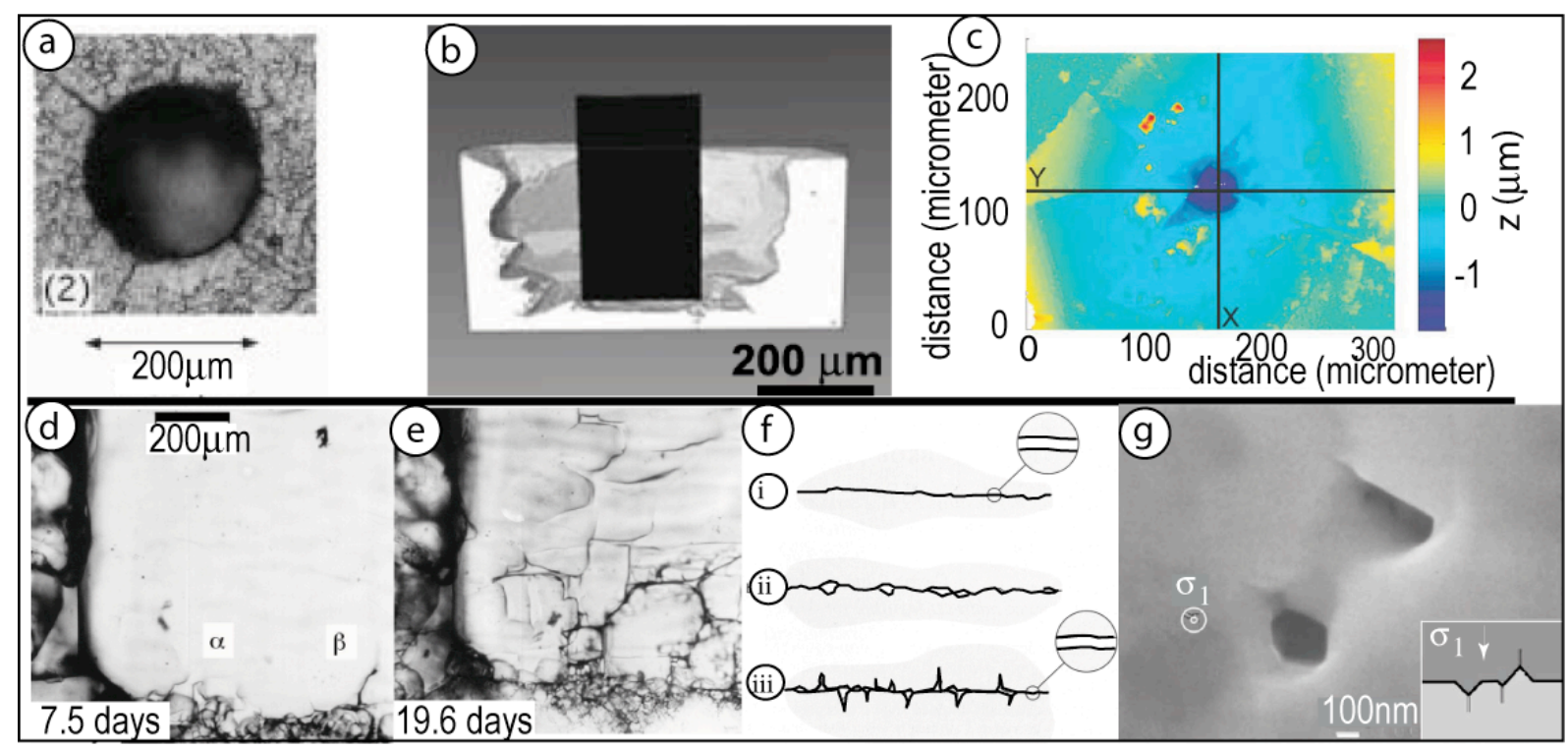

Figure 30: (a) Radial fractures emanating from a cylindrical hole in $\mathrm{NaCl}$ created by a piston indenter, adapted from (Gratier et al., 1999); (b) Dissolution hole in quartz with branched corrosion fractures, adapted from (Gratier et al., 2009); (c) Dissolution hole connected to a radial fracture in calcite, adapted from (Croize et al., 2010b); (d\&e) Cataclastic solution creep in a large grain pressed against small grains of $\mathrm{NaClO}_{3}$ and (f) Grain boundary models adapted from (den Brok et al., 2002): (i) Thin fluid film, adapted from (Rutter, 1976; Weyl, 1959), (ii) island-channel model, adapted from (Lehner, 1990; Raj, 1982; Spiers and Schutjens, 1990), (iii) island-crack model, adapted from (den Brok, 1998; Gratz, 1991); (g) axial view of dissolution pits along a dislocation at the bottom of a microstylolitic peak (Fig. 11) and cross sectional view in inset, adapted from (Gratier et al., 2005).

An example of this was given by Karcz et al. (2006) and Karcz et al. (2008) who demonstrated the plastic deformation and undercutting mechanism in in-situ experiments performed with a confocal microscope to follow the deformation of a $\mathrm{NaCl}$ cone against a silica window. Due to thermal gradients, the undercutting dissolution is fast enough to drive the system into a state where the normal stress at the glass- $\mathrm{NaCl}$ interface fluctuates around 40-60 $\mathrm{MPa}$, a stress where $\mathrm{NaCl}$ undoubtedly deforms plastically. One interesting result of their study is that if a grain contact should at some stage be stressed beyond a certain threshold and if the loading of the grains is constant, the contact may be auto-maintained in a plastic state with rapid undercutting dissolution.

\section{4-1-1-2 Effect of fracturing: $\mathrm{NaCl}$, quartz and calcite}

A study of the interplay between fracturing and pressure solution was performed by Gratier et al. (1999) combining field evidence, modelling and indenter experiments on $\mathrm{NaCl}$ (Fig. 30a). They showed that pressure solution rates were higher when the sample fractured radially under and around 
the indenter. The fractures reduced the diffusion distance, $d$, along the indenter- $\mathrm{NaCl}$ interface and the rate increased as $d^{-2}$. A larger experimental study on quartz (Gratier et al., 2009) did not show radial fractures as for $\mathrm{NaCl}$, but circular fractures that aided free surface dissolution driven by strain energy (Fig. 30b). They found that displacement rates of the indenter increase with roughness of the dissolution surface, but concluded that the indentation rate was limited by diffusion in the fluid phase trapped under stress. Zubtsov et al. (2005) measured pressure solution indentation rates on calcite and observed the tendency towards radially and crystallographically oriented fracturing. Croize et al. (2010b) (Fig. 30c) were able to demonstrate that the indentation rates were greater for cracked interfaces than for non-cracked interfaces. In some experiments the fractures propagated slowly, through so-called subcritical crack growth. The combination of pressure solution and sub-critical crack growth has also been demonstrated in aggregate compaction experiments on halite (Bos et al., 2000a), calcite (Liteanu and Spiers, 2009) and quartz (He et al., 2007; Niemeijer et al., 2002; Schutjens, 1991). den Brok et al. (2002); den Brok (1998); den Brok and Morel (2001); Morel and den Brok (2001) observed that the grain contacts that had undergone pressure solution were structured and that sodium chlorate contacts under stress in brine caused stress corrosion cracks to appear normal to the grain contact (Fig. $30 \mathrm{~d}-$ e). Such observations support the so-called static island channel model (Gratz, 1991) of grain contact (Fig. 30f), where the limiting factor is either diffusion through a 1-10nm thick fluid film over the width, $d_{i s l}$, of a typical island or outward diffusion through the channel network with a greater fluid thickness.

On the other hand, in polycrystalline aggregates like in Fig. 30d and e, tension stresses may easily occur that may cause subcritical cracks to grow. Note that at grain scale, microstylolitic peaks are rooted on dissolution pits that developed where a dislocation emerged at the solution cleavage surface, (Gratier et al., 2005) (Fig. 30g).

\section{4-1-1-3 "Electrochemistry": quartz and clays}

As mentioned previously, there is ample field evidence for the accelerating effect of clays on pressure solution. Because of the very slow dissolution rates and low solubility in this system it has been difficult to study this experimentally. A series of high-resolution experiments was performed with a Surface Forces Apparatus (SFA) on mica and quartz interfaces (Alcantar et al., 2003; Anzalone et al., 2006; Greene et al., 2009; Kristiansen et al., 2011; Meyer et al., 2006). The SFA provides very accurate control of the normal force and extremely accurate measurement of the contact area and dissolution of the surfaces. Unwanted effects such as fracturing or plastic deformation are thus avoided. In addition, to obtain accurate measurements of dissolution rates, (Greene et al., 2009) were able to control the electrical potential difference between isolated electrodes located less than $30 \mu \mathrm{m}$ from the active interface (Fig. 31). The most striking result of their study is an exponential relationship 


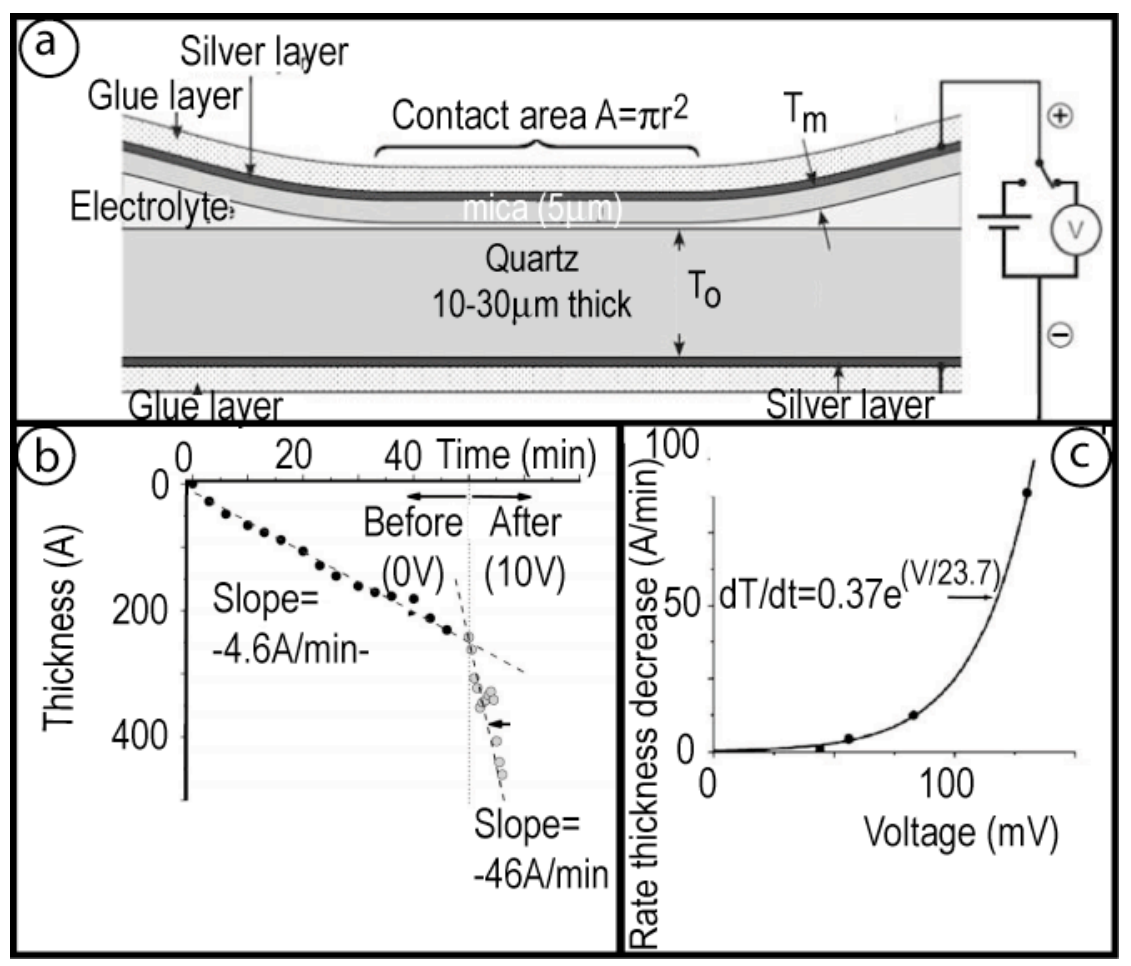

Figure 31: Dissolution force atomic experiments on mica-quartz interfaces adapted from (Greene et al., 2009): (a) Schematic drawing of the "grain contact" and the electrodes in this experiment; (b) Dissolution rate with no imposed electrical potential over the electrodes and 10-fold increase in dissolution rate immediately after a $10 \mathrm{~V}$ electrical potential was applied; (c) The measured electrical potential over the interface varied from experiment to experiment, and varied with time for a single experiment. There was, however an exponential relation between the electrical potential difference and the dissolution rate.

between the electrical potential difference and the dissolution rate (Fig. 31c). For like surfaces (quartzquartz and glass-glass) there was no passive electrical potential difference and dissolution rates were very small. For unlike surfaces the passive electrical potential difference varied between 15 and 30 $\mathrm{mV}$ (glass-mica) and 50 and $150 \mathrm{mV}$ (quartz-mica). When the electrical potential difference over a quartz-mica surface was suddenly imposed to a value of $10 \mathrm{~V}$, the dissolution rate increased tenfold instantaneously (Fig. 31b). When the applied potential difference was turned off the dissolution rate slowly returned to "normal". However, they were not able to demonstrate acceleration of like surface dissolution with forced electrical potential difference. The rates and electrical potential differences also vary with $\mathrm{pH}$ and ion content of the solution. It should be stressed that the electrodes were isolated from the electrolyte and therefore there was no electrochemical circuit transporting charges and no electrochemical work was performed. The mechanism at work is not an electrochemical cycle but rather an asymmetric ion distribution in the fluid film due to the asymmetric surface charge 
distributions of the two surfaces (or due to the external electrical field). Greene et al. (2009) suggest that calcium ions participate as a catalyst to $\mathrm{SiO}_{2}$ dissolution. It follows that, as previously suggested by Bjorkum et al. (1998), pressure is unimportant for this process, only the proximity of the mica and quartz surfaces matter and they conclude that "This electrical potential difference, for as yet unknown reasons, appears to be the driving force for the dissolution, rather than pressure."

Since no electrochemical work is done the electrical potential difference cannot be considered a driving force in the sense of irreversible thermodynamics. We have explicitly included such electrochemical effects in our treatment of the driving force and of the dissolution kinetics above, see Eq. (14). Greene et al. (2009) also report a cyclic (but not periodic) slowing down and sudden speeding-up of dissolution that resembles that described by Martin et al. (1999). The "rejuvenation" of the interface does not depend on changes in normal stress as for $\mathrm{NaCl}$ (Dysthe et al., 2002a; Dysthe et al., 2003). Kristiansen et al. (2011) have recently shown how the electrochemical potential at the contacting surfaces influences quartz dissolution. They present a microscopically based equation for the change of quartz thickness, $H$, as a function of the electrochemical potential $\Delta U$ and the pressure dependent activation energy, $E_{p}$ :

$$
\frac{d H}{d t}=-C e^{-\frac{\alpha \Delta U}{R T}} e^{-\frac{E_{p}}{R T}} .
$$

This equation expresses the strain rate as a product between a dissolution kinetic factor and a pressure factor. This study brings us a long step forward in detailing the microscopic influence of ionic concentration, $\mathrm{pH}$ and ionic strength on the surface electrochemical potential $\Delta U$, and by giving microscopic parameters to calculate the prefactor C. Another study by the same group (Valtiner et al., 2011) also demonstrates the effect of surface roughness on $\Delta U$. Unless electrochemical energy is supplied to working electrodes the only source of energy to perform deformation work is still the surface normal stress. It is evident from all these studies that the electrochemical potential is extremely important in changing the dissolution rate of quartz ( $\mathrm{g}_{\mathrm{A}}$ in Eq. 31) but the equation (31) shows that the strain rate is also proportional to a pressure dependent factor, which is the thermodynamic driving force. These results bring us much closer to an understanding of the nature of pressure solution at clay-quartz interfaces. Since field evidence also shows that clays enhance pressure solution, one may speculate whether there is a similar mechanism there.

\subsubsection{The interface stability: thin film, island - channel or contact healing}

We have already discussed the existence of a fluid film between two solid surfaces that can withstand a normal pressure much higher than the bulk fluid pressure: the so-called disjoining pressure. The fluid film thickness can vary from about $0.5 \mathrm{~nm}$ (two molecular layers) to possibly $100 \mathrm{~nm}$ depending on the nature of the mineral, fluids and the normal stress. 
Grain contacts during pressure solution cannot in general be assumed to be atomically flat, they are rather rough and dynamically changing. If it is assumed that local normal stress varies with local fluid film thickness and if one or both surfaces dissolve faster at points of higher stress (i.e. closest contact), a straightforward analysis predicts that the closest contacts will dissolve first and the interface will tend to become smoother. There are however, some possible destabilizing mechanisms: surface energy gain by creating solid-solid contacts (also called grain contact healing), transport or instabilities due to stress distributions that are non-uniform and/or not normal to the surface. The interfacial energy between two solids of the same material is much lower than the energy of a solid-confined fluid-solid phase. This means that, although the confined fluid phase can exist between two atomically flat solids, it is mostly a metastable phase. Thus, given enough time, it is to be expected that such grain boundaries would find a path to expel the fluid and gain interfacial energy. Fig. 32a shows an example of the dynamics of healing a crack or a grain boundary.

\section{4-1-2-1 Experiments on solid/fluid/solid interface stability}

Hickman and Evans (1991) opened the debate on the interface stability by demonstrating that a halite lens pressed gently onto a halite flat slab would promote contact healing (Fig. 32b) with no pressure solution occurring, while a halite lens pressed onto a silica flat slab would cause pressure solution in a (supposed) thin fluid film. The experiments were carefully controlled to avoid large contact stresses, surface damage of the crystals and temperature variations. They measured shape changes of the halite lens by microscopic imaging of interferometric fringes. Fig. 32c-d includes two examples of grain contacts obtained by pressure solution of $\mathrm{NaCl}$ and quartz where the patterns resemble healed contacts with trapped fluids.

Schutjens and Spiers (1999) took up the problem again using halite-halite and halite-glass contacts. They used prismatic crystals instead of rounded, polished crystals. Like Hickman and Evans (1991) they made in situ observations of changes in the interface. They also oriented the contacting crystals either parallel or at 45 degrees to each other. It should be noted that in neither study (Hickman and Evans, 1991; Schutjens and Spiers, 1999) did they have any independent measure of the convergence of the crystals apart from microscopy. In no experiment did (Schutjens and Spiers, 1999) observe healing of the grain contacts. The contact areas clearly seemed to grow due to (pure) pressure solution. They compared their results to those of Hickman and Evans (1991) and concluded that the most probable reason for contact healing in the earlier experiments was the small radius of curvature at the contact perimeter of the lens against the flat. This small curvature is a major driving force for recrystallization. Since there is an interfacial energy gain when $\gamma_{\mathrm{ss}}<2 \gamma_{\mathrm{sl}}$, the state of a grain contact is dependent on its geometry and history. They also calculated the product $\Delta_{g b} D$ to be in the range of $10^{-}$ ${ }^{19}$ to $10^{-16} \mathrm{~m}^{3} \mathrm{~s}^{-1}$, i.e. the higher values are larger than what can be explained with the fluid film model. 


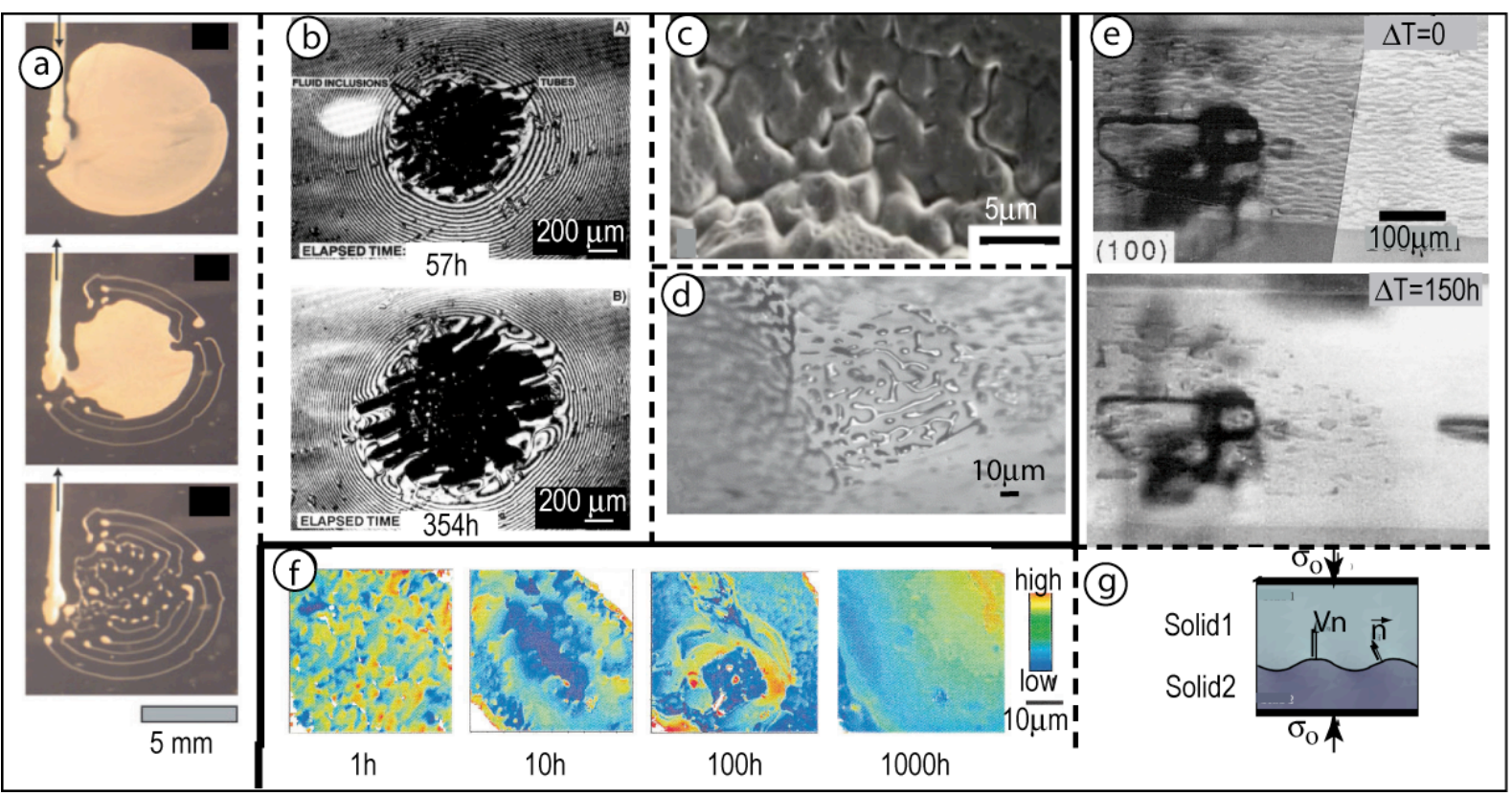

Figure 32: Interface destabilization and subsequent stabilization by (a-d): healing (expelling fluid) and (e-g) Asaro-Tiller-Grinfeld (ATG) instability and subsequent Ostwald ripening: (a) Crack healing dynamics in laponite initiating at one point, driving fluid out while leaving a cylindrical track that ends up as small fluid inclusions, adapted from (Renard et al., 2009); (b) NaCl lens pressed carefully against flat $\mathrm{NaCl}$ crystal: the growing black region is a dry grain boundary with crystallographically oriented fluid tubes and inclusions, adapted from (Hickman and Evans, 1991); (c) Trace of pressure solution grain boundary of a small quartz grain indenting on polished quartz, adapted from (den Brok and Spiers, 1991); (d) NaCl grain boundary from compaction by pressure solution of $\mathrm{NaCl}$ powder, fluid tubules and circular inclusions are seen, adapted from (Ghoussoub and Leroy, 2001), courtesy of C. Spiers; (e) In situ image of NaCl-glass contact immediately following a normal force increase that induced roughness formation of the surface, and the same interface 150 hours later where all the small scale roughness has disappeared, adapted from (Schutjens and Spiers, 1999); (f) Ex situ white light interferometry surface measurements of $\mathrm{NaCl}$-gold contacts where surface smoothing was stopped after 1, 10, 100 and 1000 hours, adapted from (Dysthe et al., 2002a; Dysthe et al., 2003); (g) Illustration of ATG instability mechanism, adapted from (Angheluta et al., 2009) and subsequent smoothing driven by surface tension as in Ostwald ripening and spinodal decomposition

Another, very interesting observation reported by Schutjens and Spiers (1999) was that, when the normal load was increased, the grain contact immediately became rougher, creating a dynamic islandchannel geometry (Fig. 32e). This roughness gradually disappeared with time after the load increase. This roughening and time-dependent restructuring of the rough surface was later studied systematically by Dysthe et al. (2002a) and Dysthe et al. (2003) using high resolution dilatometers and a white light interferometer (Fig. 32f). The most probable explanation of the destabilization leading to 
immediate roughening is the Asaro-Tiller-Grinfeld (ATG) instability (Fig. 32g) that occurs under normal stress between two solid surfaces when they have different dimensions or elastic properties (Angheluta et al., 2009; Gal and Nur, 1998; Gal et al., 1998) or if there is a fluid film that does not transmit shear stress (Bonnetier et al., 2009) (see discussion in section 3.4.2). Most single interphase experiments have found similar curves with initial rapid convergence (indentation) that slows down progressively (Fig. 33a-b-c). When the vertical resolution of the experiment is not sufficient, the data is often interpreted as reaching a steady state. Careful analyses of high resolution measurements have revealed, however, that the pressure solution convergence is a power law with a time exponent of $1 / 3$, like the time exponent of the length scale of roughness in the contact (Fig. 33d-e). Dysthe et al. (2002a) found accordingly that the characteristic length scale of the dynamic island channel structure, $d_{i s l}$, increased with time to the power $1 / 3: d_{i s l} \propto t^{1 / 3}$. This is characteristic of diffusion-limited coarsening driven by surface tension (like Ostwald ripening). Since the size of the islands of contact determines the diffusion distance for pressure solution, the scaling of the island sizes could also explain the measured change of convergence rate with time to the power $-2 / 3: d z / d t \propto d_{i s l}^{-2} \propto t^{-2 / 3}$. The determination of these scaling relations provided an explanation of the characteristic slowing down of pressure solution rate.

Another instrument constructed to study the surface dynamics was a Linnick interferometer (Jordan et al., 2005; Lohkamper et al., 2003) that measured crystal topography in situ. These studies showed that damaged surfaces evolve in a complicated manner, but the convergence rate decreases with time as found in other studies.

Schenk et al. (2006) were able to visualize directly the brine in grain boundaries and pores of halite aggregates. By quenching the samples to $-190^{\circ} \mathrm{C}$ the brine segregated by spinodal decomposition to a fine-grained $(\mathrm{R} \sim 100 \mathrm{~nm})$ foam of "hydrohalite" and ice. Cryo-SEM observations then clearly distinguished between the quenched foam, halite grains and air. The study confirmed the existence of both thin $(<30 \mathrm{~nm})$ brine films, irregular (island channel like) boundaries and healed grain boundaries. It may therefore be concluded that, for single contacts with $\mathrm{NaCl}$, unless some special geometry causes the grain contact to heal, pressure solution occurs in grain contact with dynamic island-channel geometry where the length scale coarsens with time due to surface tension and the pressure solution rate (which is controlled by outward diffusion from the island contacts) slows down with time. We may also conclude that the breakdown of the Weyl's type continuum picture of the fluid film does not provide (for now) any new, usable model of basic mechanisms. It should also be noted that grain contact healing and intergranular sealing plays a major role in natural sedimentary rocks. 


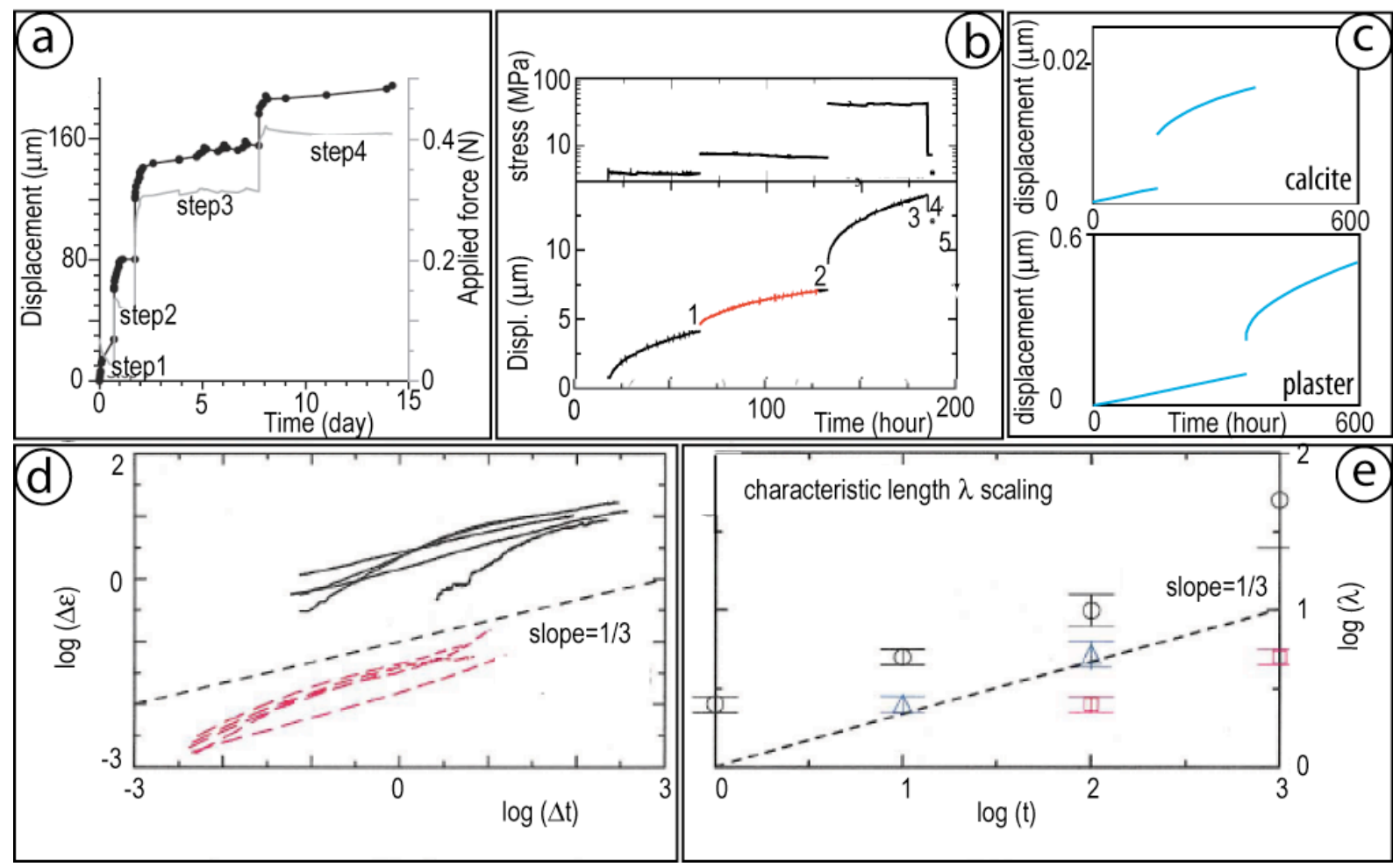

Figure 33: Typical indentation-time curves following stress increase: (a) $\mathrm{NaCl}-\mathrm{CaF}_{2}$ glass, adapted from (de Meer et al., 2005); (b) NaCl-gold, adapted from (Dysthe et al., 2003) (1=36 nm/h; $2=21$ $\mathrm{nm} / \mathrm{h} ; 3=43 \mathrm{~nm} / \mathrm{h} ; 4=7 \mathrm{~nm} / \mathrm{h} ; 5=5 \mathrm{~nm} / \mathrm{h})$; (c) calcite and plaster indenting with dynamic loading: dropping ball (shock), adapted from (Gratier, 2011b); (d) Compilation of many indentation experiments with a single load (black) and with load increments (red) showing the same power law exponent 1/3; (e) Power law scaling 1/3 of roughness length scale characteristic of Ostwald ripening/spinodal decomposition, adapted from (Dysthe et al., 2002a).

\section{4-1-2-2 The real confined film}

de Meer et al. (2005) and de Meer et al. (2002) employed two new experimental techniques to study the nature of the grain boundary contact during pressure solution of $\mathrm{NaCl}$. In the first study they used resistivity measurements to estimate independently the product of diffusion coefficient and fluid film thickness, $\Delta_{g b} D$, where $D$ is the diffusion coefficient in the grain boundary and $\Delta_{g b}$ is the average thickness of the disjoining fluid film. They measured $\Delta_{g b} D$ values between $10^{-19}$ and $10^{-17} \mathrm{~m}^{3} \mathrm{~s}^{-1}$, in good agreement with values estimated from pressure solution experiments and the range of values estimated for an atomically flat interface. They also found an inverse relationship between $\Delta_{g b} D$ and normal stress. The optical resolution was not high enough to resolve the structure in the grain contact. In the second study, they applied infrared spectroscopic microscopy to a $\mathrm{NaCl}-\mathrm{CaF}_{2}$ grain contact. The general conclusion was that the amount of water measured in the interface was too large to be explained by a fluid film model and that there had to be some sub-optical roughness in the grain 
contact. The convergence rates increased every time the stress was increased and then slowed down continuously (see Fig. 33a). Thus both observations are compatible with the dynamic island channel model of Dysthe et al. (2003).

Experiments performed by Espinosa-Marzal et al. (2012) with the SFA using two mica surfaces in solutions of water and $\mathrm{KNO}_{3}$ gave interesting results. $\mathrm{KNO}_{3}$ has a bulk solubility of about $3 \mathrm{M}$ at room temperature. At high ionic concentrations $(c>0.1 \mathrm{M})$ attractive forces are observed between the mica surfaces at separations between 2 and $5 \mathrm{~nm}$. At separations below $2 \mathrm{~nm}$ there is a strong repulsive force. When the surfaces are pressed together to $2 \mathrm{~nm}$ separation there is still a liquid film between the mica surfaces and there is no hysteresis in the force curve when moving the surfaces apart. It was found however, that when the bulk solution concentration was increased to $1 \mathrm{M}$ the force curve on approaching $2 \mathrm{~nm}$ showed a disjoining pressure and when moving the surfaces apart an attractive force appeared between the surfaces. Such an attractive force appears when two solid surfaces are in contact. The appearance of an attractive force at a distance of $2 \mathrm{~nm}$ may be interpreted as a solidification of the $2 \mathrm{~nm}$ thick film between the mica surfaces. In one experiment at $1 \mathrm{M}$ bulk concentration, the two surfaces were kept under constant compressive force initially at a separation of $2 \mathrm{~nm}$ and the separation was measured to increase by $0.5 \mathrm{~nm}$ to $2.5 \mathrm{~nm}$. The questions that arise are:

- Does the confinement induce crystallization at a bulk concentration that is far smaller than the saturation concentration?

- Can this be related to other effects of confinement like capillary condensation and a twofold lowering of solubility of $\mathrm{NaCl}$ in a $0.8 \mathrm{~nm}$ slit pore (Malani et al., 2006)?

- Can an undersaturated bulk solution supply ions to a confined "crystal" that performs work $(0.5 \mathrm{~nm} *$ force $)$ on solid, spring-loaded mica surfaces?

- What is the energy source of such work? The only available energy source must be a gradient in the chemical potential between the bulk fluid and the confined phase?

- For how long can the confined phase perform such a work? Only as long as the resulting confined "crystal" has a lower chemical potential than the bulk fluid?

If the resulting confined "crystal" grows to macroscopic dimensions it will be a macroscopic crystal under stress, which should normally have a larger chemical potential than an unstressed crystal. And since the bulk fluid is at $1 / 3$ of the saturation concentration, it clearly has a chemical potential lower than that of an unstressed crystal. It must therefore be concluded that the solidification of the confined phase and the work performed by this solid-like phase has an effect of small linear extent and cannot be sustained. However, it is also clear that the confined phase should be treated as a separate thermodynamic phase. This is the most recent example in this field that new high resolution experiments bring radically new knowledge and new questions. 


\section{2 - Deformation of aggregates}

Single interface experiments performed over the past 20 years have demonstrated that grain contacts may evolve to a number of different states (fluid film, island - channel, solid (healed), plastically flowing) depending on whether the contacts are monomineralic, their orientation, the interface angles (driving healing), the initial contact stress (causing plastic or brittle deformation) and the timedependent changes in contact stress. When reviewing aggregate experiments, it is useful to remember that an aggregate will have a large number of grain contacts with a distribution of (single contact) properties. As the aggregate is deformed, grains will move relative to each other causing rupturing and reforming of contacts and changing contact stresses at intact contacts. Several experiments performed on rock core samples or relatively large slabs of crystals (Hellmann et al., 2002b; Le Guen et al., 2007; Rutter and Mainprice, 1978; Sprunt and Nur, 1977) show very small strains even after durations lasting for almost two years in certain cases. For this reason, most pressure solution experiments have been based on uniaxial or triaxial creep compression tests of monomineralic granular aggregates of various materials: ionic salts (den Brok et al., 1999; Raj, 1982; Renard et al., 2004a; Renard et al., 2001; Rutter, 1976; Spiers et al., 1990; Zubtsov et al., 2004), calcite and other carbonates (Baker et al., 1980; Croize et al., 2010b; Liteanu and Spiers, 2009; Rutter, 1983; Zhang et al., 2002; Zhang and Spiers, 2005a; Zhang et al., 2010; Zhang et al., 2011; Zhang and Spiers, 2005b), quartz (Chester et al., 2007; Cox and Paterson, 1991; de Boer et al., 1977; Dewers and Hajash, 1995; Elias and Hajash, 1992; Gratier and Guiguet, 1986; Gratier et al., 2005; Hangx et al., 2010; He et al., 2007; Kay et al., 2006; Niemeijer et al., 2002; Renton et al., 1969; Rutter et al., 1986; Schutjens, 1991; van Noort et al., 2008a), and gypsum (de Meer et al., 1997; Meer and Spiers, 1997). The experimental conditions are summarized in Table 4. These studies most often include micrographs of the microstructures showing truncated/indented grains and overgrowths. They show that several processes are at work and are responsible for the observed strain: pressure solution creep, grain boundary healing, subcritical crack growth, dynamic fracturing They normally compare the rate of compaction to experiments without water to show that a water mediated process is at work. Some of the studies also quantify the compaction rates.

In another kinds of experiments, the aggregate is sheared in the presence of a reactive fluid and the shear strength of the medium is measured using slide-hold-slide tests (Bos et al., 2000a; Bos et al., 2000b; Bos and Spiers, 2000; Chester and Higgs, 1992; Karner et al., 1997; Lockner et al., 1986; Niemeijer et al., 2010; Niemeijer et al., 2008b). These kinds of studies were aimed at understanding the frictional properties of fault gouge (Fitzenz et al., 2007) and demonstrated how healing of the fault gouge proceeds during the interseismic period.

\subsubsection{Treatment of aggregate compression data}


The experimental compaction of originally loose aggregates of mineral grains subjects the aggregate to the same processes as in Nature. Most published studies of wet compacted aggregates show microstructures evidencing grain indentation, truncation and overgrowth. The laboratory timescale of these experiments is compatible with the pressure solution process. Grain contact healing is, however, not so simple to prove in microstructures (see (Schenk et al., 2006) for a positive exception). Contact healing has clearly been identified as rate limiting in the experiments of Zubtsov et al. (2004) where the volume ratio of grains that undergo pressure solution (and contact healing) and inert grains was varied. The maximum compaction rate was found for a finite volume of about $33 \%$ of inert particles, a result that could be explained quantitatively by the number of grain contacts that could heal or not. It is in general not always clear whether the time scale of grain contact healing is comparable to the experiment timescale. It is also not clear what functional form an experimental porosity-time curve should have and what the limit should be, $\phi=\phi_{c}$ or $\phi=0$. Models using simple geometrical stacks of spherical grains predict a slowing down of compaction rate due to growth of the grain contact areas (Gundersen et al., 2002a; Gundersen et al., 2002b), but the functional form of these compaction curves does not fit experimental data well and one ends up with purely empirical fits of the data.

Experimental compaction of aggregates by pressure solution (Fig. 34) can usually be described by a power law behaviour expressed by the equation $\varepsilon=\alpha\left(t / t_{0}\right)^{\beta}$ (Renard et al., 2001) or equivalently, $t_{0} \frac{d \varepsilon}{d t}=\kappa \varepsilon^{-\tau}$ (Spiers et al., 1990), where $\varepsilon$ is strain, $t$ is time, $\tau=1+1 / \beta, \kappa=\beta \alpha^{1 / \beta}$ and $t_{0}$ is a time base. This is a purely empirical relationship that has not been derived from first principles except for the specific exponents $\tau=1$ for dissolution rate limitation (Eq. 21) and $\tau=2$ (Eq. 33). The time exponent $\beta$ (or $\tau$ ) can be argued to be the same for aggregates deforming by the same mechanism and with the same particle size distribution function (irrespective of the mean value). When the relative importance of processes (like contact healing versus pressure solution) changes, the time exponent changes (Zubtsov et al., 2004). It should be noted that unless data are plentiful and of good quality it is difficult to determine accurately time exponents $\beta$ smaller than 0.5 and to be sure that the data are not in fact logarithmically time-dependent, as proposed for example for the healing rate of gouge materials (Karner et al., 1997; Lockner et al., 1986). The prefactors $\kappa$ and $\alpha$ are functions of mean particle size, $d$, and stress, $\sigma$. If experiments are performed over a sufficiently wide range of particle sizes and stresses the data can be fitted to a power law $\kappa=\beta \alpha^{1 / \beta} \propto d^{-v} \sigma^{\lambda}$, where $v=3$ and $\lambda=1$ for thin film diffusion-limited pressure solution and $v=1$ and $\lambda=$ the order of the rate law for dissolution/precipitation limited pressure solution (Table 3), assuming no influence of contact healing. Experimental data from compaction experiments have often been plotted individually to extract the exponents $\tau$, $v$ and $\lambda$, (Fig. 34b-c-d) but only a few studies have combined all data (Fig. 34e) in a single regression to obtain serious estimates with error bars (Fig. 34f) (Renard et al., 2001). When the 


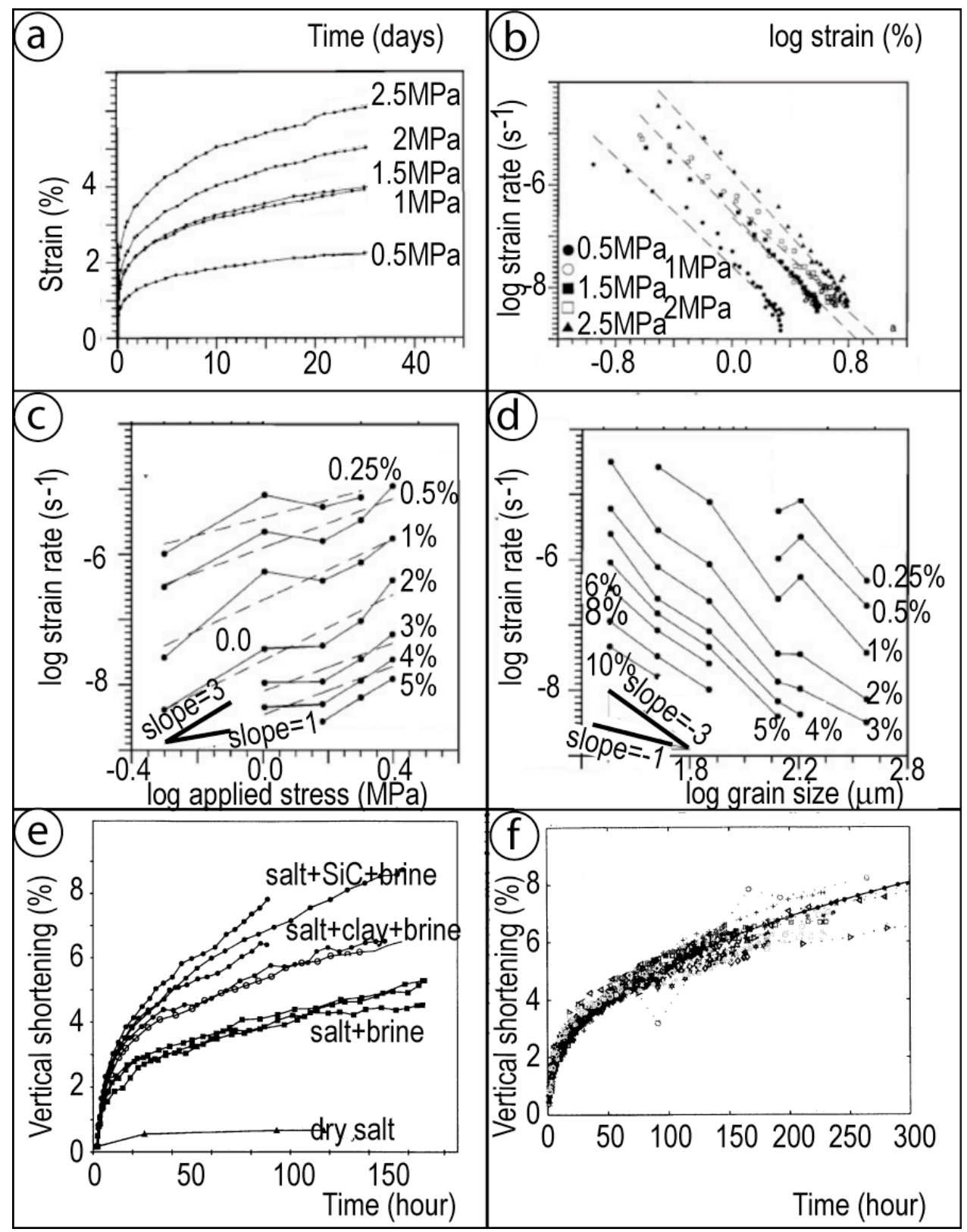

Figure 34: Graphical representation of compaction data: $(\boldsymbol{a}-\boldsymbol{e})$ raw compaction data; (a) strain versus time; (b) strain rate versus strain deduced by numerical differentiation of curves in (a). Straight line fits to $t_{0} \frac{d \varepsilon}{d t}=\kappa \varepsilon^{-\gamma}$ are performed individually; (c) Strain rates for a single grain size at different strains versus applied stress; (d) Strain rates for a single applied stress at different strains versus grain size; (a-d) adapted from (deMeer and Spiers, 1997); (e) experimental compaction curve for various clay contents: without clay (square), 10\% clay (circle), SiC (open circle); (f) simultaneous fit of all data in $\boldsymbol{e}$ to a single master curve $\varepsilon=\alpha\left(t / t_{0}\right)^{\beta}$, no differentiation is performed first as in $\boldsymbol{b}$. (e-f) adapted from (Renard et al., 2001) vertical stress $=4.7$ bars, temperature $=22^{\circ} \mathrm{C}$, salt grain size $180-250 \mu \mathrm{m}$. 


\begin{tabular}{|c|c|c|c|c|c|c|c|c|}
\hline Material & & $\sigma_{\text {eff }}$ & $\mathrm{T}$ & $\mathrm{d}$ & $t_{\max }$ & $\tau$ & $v$ & $\lambda$ \\
\hline & & $\mathrm{MPa}$ & $\mathrm{C}$ & $\mu \mathrm{m}$ & $\mathrm{h}$ & & & \\
\hline $\mathrm{NaClO}_{3}$ & $\mathrm{~A}$ & $2.4-5$ & 22 & $75-500$ & 80 & $2-4$ & $2-3$ & $1-2$ \\
\hline Gypsum & B & $1-4$ & 22 & $74-282$ & 840 & $2-4$ & $3-4$ & $2-3$ \\
\hline $\mathrm{NaCl}$ & $\mathrm{C}$ & $0.1-4$ & 22 & $106-250$ & 360 & 3.5 & - & - \\
\hline $\mathrm{NaCl}$ & $\mathrm{D}$ & $0.5-2.2$ & $20-90$ & $100-275$ & 240 & $2-5$ & $2-3$ & $1-2$ \\
\hline $\mathrm{CaCO} 3$ & $E$ & $1-4$ & 22 & $6-22$ & 480 & 3 & $4-5$ & $1-3$ \\
\hline $\mathrm{CaCO} 3$ & $\mathrm{~F}$ & $20-47$ & $28-150$ & $12-86$ & 926 & - & $2-3$ & $1-3$ \\
\hline Quartz & G & $9-20$ & $150-350$ & $20-100$ & 2200 & $1-8$ & - & $2-4$ \\
\hline Quartz & $\mathrm{H}$ & $50-300$ & $400-600$ & $28-125$ & 250 & $5-10$ & $\begin{array}{l}0.5- \\
1.5\end{array}$ & 3 \\
\hline Quartz & I & $25-100$ & $300-600$ & $3-129$ & 310 & 10 & 1 & $3-4$ \\
\hline
\end{tabular}

Table 5: Experiments of compaction of granular aggregates that have been used to fit the power law relation $\frac{d \varepsilon}{d t} \propto d^{-v} \sigma_{e f f}^{\lambda} \varepsilon^{-\tau}$, where $\varepsilon$ is strain, $d$ the mean grain size and $\sigma_{\text {eff }}$ the effective stress driving pressure solution. Cited work: A (den Brok et al., 1999); B: (de Meer and Spiers, 1999); C (Renard et al., 2001); D (Spiers et al., 1990); E (Zhang et al., 2010) F (Zhang et al., 2010); G: (Schutjens, 1991) H: (Niemeijer et al., 2002 ; van Noort et al., 2008a).

data have been treated at separate strains and not been subject to a single regression it is hard to know how to pick data to predict compaction rates for a given situation. For example, using Figure 6 in (Zhang and Spiers, 2005a) to extrapolate to a mean grain size of $3 \mu \mathrm{m}$ a value of $\alpha=0.023$ is obtained. A more conservative extrapolation is obtained from the final strains in their figure 3 yielding $\alpha=$ 0.00058 , smaller by a factor of 40 . This may not seem too bad, but since $\beta=0.25$ from the same data this translates to a factor $10^{6}$ difference in the estimated time needed to reach a strain $\varepsilon=1$ (40 days vs. 300000 years). More elaborate models to fit experimental data have been based on a geometrical model of regular grain stacks (van Noort et al., 2008b; Zhang et al., 2010) or explicit modelling of the grain contact (van Noort et al., 2008b), but none of them can be said to fit the time-dependent (strain) change in compaction very well. 


\section{4-2-2 Dependence on time, grain size and stress}

Very many labs around the world have at some time published a study of uniaxial compaction of granular aggregates of a mineral (Table 4). Most of these studies are qualitative in nature although some curves and numbers are presented. Although these studies have often contributed to a gradual enhancement of our understanding, the focus here will be on a selection of them that have been quantitative to the extent that some generalization may be achieved from least square fits. The Utrecht group has pioneered quantitative compaction experiments and has contributed by far the most data on different systems. They also pioneered the use of compaction data to determine the rate limiting process. Table 5 lists some quantitative compaction studies on different minerals, the experimental parameters and the power law exponents of time, $\tau$, grain size, $v$, and stress, $\lambda$ that have been derived. Note that the uncertainty in the exponents is often large. Determination of the rate limiting process through the grain size exponent, $v$, is therefore approximate. It is not always sufficient only to know $v$. In the case of gypsum (de Meer and Spiers, 1999) the dependency of the rate on the salinity of the solution suggested dissolution/precipitation control, contradicting the diffusion control indicated by the exponent $v=3$. The discussion yielding Eq. (28) and the expressions in Table 3 suggest that the stress exponent should always be $\lambda=1$ for low stress values (Rutter, 1976; Weyl, 1959) and exponentially dependent on stress for higher stresses (Dewers and Ortoleva, 1990; Gratier et al., 2009). For gypsum and quartz it is found that $\lambda \geq 2$. The time exponents, $\tau$, are also found to be much larger for quartz than for other minerals. In fact the raw strain-time curves flatten out completely (within the error bars) at long times. This indicates that the decrease of porosity is limited or that the time dependence is logarithmic. It is also interesting to note that for quartz compaction the stress exponent is typically $\lambda=3$, that is much higher than for other minerals. However, this may result from the effect of the coupling of several processes: strain rates are higher in the lab than in nature, the higher the strain rate the more the time-independent processes (friction, plasticity) dominated the timedependent process (viscosity). From the study of Greene et al. (2009) the addition of muscovite would be expected to increase compaction rate and change the stress exponent to $\lambda=1$. This is not always the case due to the complex interaction between several mechanisms (Niemeijer and Spiers, 2002; Zubtsov et al., 2004). Niemeijer and Spiers (2005); Niemeijer and Spiers (2006) showed the velocity dependence of strength and healing behaviour in a simulated phyllosilicate-halite bearing fault gouge. They found that "at low velocity, strength increases with increasing velocity and normal stress and a foliation develops. This behaviour results from pressure solution in the halite grains, which accommodate sliding on the phyllosilicates." They also show no healing during low velocity permanent deformation probably due to the absence of halite-halite contact in this case. In contrast, at high velocity, velocity-weakening frictional behaviour occurs with cataclastic deformation and healing 
occurs during periods of zero slip. This is a good example of the transition between viscous (velocitystrengthening) and cataclastic (velocity-weakening) processes.

\section{5 - Applications in sedimentary basins, faults and shear zones}

\section{1 - Viscous versus plastic rheology during compaction of sediments}

The porosity reduction of sedimentary rocks with burial depth has been the subject of extensive research since Athy proposed an exponential porosity-depth equation more than 80 years ago (Athy, 1930; Giles et al., 1998). Most compaction processes observed in Nature and those described theoretically vary slowly in space and time. Compilations of porosity-depth data for sedimentary basins around the world typically show a slow, exponential-like variation in porosity with depth (Athy, 1930; Giles et al., 1998; Sclater and Christie, 1980).

Tentative models of quartz sediment compaction using grain scale processes were proposed either with immobile pore fluid (Dewers and Ortoleva, 1990) or allowing pore fluid flow (Gundersen et al., 2002b; Lehner, 1995; Lehner and Leroy, 2003). Their idea was to represent grains by truncated spheres (Fig. 29) where the dissolution along the grain contacts induces an overall deformation of the aggregate. This approach was applied to calculate the porosity-depth relationship for North Sea sandstones (Renard et al., 2000b). Depending on the sedimentation rate, that imposes the time scale of the compaction process, different porosity-depth relationships could be calculated and fit reasonably the natural data (Fig. 35).

Other studies have proposed a porosity-effective stress relationship that is independent of burial time and that describes a plastic rheology in the sense that an increment of finite stress results in a finite porosity decrement. Microstructural studies of sediments and experimentally compacted samples show that grain rearrangement, grain crushing, and pressure solution are the main compaction mechanisms which smoothly and sequentially overtake each other in importance with progressive depth of burial (Bjorlykke and Hoeg, 1997). The first two mechanisms lead to plastic rheologies whereas, on the other hand, pure pressure solution of an unconsolidated aggregate is a time-dependent creep process that, for any finite effective stress, will (given enough time) result in zero porosity. Thus, even when pressure solution is the mechanism responsible for indentation and truncation of grains leading to porosity loss, grain contact healing and overgrowth may inhibit the pressure solution process and stop compaction at a finite porosity $\phi_{c}$. Even though the question of a finite porosity $\phi_{c}$ was clearly posed in 1976 (Sprunt and Nur, 1976), little research has been conducted on understanding the change towards consolidation during compaction and it is not clear whether the consolidated porosity $\phi_{c}$ is mainly a function of time 


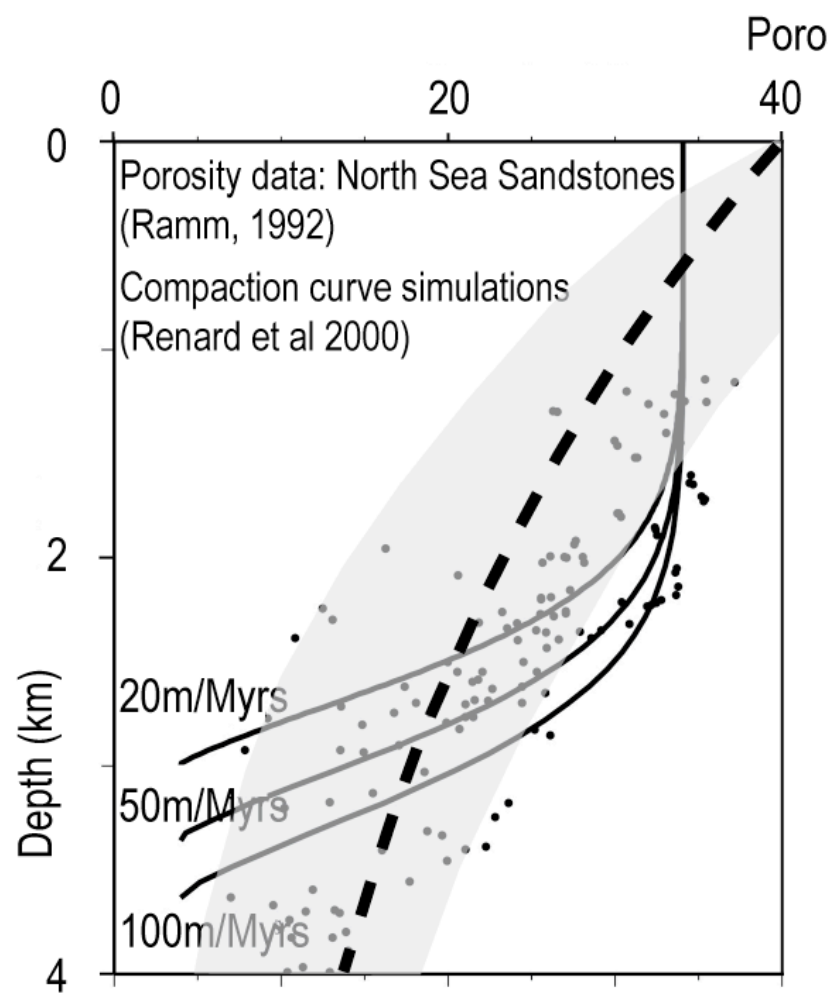

Figure 35: Porosity-depth relationships in North Sea sandstones: the porosity decreases with depth (data from (Ramm, 1992). The curves represent simulations of porosity-depth relationships assuming that porosity is reduced by pressure solution creep, adapted from (Renard et al., 2000a). The gray zone is the extent of various exponential porosity-depth models for sandstones, the heavy line being the mean value, adapted from (Giles et al., 1998)

or of stress. Revil (1999) and Revil (2001) started from observations that a viscous type rheology was not sufficient to explain compaction of sedimentary basins and constructed a "poro-visco-plastic" model of pressure solution with a plastic bulk modulus $\beta$ in parallel with the creep viscosity $\Theta$ in the deformation law $\sigma=\beta^{-1} \varphi+\Theta^{-1} d \varphi / d t$. The characteristic timescale for crossover between viscous behaviour at short times and plastic behaviour at long times is given by $\tau=\beta / \Theta$. The parameters may be calculated from measurable quantities in this phenomenological model and were used for comparison with quartz compaction data. The model has been modified and refined by others (Taron and Elsworth, 2010; Yasuhara et al., 2003) to include the strain hardening effect of growing grain contact areas. The idea of finding a time scale for the transition between viscous and plastic is intriguing, it would help analysis and application of compaction data, but the basis of this model is in our opinion incorrect: a plastic pore compressibility does not relieve stress from the grain contacts 
where pressure solution occurs, in other words the viscous and plastic elements should be in series, not in parallel.

Strain hardening during pressure solution compaction is found partially in the change in grain packing and contact sizes, and partially in the grain contact structure. van Noort et al. (2008b) formulated a model based on the changing grain contact structure. They assumed a specific island-channel type structure with width (heights of channels) $\delta$ and where the load-bearing solid area fraction is $\alpha$. The balance between chemical potential driving dissolution (strain energy, Eq. 9 above) and that driving precipitation/healing (surface tension, Eq. 10 above) yields a simple criterion for the stability of the island channel structure: $\left(\left(\sigma_{n}-P_{f}\right) / \alpha\right)^{2} / E=4 \gamma / \delta$ where $\sigma_{n}$ is the normal stress, $P_{f}$ is the fluid pressure, $E$ is the Young's modulus of the solid, $\gamma$ is the surface tension, $\delta$ is the size of the channels and $\alpha$ is the fraction of the surface area that contains actual contacts. This general criterion was applied to quartz aggregates to predict a finite porosity-stress relationship where the dynamic dissolution and growth of island contacts stop due to contact healing. van Noort et al. (2008b) also included a dihedral angle term that has been omitted here because the finite width geometry chosen renders this factor useless. They compared their model with experiments and field data with $\alpha$ and $\delta$ as free parameters because experiments do not allow their limits to be accurately defined. The lack of theoretical bounds on the width parameter $\delta$ in the model calls for more fundamental studies that do not assume the structure to start with. The question points back to the importance of the stability of the intergranular liquid film discussed above.

\section{2 - Steady state pressure solution creep law: modelling an aseismically creeping zone such as the San Andreas Fault}

In this section, a pressure solution creep law is applied to explain how a fault zone may creep and data on the San Andreas Fault (SAF) in California are used for this purpose. Because a pressure solution creep law, derived experimentally, requires a large number of parameters, it is necessary to combine studies of rock microstructures and experimental results. The goal is to show that pressure solution creep is a viable deformation mechanism to explain the aseismic strain observed on the aseismic creep segment of the SAF. There is a well-known $175 \mathrm{~km}$ long creeping zone in the central part of the San Andreas Fault, north of Parkfield. Geodetic measurements reveal a permanent displacement rate of about $28 \mathrm{~mm} /$ year at its maximum over a narrow zone of less than $20 \mathrm{~m}$ (Titus et al., 2006). Bore hole drilling through the SAF allowed to correlate fault rock microstructures with real time geophysical data and therefore provides useful information to identify aseismic mechanisms (Bradbury et al., 2011; Holdsworth et al., 2011; Schleicher et al., 2009; Solum et al., 2006; Zoback et al., 2010). 
Based on microstructural studies of rock samples collected from the San Andreas Fault Observatory at Depth (SAFOD) (Gratier et al., 2011) proposed that pressure solution mass transfer can account for aseismic deformation. Experimental data on minerals such as quartz and calcite are used to demonstrate that such a creep mechanism can accommodate the present displacement rate of the SAF creeping zone. An experimental pressure solution creep law can be written as:

$$
\dot{\varepsilon}=\Delta d /(d \Delta t)=8 D \delta c V_{s}\left(e^{3 \Delta \sigma_{n} V_{s} / R T}-1\right) / d^{3}
$$

where $c$ is the solubility of the diffusing solid $\left(\mathrm{mol} \mathrm{m}^{-3}\right), V_{s}$ is the molar volume of the stressed solid $\left(\mathrm{m}^{3} \mathrm{~mol}^{-1}\right), R$ is the gas constant $\left(8.31 \mathrm{~J} \mathrm{~mol}^{-1} \mathrm{~K}^{-1}\right), T$ is the temperature $(\mathrm{K}), D$ is the diffusion constant along the stressed interface $\left(\mathrm{m}^{2} \mathrm{~s}^{-1}\right), \delta$ is the thickness of the fluid interface $(\mathrm{m})$ along which diffusion occurs, $t$ is time, $\Delta \sigma_{\mathrm{n}}$ is the driving stress defined as the difference between normal stress on a dissolution surface and the fluid pressure in the open spaces (cracks, pores), and $d$ is the indenter diameter (Gratier et al., 2009). From experiments, all the parameters of the law are known for quartz at $350^{\circ} \mathrm{C}$. The values of the parameters at other temperatures for quartz and for other minerals that are seen to dissolve (Fig. 8a \& 17a, b) may be derived from the literature, see references in (Gratier et al., 2009): (i) Solubility: at $3-10 \mathrm{~km}$ for quartz $\left(0.003 \times 10^{3}-0.03 \times 10^{3} \mathrm{~mole} / \mathrm{m}^{3}\right)$, calcite $(0.005-0.0005$ x $\left.10^{3} \mathrm{~mole} / \mathrm{m}^{3}\right)$, feldspar $\left(0.0003 \times 10^{3}-0.001 \times 10^{3} \mathrm{~mole} / \mathrm{m}^{3}\right)$; (ii) molar volume: for quartz $\left(2.2 \times 10^{-}\right.$ $\left.{ }^{5} \mathrm{~m}^{3} / \mathrm{mole}\right)$, calcite $\left(3.69 \times 10^{-5} \mathrm{~m}^{3} / \mathrm{mole}\right)$, feldspar $\left(10.3 \times 10^{-5} \mathrm{~m}^{3} / \mathrm{mole}\right)$; (iii) activation energy of the diffusion in water $(15 \mathrm{~kJ} / \mathrm{mole} / \mathrm{K})$ is used to calculate the variation in $D, \delta$ being considered as constant of the order of 1-10 nanometres.

For an application to Nature, the imposed displacement rate is known and the creeping zone at depth is estimated to range from 1 to 3 metres width. The displacement rate at the SAFOD site is about 20 $\mathrm{mm} / \mathrm{y}$. Such a displacement rate accommodated by a 1-metre thick shear zone implies a total shear strain $\gamma=0.02$, corresponding to a strain-rate of $3.3 \times 10^{-10} \mathrm{~s}^{-1}(\gamma=2 \Delta l / l)$. Instead, if the shear zone was $3 \mathrm{~m}$ thick the strain rate would be equal to $1.1 \times 10^{-10} \mathrm{~s}^{-1}$. To complete the modelling, the driving force $\Delta \sigma_{\mathrm{n}}$ must be known. The driving stress value was measured to be about $60 \mathrm{MPa}$ at $3 \mathrm{~km}$ depth (Hickman and Zoback, 2004). The same value is used at all depths in the model. For these given strain rate and stress values, it is possible to model the behaviour of quartz, calcite and feldspar in a mass transfer distance versus depth diagram (Fig. 36a). The opposite behaviour of quartz and calcite due to the different change in their solubility with temperature is worthy of note. It is clear that a maximum mass transfer distance of about 100 microns is required in order to accommodate the shearing deformation by pressure solution through the entire upper crust as observed. In nature, the distance $d$ is either the spacing between fractures (Fig. 19) or the mean grain size (Fig. 25). In both cases the value of $d$ is well below 100 microns. This means that pressure solution can accommodate the measured aseismic displacement. However, there are several open questions. 

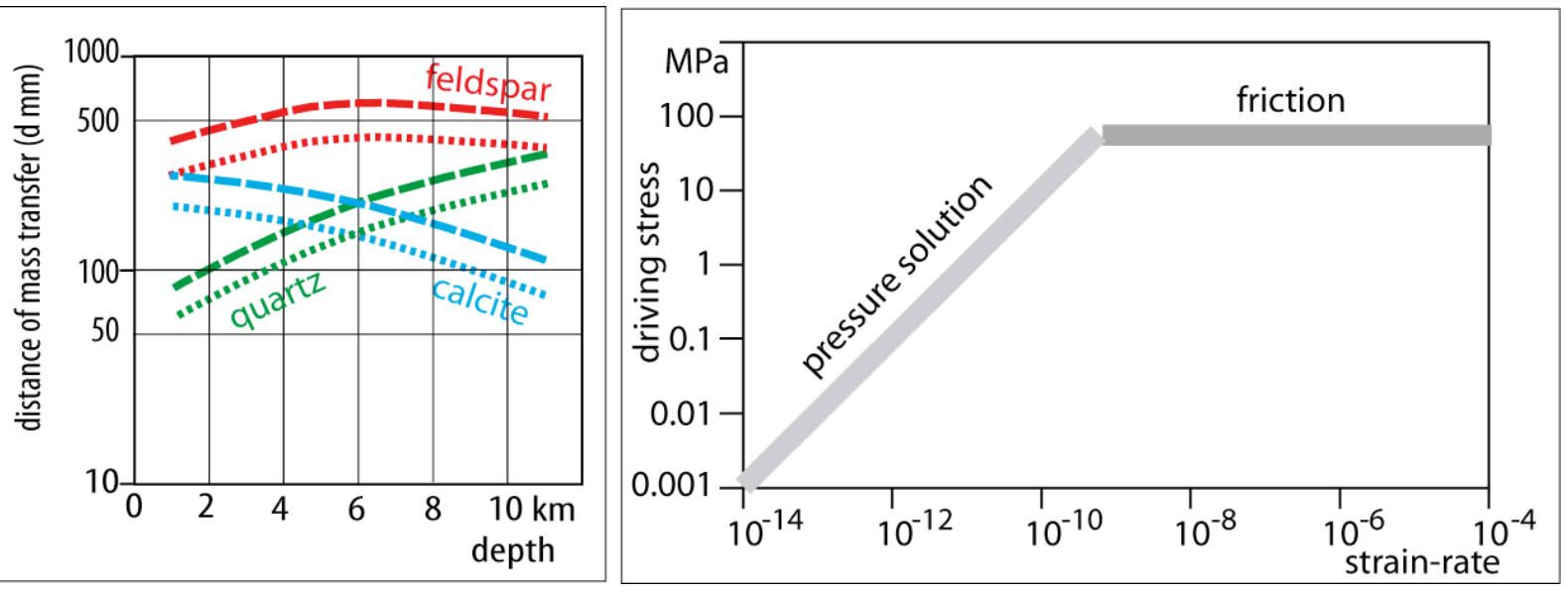

Figure 36: (a) Steady state modelling of pressure solution creep of various minerals in the upper crust: mass transfer distance $d$ versus depth for various minerals required to accommodate a 20 $\mathrm{mm} / \mathrm{yr}$ horizontal displacement rate by pressure solution creep in vertical shear zone of $1 \mathrm{~m}$ width (dotted line, strain-rate of $3.3 \times 10^{-10} \mathrm{~s}^{-1}$ ) or $3 \mathrm{~m}$ width (dashed lines, strain rate of $1.1 \times 10^{-10} \mathrm{~s}^{-1}$ ), adapted from (Gratier et al., 2011); (b) Schematic variation in the driving force for friction $\left(\tau-\sigma_{n}\right)$ and pressure solution $\left(\sigma_{n}-P_{f}\right)$ depending on the strain rate.

The first is to know how the mass transfer distance was reduced: initial grain sizes found away from the creeping zone are much larger. Two processes may combine: fragmentation of the rock that may be linked to seismic fault activity and some processes that avoid the healing of these fractures such as the relative displacement of the fragments and the growth of phyllosilicates (Holdsworth et al., 2011). It must also be noted that the calculation corresponds to a stable behaviour. It has been seen that fracturing may accelerate the pressure solution kinetics (Fig. 33c) and, conversely, sealing may decrease this kinetics (Fig. 33c). Future models should include this interaction between fracturing and sealing that occurs at a time scale ranging from days to millennia (see below).

Another question is the change in the creeping zone over longer time scales: millennia to millions of years. Pressure solution is associated with progressive change of volume (Fig. 7 \& 18), or to layering development (Fig. 16). Both processes could modify the behaviour of the rock and, consequently, strengthening (effect of precipitation, contact healing) or weakening (effect of passive concentration of insoluble minerals) may develop with time depending on the deformation conditions. Based on observations of the SAF, weakening seems to have occurred in the creeping zone but the damaged zone remains rigid enough to promote microseismic activity.

It has been argued from experiments on a synthetic gouge (grounded SAF gouge) (Carpenter et al., 2011; Lockner et al., 2011) that the creeping zone has very low friction values (up to 0.15) due to the presence of very soft phyllosilicates, such as saponite. This may be true if the effect of grinding the gouge is not too great. However, it is also well known that saponite and other soft phyllosilicates such 
as corrensite are not stable below depths of 3 or 4 kilometres and cannot explain the creep observed below these depths. There are no other soft minerals in the gouge except some very rare evidence of talc (Holdsworth et al., 2011; Moore and Rymer, 2007). So it is likely that, at depth, pressure solution plays a key role in accommodating aseismic deformation.

Finally, from a more general point of view, friction and pressure solution may be compared in a strain rate versus driving stress diagram (Fig. 36b). Friction has a weak, logarithmic dependence on strain rate over geological time scales and requires a relatively high shear stress to initiate, of the order of the static friction coefficient times the normal stress. Conversely, pressure solution may strongly depend on the strain rate and requires more modest shear stress. This diagram shows that at geological strain rates (from $10^{-10} \mathrm{~s}^{-1}$ in active creeping faults to $10^{-14} \mathrm{~s}^{-1}$ in tectonic processes) pressure solution requires much less differential stress than friction. Several key parameters are however necessary: presence of fluids, mass transfer distance as small as possible (so most often fragmentation is necessary to achieve small grain sizes), some process to avoid the healing of the fractures and the grain contacts and the presence of phyllosilicates that activates the process.

\section{3 - Non-steady state: fault gouge and shear zone strengthening and weakening}

As seen above, steady state modelling of pressure solution is only a very crude approximation of the reality, as good evidence of strengthening and weakening processes that must lead to non-steady creep is observed in Nature in various active faults and shear zones.

\section{5-3-1 Strengthening processes}

Over the past ten years, increased interest has been shown in studying the mechanism of timedependent fault gouge strengthening that is found in all friction experiments. Although the original formulation of the rate-and-state friction law (Scholz, 1998) considers plastic deformation of contact asperities, there has been an increased awareness that fluid-assisted processes at hydrothermal conditions contribute strongly to the changes in strength. There has been a recent wave of experimental studies on gouge strengthening in the presence of aqueous fluids (Bos et al., 2000a; Bos et al., 2000b; Bos and Spiers, 2002; Kanagawa, 2002; Kay et al., 2006; Nakatani and Scholz, 2004; Niemeijer et al., 2008a; Niemeijer et al., 2010; Niemeijer et al., 2008b; Tenthorey and Cox, 2006; Yasuhara et al., 2005). They all discuss if dissolution-precipitation processes are compatible with rateand-state friction laws and to which extend they are the dominant mechanisms for strengthening. Several experiments where the strength will be strongly affected by contact healing are modelled by pure pressure solution (Bos et al., 2000b; Yasuhara et al., 2005). It should, however be made clear that 

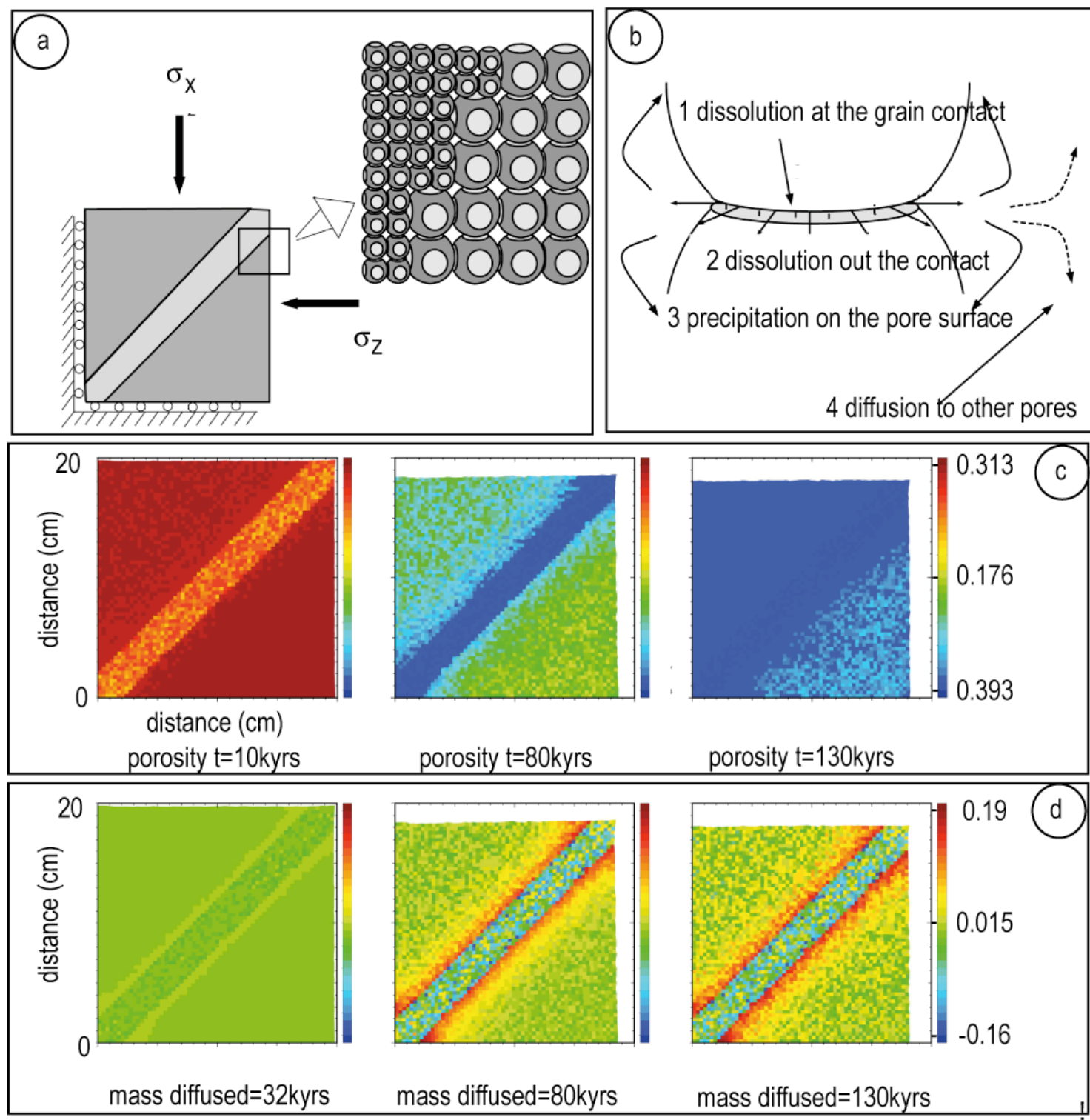

Figure 37: Simulation of the compaction of a fault gouge in a sandstone (100\% quartz) where grains are represented as truncated spheres. a) At the grain scale, the three steps of pressure solution, i.e. dissolution, diffusion along the grain boundary, and precipitation on the free face, are calculated. The effect of transport between the pores is also accounted for; $\boldsymbol{b})$ The rock is modelled as a 2D packing of individual grains where the gouge zone is made of smaller grains. The system size is $20 \times 20 \mathrm{~cm}$; ) With time, the rock compacts. Because the gouge contains smaller grains, it compacts faster; d) Dissolved quartz from the gouge is also transported to the two sides on the fault zone and induces excess cementation of the walls, adapted from (Gundersen et al., 2002b). 
several processes at different time scales are also involved in fault gouge strengthening. Also in the study of frictional strength, single contact experiments (Renard et al., 2012; Voisin et al., 2007) (as opposed to aggregate experiments) may reveal more clearly the distinct mechanisms and rate limiting steps. In Nature, characteristic healing times no doubt vary from years (in the case of fast microfracture healing, Fig. 32) to millions of years (in the case of slow vein sealing, Fig. 16, 26).

By representing grains as truncated spheres and modelling pressure solution creep as the collective deformation of individual grains (Dewers and Ortoleva, 1990; Lehner, 1995), a model of the strengthening and compaction of a gouge was proposed (Gundersen et al., 2002b). Fig. 37a-b presents the model where the fault gouge contains smaller grains. With time, the rock compacts (Fig. 37c), as compaction occurs faster in the gouge because of the grain size difference, the concentration in the pore fluid is slightly higher in the gouge. This induces a concentration gradient between the gouge and the walls of the fault. This results in precipitation in the fault walls (Fig. 37d). Fault strengthening thus occurs by the combined effects of gouge compaction and walls cementation.

\section{5-3-2 Weakening processes}

In parallel, weakening processes linked to two types of processes have also been described. Dynamic indenting experiments show that fracturing accelerates pressure solution by increasing the outward diffusion flux from the dissolution contact (Fig. 30, 33c). However, this effect is strongly non-linear as fracture healing progressively strengthens the rocks. The characteristic time of such a process is of the order of magnitude of the earthquake cycle: from tens to thousand of years (Gratier, 2011a). Another weakening mechanism is the change in phyllosilicates content in the rocks. The crucial role of phyllosilicates in accelerating pressure solution has already been mentioned (Fig. 14, 31). There are at least two different mechanisms that can change the phyllosilicates content in a deforming rock: either the passive phyllosilicates concentration by the dissolution of soluble species or the growth of clay minerals due to metamorphic reactions. Both processes tend to promote pressure solution by facilitating diffusion and by avoiding sealing between the grains. However, the characteristic times of these processes are different. Passive concentration occurs at geological times (hundred thousand to millions of years) associated with progressive development of tectonic layering (Fig. 16). Conversely, fluid flow during inter-seismic periods (years to millennia) may lead to clay deposition and thus to local weakening by facilitating pressure solution (Fig. 17) and decreasing friction (Lockner et al., 2011). 


\section{6 - Conclusion}

In the past 150 years researchers have compiled much evidence on the importance of pressure solution creep in Nature. Thermodynamic pressure solution models have been fortified by theoretical and experimental work. Most observations both in Nature and by experiment show a clear relation between dissolution structures and stress. However, the driving effects of fracturing, healing, grain contact dynamics, and the role of phyllosilicates need to be better understood and will involve a nonsteady-state creep pressure solution model.

- Fracturing (weakening effect) competes with healing (strengthening effect) during earthquake cycles and the change in shear zones, and probably also in all the deformation processes that are triggered by human activity (fluid extraction or geological storage).

- Phyllosilicates content increase (weakening effect) competes with vein sealing (strengthening) at all time scales from earthquake cycles to basin compaction or mountain building leading to tectonic segregation.

This complex behaviour is true for all the stress-driven mass transfer mechanisms including metamorphic reactions when they imply a thin fluid phase trapped under stress.

Considerable work has been done on pressure solution creep over the last 20 years, including trying to integrate non-linear processes but at least four important questions represent challenges for future studies:

- Is there a time-independent porosity-depth relation for buried sediments? Compilation of data from sedimentary basins suggests that this is the case, the simplistic (pure) pressure solution model contradicts this.

- What is the relative importance of pressure solution, fracturing and contact healing in the development of a stressed aggregate? Until now, modelling has been based entirely on the first process, but some evidence suggests the other two may play a controlling role.

- How can the stability and development of a grain contact under stress be described? Evidence seems to point in different directions. Without answering this, it will be difficult to predict anything and to propose a creep law for pressure solution.

- How can the experimental and natural observations of the crucial role of phyllosilicates in dissolution be integrated in creeping laws?

Only the future will tell whether the solution lies in embracing the complexity and complicated nature of reality or whether a simple, comprehensive picture of the processes generally called pressure solution does exist. 


\section{Acknowledgments:}

We thank R. Van Noort and two anonymous reviewers for their comments that significantly improved the manuscript. We also thank P. Vialon, J-F. Gamond and A-M. Boullier for their help in interpreting and presenting natural structures and R. Guiguet, L. Jenatton and B. Vial for their help in building and running experiments. We also thank Jens Feder and Bjørn Jamtveit for their contributions. 


\section{References}

Aharonov, E., and Katsman, R. (2009). Interaction between pressure solution and clays in stylolites development: insights from modeling. American Journal of Science 309, 607-632.

Alcantar, N., Israelachvili, J., and Boles, J. (2003). Forces and ionic transport between mica surfaces: Implications for pressure solution. Geochimica et Cosmochimica Acta 67, 1289-1304.

Anderson, O. L., and Grew, P. C. (1977). Stress corrosion theory of crack propagation with application to geophysics. Review of Geophysics 15, 77-104.

Andrade, E. N. D., Randall, R. F. Y., and Makin, M. J. (1950). The Rehbinder Effect. Proceedings of the Physical Society of London Section B 63, 990-995.

Andrews, L. M., and Railsback, L. B. (1997). Controls on stylolite development: Morphologic, lithologic, and temporal evidence from bedding-parallel and transverse stylolites from the US Appalachians. Journal of Geology 105, 59-73.

Angheluta, L., Jettestuen, E., and Mathiesen, J. (2009). Thermodynamics and roughening of solidsolid interfaces Physical Review E 79, doi:10.1103/PhysRevE.79.031601.

Angheluta, L., Jettestuen, E., Mathiesen, J., Renard, F., and Jamtveit, B. (2008). Stress-driven phase transformation and the roughening of solid-solid interfaces. Physical Review Letters 100, doi:10.1103/PhysRevLett.100.096105

Angheluta, L., Mathiesen, J., Misbah, C., and Renard, F. (2010). Morphological instabilities of stressed and reactive geological interfaces. Journal of Geophysical Research-Solid Earth 115, doi:10.1029/2009JB006880

Anzalone, A., Boles, J., Greene, G., Young, K., Israelachvili, J., and Alcantar, N. (2006). Confined fluids and their role in pressure solution. Chemical Geology 230, 220-231.

Argand, E. (1924). "La tectonique de 1'Asie, XIII Congrès géologique international 1922."

Arthaud, F., and Mattauer, M. (1969). Exemples de stylolites d'origine tectonique dans le Languedoc, leur relation avec la tectonique cassante. Bulletin de la Société Géologique de France 11, 738744.

Asaro, R. J., and Tiller, W. A. (1972). Interface morphology development during stress corrosion cracking: Part I. Via surface diffusion Metallurgical and Materials Transactions B 3, 17891796.

Ashby, M., and Verrall, R. (1973). Diffusion-accommodated flow and superplasticity. Acta Metallurgica, 21, 149-163.

Athy, L. F. (1930). Density, porosity and compactation of sedimentary rocks. American Associaton of Petroleum Geology Bulletin 14, 1-24.

Atkinson, B. K. (1984). Subcritical crack-propagation in geological materials. Journal of Geophysical Research--Solid Earth 89, 4077-4114.

Baker, P. A., Kastner, M., and Byerlee, D. A. (1980). Pressure solution and hydrothermal recrystallization of carbonate sediments: an experimental study. Marine Geology 38, 185-203.

Barnes, R. B. (1933). The plasticity of rocksalt and its dependence upon water. Physical Review 44, 0898-0902.

Baron, M., and Parnell, J. (2007). Relationships between stylolites and cementation in sandstone reservoirs: Examples from the North Sea, UK and East Greenland. Sedimentary Geology 194, 17-35.

Bathurst, R. G. C. (1971). "Carbonate sediments and their diagenesis." Elsevier, Amsterdam.

Bauerle, G., Bornemann, O., Mauthe, F., and Michalzik, D. (2000). Origin of stylolites in Upper Permian Zechstein anhydrite (Gorleben salt dome, Germany). Journal of Sedimentary Research 70, 726-737.

Berton, J. R., Durney, D. W., Wheeler, J., and Ford, J. M. (2006). Diffusion-creep modelling of fibrous pressure-shadows. Tectonophysics 425, 191-205.

Beutner, E. C., and Diegel, F. A. (1985). Determination of fold kinematics from syntectonic fibers in pressure shadows, Martinsburg slate, New Jersey. American Journal of Science 285, 16-50. 
Bisschop, J., and Dysthe, D. (2006). Instabilities and coarsening of stressed crystal surfaces in aqueous solution Physical Review Letters 96, 146103

Bjorkum, P. A., Oelkers, E. H., Nadeau, P. H., Walderhaug, O., and Murphy, W. M. (1998). Porosity prediction in quartzose sandstones as a function of time, temperature, depth, stylolite frequency, and hydrocarbon saturation. American Association of Petroleum Geologists Bulletin 82, 637-648.

Bjorlykke, K., and Hoeg, K. (1997). Effects of burial diagenesis on stresses, compaction and fluid flow in sedimentary basins. Marine and Petroleum Geology 14, 267-276.

Bonamy, D., Prades, S., Rountree, C. L., Ponson, L., Dalmas, D., Bouchaud, E., Ravi-Chandar, K., and Guillot, C. (2006). Nanoscale damage during fracture in silica glass. International Journal of Fracture 140, 3-14.

Bonnetier, E., Misbah, C., Renard, F., Toussaint, R., and Gratier, J. P. (2009). Does roughening of rock-fluid-rock interfaces emerge from a stress-induced instability? European Physical Journal B 67, 121-131.

Bos, B., Peach, C. J., and Spiers, C. J. (2000a). Frictional-viscous flow of simulated fault gouge caused by the combined effects of phyllosilicates and pressure solution. Tectonophysics 327, 173-194.

Bos, B., Peach, C. J., and Spiers, C. J. (2000b). Slip behavior of simulated gouge-bearing faults under conditions favoring pressure solution. Journal of Geophysical Research-Solid Earth 105, 16699-16717.

Bos, B., and Spiers, C. J. (2000). Effect of phyllosilicates on fluid-assisted healing of gouge-bearing faults. Earth and Planetary Science Letters 184, 199-210.

Bos, B., and Spiers, C. J. (2002). Fluid-assisted healing processes in gouge-bearing faults: Insights from experiments on a rock analogue system. Pure and Applied Geophysics 159, 2537-2566.

Boullier, A. M., and Guéguen, Y. (1975). S.P.-Mylonites: origin of some mylonites by superplastic flow. Contributions to Mineralogy and Petrology 50, 93-104.

Bradbury, K. K., Evans, J. P., Chester, J. S., Chester, F. M., and Kirschner, D. (2011). Lithology and internal structure of the San Andreas fault at depth based on characterization of Phase 3 whole-rock core in the San Andreas Fault Observatory at Depth (SAFOD) borehole. Earth and Planetary Science letters 310, 131-144.

Bresme, F., and Cámara, L. G. (2006). Computer simulation studies of crystallization under confinement conditions. Chemical Geology 230, 1997-2006.

Brouste, A. F., Renard, J. P., Gratier, J., and Schmittbuhl, J. (2007). Variety of stylolites morphologies and statistical characterization of the amount of heterogeneities in the rock. Journal of Structural Geology 29, 422-434.

Burkhard, M. (1992). Calcite twins, their geometry, appearance and significance as stress-strain markers and indicators of tectonic regime: a review. Journal of Structural Geology 15, 351368.

Byerlee, J. D. (1978). Friction of rocks. Pure and Applied Geophysics 116, 615-626.

Cahn, J. W., and Hilliard, J. E. (1958). Free energy of a nonuniform system (I): Interfacial energy. Journal of Chemical Physics, 28.

Carpenter, B. M., Marone, C., and Saffer, D. M. (2011). Weakness of the San Andreas Fault revealed by samples from the active fault zone. Nature Geoscience 4, 251-254.

Carrio-Schaffhauser, E., Raynaud, S., Latière, H. J., and Mazerolles, F. (1990). Propagation and localization of stylolites in limestones. Geological Society of London, Special Publication 54, 193-199.

Carter, N. L., Horseman, S. T., Russell, J. E., and Handin, J. (1993). Rheologie of rock-salt. Journal of Structural Geology 15, 1257-1271.

Chen, W. P., and Molnar, P. (1983). Focal depths of intracontinental and intraplate earthquakes and their implications for the thermal and mechanical properties of the lithosphere. Journal of Geophysical Research-Solid Earth 88, 4183-4214. 
Chester, F. M., Chester, J. S., Kronenberg, A. K., and Hajash, A. (2007). Subcritical creep compaction of quartz sand at diagenetic conditions: Effects of water and grain size. Journal of Geophysical Research-Solid Earth 112, doi:10.1029/2006JB004317.

Chester, F. M., and Higgs, N. G. (1992). Multimechanism friction constitutive model for ultrafine quartz gouge at hypocentral conditions. Journal of Geophysical Research-Solid Earth 97, $1859-1870$.

Cobbold, P. R. (1979). Removal of finite deformation using strain trajectories Journal of Structural Geology 1, 67-72.

Coble, R. L. (1963). A model for boundary diffusion controlled creep in polycristalline material. Journal of Applied Physics 34, 1679-1682.

Cosgrove, J. W. (1976). The formation of crenulation cleavage. Journal of the Geological Society of London 132, 155-178.

Cox, S. F., and Etheridge, M. A. (1989). Coupled grain-scale dilatancy and mass transfer during deformation at high fluid pressures: examples from Mount Lyell, Tasmania. Journal of Structural Geology 11, 147-162.

Cox, S. F., and Paterson, M. S. (1991). Experimental dissolution-precipitation creep in quartz aggregates at high temperatures. Geophysical Research Letters 78, 1401-1404.

Croize, D., Bjorlykke, K., Jahren, J., and Renard, F. (2010a). Experimental mechanical and chemical compaction of carbonate sand. Journal of Geophysical Research-Solid Earth 115.

Croize, D., Renard, F., Bjorlykke, K., and Dysthe, D. K. (2010b). Experimental calcite dissolution under stress: Evolution of grain contact microstructure during pressure solution creep. Journal of Geophysical Research-Solid Earth 115, B09207, doi:10.1029/2010JB000869.

de Boer, R. B. (1977). On the thermodynamics of pressure solution-interaction between chemical and mechanical forces. Geochimica et Cosmochimica Acta 41, 246-256.

de Boer, R. B., Nagtegaal, P. J. C., and Duyvis, E. M. (1977). Pressure solution experiments on quartz sand. Geochimica et Cosmochimica Acta 41, 257-264.

de Groot, S. R., and Mazur, P. (1984). "Non-Equilibrium thermodynamics." Dover publication, New York.

de Meer, S., and Spiers, C. J. (1999). Influence of pore-fluid salinity on pressure solution creep in gypsum. Tectonophysics 308, 311-330.

de Meer, S., Spiers, C. J., and Nakashima, S. (2005). Structure and diffusive properties of fluid-filled grain boundaries: An in-situ study using infrared (micro) spectroscopy. Earth and Planetary Science letters 232, 403-414.

de Meer, S., Spiers, C. J., and Peach, C. (1997). Pressure solution creep in gypsum: Evidence for precipitation reaction control. Physics and Chemistry of the Earth 22, 33-37.

de Meer, S., Spiers, C. J., Peach, C. J., and Watanabe, T. (2002). Diffusive properties of fluid-filled grain boundaries measured electrically during active pressure solution. Earth and Planetary Science letters 200, 147-157.

deMeer, S., and Spiers, C. J. (1997). Uniaxial compaction creep of wet gypsum aggregates. Journal of Geophysical Research-Solid Earth 102, 875-891.

den Brok, B., Morel, J., and Zahid, M. (2002). In situ experimental study of roughness development at a stressed solid/fluid interface. Geological Society of London, Special Publication 200, 73-83.

den Brok, B., and Spiers, C. J. (1991). Experimental evidence for water weakening of quartzite by microcracking plus pressure solution-precipitation creep. Journal of the Geological Society 148, 541-548.

den Brok, B., Zahid, M., and Passchier, C. W. (1999). Pressure solution compaction of sodium chlorate and implications for pressure solution in NaCl. Tectonophysics 307, 297-312.

den Brok, S. W. J. (1998). Effect of microcracking on pressure-solution strain rate: The Gratz grainboundary model. Geology 26, 915-918.

den Brok, S. W. J., and Morel, J. (2001). The effect of elastic strain on the microstructure of free surfaces of stressed minerals in contact with an aqueous solution. Geophysical Research Letters 28, 603-606. 
Dewers, T., and Hajash, A. (1995). Rate laws for water-assisted compaction and stress-induced waterrock interaction in sandstones. Journal of Geophysical Research-Solid Earth 100, 1309313112.

Dewers, T., and Ortoleva, P. (1990). A coupled reaction / transport / mechanical model for intergranular pressure solution stylolites, and differential compaction and cementation in clean sandstones. Geochimica et Cosmochimica Acta 54, 1609-1625.

Drummond, C. N., and Sexton, D. N. (1998). Fractal structure of stylolites. Journal of Sedimentary Research 68, 8-10.

Dunnington, H. V. (1954). Stylolites development post-date rock induration. Journal of Sedimentary Petrology 24, 27-49.

Durney, D. W., and Ramsay, J. G. (1973). Incremental strains measured by syntectonic crystal growth. In "Gravity and tectonics." (K. A. De Jong, and R. Scholten, Eds.), pp. 67-96. John Wiley, New york.

Dysthe, D. K., Podladchikov, Y., Renard, F., Feder, J., and Jamtveit, B. (2002a). Universal scaling in transient creep. Physical Review Letters 89, doi:10.1103/PhysRevLett.89.246102.

Dysthe, D. K., Renard, F., Feder, J., Jamtveit, B., Meakin, P., and Jøssang, T. (2003). High resolution measurements of pressure solution creep. Physical Review E 68, doi:10.1103/PhysRevE.68.011603.

Dysthe, D. K., Renard, F., Porcheron, F., and Rousseau, B. (2002b). Fluid in mineral interfaces molecular simulations of structure and diffusion. Geophysical Research Letters 29.

Ebner, M., Koehn, D., Toussaint, R., Renard, F., and Schmittbuhl, J. (2009). Stress sensitivity of stylolite morphology. Earth and Planetary Science Letters 277, 394-398.

Ebner, M., Piazolo, S., Renard, F., and Koehn, D. (2010a). Stylolite interfaces and surrounding matrix material: Nature and role of heterogeneities in roughness and microstructural development. Journal of Structural Geology 32, 1070-1084.

Ebner, M., Toussaint, R., Schmittbuhl, J., Koehn, D., and Bons, P. (2010b). Anisotropic scaling of tectonic stylolites: A fossilized signature of the stress field? Journal of Geophysical ResearchSolid Earth 115, doi:10.1029/2009JB006649.

Ehrenberg, S. N. (2006). Porosity destruction in carbonate platforms. Journal of Petroleum Geology 29, 41-51.

Elias, B. P., and Hajash, A. (1992). Changes in quartz solubility and porosity due to effective stress: An experimental investigation of pressure solution. Geology 20, 451-454.

Elliott, D. (1973). Diffusion flow laws in metamorphic rocks. Geological Society of America Bulletin 84, 2645-2664.

Engelder, T. (1974). Microscopic wear grooves on slikensides: indicators of paleoseismicity. Journal of Geophysical Research-Solid Earth 79, 4387-4392.

Engelder, T. (1982). A natural example of the simultaneous operation of free-face dissolution and pressure solution. Geochimica et Cosmochimica Acta 46, 69-74.

Espinosa-Marzal, R. M., Drobek, T., Balmer, T., and Heuberger, M. P. (2012). Hydrated-ion ordering in electrical double layers. Physical Chemistry Chemical Physics 14, 6085-6093.

Etchecopar, A., and Malavieille, J. (1987). Computer models of pressure shadows: a method for strain measurement and shear-sense determination. Journal of Structural Geology 9, 667-677.

Farver, J., and Yund, R. (2000). Silicon diffusion in a natural quartz aggregate: constraints on solution-transfer diffusion creep. Tectonophysics 325, 193-205.

Fischer, G. W., and Elliott, D. (1974). Criteria for quasi-steady diffusion and local equilibrium in metamorphism. In "Geochemical transports and kinetics." (A. W. Hofmann, B. J. Giletti, H. S. Yoder, and R. Yund, Eds.), pp. 77-89. Carnegie Inst. Washington Publ., Washington.

Fitzenz, D. D., Jalobeanu, A., and Hickman, S. H. (2007). Integrating laboratory creep compaction data with numerical fault models: A Bayesian framework. Journal of Geophysical ResearchSolid Earth 112, doi:10.1029/2006JB004792.

Fletcher, R. C., and Pollard, D. D. (1981). Anticrack model for pressure solution surfaces. Geology 9, 419-424. 
French, R. H., Parsegian, V. A., Podgornik, R., Rajter, R. F., Jagota, A., Luo, J., Asthagiri, D., Chaudhury, M. K., Chiang, Y. M., Granick, S., Kalinin, S., Kardar, M., Kjellander, R., Langreth, D. C., Lewis, J., Lustig, S., Wesolowski, D., Wettlaufer, J. S., Ching, W. Y., Finnis, M., Houlihan, F., von Lilienfeld, O. A., van Oss, C. J., and Zemb, T. (2010). Long range interactions in nanoscale science. Reviews of Modern Physics 82, 1887-1944.

Frenkel, D., and Smit, B. (2002). "Understanding molecular simulation: from algorithms to applications." Academic Press.

Fry, N. (1979). Ramdom point distribution and strain measurements in rocks. Tectonophysics 60, 89105.

Gal, D., and Nur, A. (1998). Elastic strain energy as a control in the evolution of asymmetric pressuresolution contacts. Geology 26, 663-665.

Gal, D., Nur, A., and Aharonov, E. (1998). Stability analysis of a pressure-solution surface. Geophysical Research Letters 25, 1237-1240.

Ghoussoub, J., and Leroy, Y. M. (2001). Solid-fluid phase transformation within grain boundaries during compaction by pressure solution. Journal of the Mechanics and Physics of Solids 49, 2385-2430.

Gibbs, J. W. (1877). On the equilibrium of heterogeneous substances. Transactions of the Connecticut Academy 3, 108-248 and 343-524.

Giles, M. R., Indrelid, S. L., and D. M. D. James (1998). Compaction - the great unknown in basin modelling. Geological Society of London, Special Publication 141, 15-43.

Goguel, J. (1948). Introduction à l'étude mécanique des déformations de l'écorce terrestre. Memoire du service de la carte géologique de France, 540p.

Grant, J. A. (2005). Isocon analysis: a brief review of the method and applications. Physics and Chemistry of the Earth 30, 997-1004.

Gratier, J.-P., Richard, J., Renard, F. S., Mittempergher, S., Doan, M. L., Di Toro, G., Hadizadeh, J., and A-M. Boullier, A. M. (2011). Aseismic sliding of active faults by pressure solution creep: evidence from the San Andreas Fault Observatory at Depth. Geology 39, 1131-1134.

Gratier, J. P. (1976). Déformation et changement de volume dans un marbre à stylolithes de la région de Rabat (Maroc). Bulletin de la Société géologique de France 7, XVIII, 1461-1469.

Gratier, J. P. (1979). Successive Deformations and Progressive Deformation - Importance of the Earliest Structures on the Later - Example of the Upper Central Atlas of Morocco. Comptes Rendus Hebdomadaires Des Seances De L Academie Des Sciences Serie D 288, 303-306.

Gratier, J. P. (1983). Estimation of volume change by comparing chemical analyses in heterogeneously deformed rocks. Journal of Structural Geology 5, 329-339.

Gratier, J. P. (1987). Pressure solution-deposition creep and associated tectonic differentiation in sedimentary rocks. Geological Society of London Special Publication 29, 25-38.

Gratier, J. P. (1993). Experimental pressure solution of halite by an indenter technique. Geophysical Research Letters 20, 1647-1650.

Gratier, J. P. (2011a). Fault permeability and strength evolution related to fracturing and healing episodic processes (years to millennia): the role of pressure solution. Oil \& Gas Science and Technology 3, 491-506.

Gratier, J. P. (2011b). The role of pressure solution in aseismic creep and the dynamic equilibrium between fracturing and sealing processes in active faults. In "EGU ", Vienna.

Gratier, J. P., Favreau, P., and Renard, F. (2003). Modeling fluid transfer along California faults when integrating pressure solution crack sealing and compaction processes. Journal of Geophysical Research-Solid Earth 108, 28-52.

Gratier, J. P., Frery, E., Deschamps, P., Røyne, A., Renard, F., Dysthe, D., Ellouz-Zimmerman, N., and Hamelin, B. (2012). How travertine veins grow from top to bottom and lift the rocks above them: the effect of crystallization force. Geology, 40, 1015-1018.

Gratier, J. P., and Gamond, J. F. (1990). Transition between seismic and aseismic deformation in the upper crust. Geological Society of London, Special Publication 54, 461-473.

Gratier, J. P., and Guiguet, R. (1986). Experimental pressure solution-deposition on quartz grains: the crucial effect of the nature of the fluid. Journal of Structural Geology 8, 845-856. 
Gratier, J. P., Guiguet, R., Renard, F., Jenatton, L., and Bernard, D. (2009). A pressure solution creep law for quartz from indentation experiments. Journal of Geophysical Research-Solid Earth 114, doi:10.1029/2008JB005652.

Gratier, J. P., Muquet, L., Hassani, R., and Renard, F. (2005). Experimental microstylolites in quartz and modeled application to natural stylolitic structures. Journal of Structural Geology 27, 89100 .

Gratier, J. P., Renard, F., and Labaume, P. (1999). How pressure solution creep and fracturing processes interact in the upper crust to make it behave in both a brittle and viscous manner. Journal of Structural Geology 21, 1189-1197.

Gratier, J. P., and Vialon, P. (1980). Deformation pattern in a heterogeneous material: folded and cleaved sedimentary cover immediately overlying a crystalline basement (Oisans, French Alps). Tectonophysics 65, 151-180.

Gratz, A. J. (1991). Solution-transfer compaction of quartzites: Progress toward a rate law. Geology 19, 901-904.

Green, H. W. (1984). "Pressure solution" creep: some causes and mechanisms. Journal of Geophysical Research-Solid Earth 89, 4313-4318.

Greene, G. W., Kristiansen, K., Meyer, E. E., Boles, J. R., and Israelachvili, J. N. (2009). Role of electrochemical reactions in pressure solution. Geochimica et Cosmochimica Acta 73, 2862 2874.

Gresens, R. L. (1967). Composition volume relations of metasomatism. Chemical Geology 2, 47-65.

Griggs, D. (1967). Hydrolytic Weakening of Quartz and Other Silicates. Geophysical Journal of the Royal Astronomical Society 14, 19-\&.

Grinfeld, M. A. (1986). Instability of interface between nonhydrostatically stressed elastic body and melts Doklady Akademii NAUK SSSR 290, 1358-1363.

Gundersen, E., Dysthe, D. K., Renard, F., Bjorlykke, K., and Jamtveit, B. (2002a). Numerical modelling of pressure solution in sandstone, rate-limiting processes and the effect of clays. Geological Society of London Special Publication 200, 41-60.

Gundersen, E., Renard, F., Dysthe, D. K., Bjorlykke, K., and Jamtveit, B. (2002b). Coupling between pressure solution creep and diffusive mass transport in porous rocks. Journal of Geophysical Research-Solid Earth 107, doi:10.1029/2001JB000287.

Guzzetta, G. (1984). Kinematics of stylolite formation and physics of the pressure-solution process. Tectonophysics 101, 383-394.

Hadizadeh, J. and Rutter, E. H. (1983). The low temperature Brittle-Ductile transition in a quartzite and the occurence of cataclastic flow in Nature. Geologische Rundschau 72, 493-509.

Hangx, S. J. T., Spiers, C. J., and Peach, C. J. (2010). Creep of simulated reservoir sands and coupled chemical-mechanical effects of $\mathrm{CO} 2$ injection. Journal of Geophysical Research-Solid Earth 115, doi:10.1029/2009JB006939.

Hassan, H. M., Korvin, G., and Abdulraheem, A. (2002). Fractal and genetic aspects of Khuff reservoir stylolites, Eastern Saudi Arabia. Arabian Journal for Science and Engineering 27, $29-56$.

Hauck, M. L., Nelson, K. D., Brown, L. D., Zhao, W., and Ross, A. R. (1998). Crustal structure of the Himalaya orogen at $90^{\circ}$ east logitude from project INDEPTH deep reflexion profile. Tectonics 17, 481-500.

He, W. W., Hajash, A., and Sparks, D. (2003). Creep compaction of quartz aggregates: Effects of pore-fluid flow - A combined experimental and theoretical study. American Journal of Science 303, 73-93.

He, W. W., Hajash, A., and Sparks, D. (2007). Evolution of fluid chemistry in quartz compaction systems: Experimental investigations and numerical modeling. Geochimica et Cosmochimica Acta 71, 4846-4855.

Heald, M. T. (1955). Stylolites in sandstones. The Journal of Geology 63, 101-114.

Heidug, W. K. (1995). Intergranular solid-fluid phase transformations under stress: The effect of surface forces. Journal of Geophysical Research-Solid Earth 100, 5931-5940. 
Heidug, W. K., and Leroy, Y. M. (1994). Geometrical evolution of stressed and curved solid-fluid phase boundary. 1. Transformation kinetics. Journal of Geophysical Research-Solid Earth 99, 505-515.

Hellmann, R., Gaviglio, P., Renders, P., Gratier, J. P., Békri, S., and Adler, P. (2002a). Experimental pressure solution compaction of chalk in aqueous solutions: Part 2: deformation examined by SEM, porosimetry, synthetic permeability and X-ray computerized tomography. In "WaterRock Interactions, Ore Deposits, and Environmental Geochemistry: A tribute to David A. Crerar." (R. Hellmann, and S. A. Wood, Eds.), pp. 153-178. Geochimical society.

Hellmann, R., Renders, P., Gratier, J. P., and Guiguet, R. (2002b). Experimental pressure solution compaction of chalk in aqueous solutions: Part 1 deformation behavior and chemistry. In "Water-Rock Interactions, Ore Deposits, and Environmental Geochemistry: A tribute to David A. Crerar." (R. Hellman, and S. A. Wood, Eds.), pp. 129-152. Geochemical society.

Herring, C. (1950). Diffusional viscosity of a polycrystalline solid. Journal of Applied Physics 21, 437-445.

Hickman, S. H. (1989). "Experimental studies of pressure solution and crack healing in halite and calcite." Unpublished $\mathrm{PhD}$ thesis, Massassuchets Institute of Technology.

Hickman, S. H., and Evans, B. (1991). Experimental pressure solution in halite: the effect of grain/ interphase boundary structure. Journal of the Geological Society of London 148, 549-560.

Hickman, S. H., and Evans, B. (1995). Kinetics of pressure solution at halite-silica interfaces and intergranular clay films. Journal of Geophysical Research-Solid Earth 100, 13113-13132.

Hickman, S. H., and Zoback, M. (2004). Stress orientations and magnitudes in the SAFOD pilot hole. Geophysical Research Letters 31, doi: 10.1029/2004GL020043

Hobbs, B. E., Means, W. D., and Williams, P. F. (1976). "An outline of structural geology." Wiley and Sons.

Holdsworth, R. E., van Diggelen, E. W. E., Spiers, C. J., de Bresser, J. H. P., Walker, R. J., and Bowen, L. (2011). Fault rocks from the SAFOD core samples: Implications for weakening at shallow depths along the San Andreas Fault, California. Journal of Structural Geology 33, $132-144$.

Horn, R. G., Clarke, D. R., and Clarkson, M. T. (1988). Direct measurements of surface forces between sapphire crystals in aqueous solutions. Journal of Materials Research 3, 413-416.

Horn, R. G., and Israelachvili, J. (1981). Direct measurements of structural forces between 2 surfaces in a non-polar liquid. Journal of Chemical Physics 75, 1400-1411.

Horn, R. G., Smith, D. T., and Haller, W. (1989). Surface forces and viscosity of water measured between silica sheets. Chemical Physics Letters 162, 404-408.

Israelachvili, J. N. (1986). Measurement of the viscosity of liquids in very thin films. Journal of Colloid and Interface Science 110, 263-271.

Israelachvili, J. N. (2012). "Intermolecular and surface forces", Third edition, Academic Press.

Jettestuen, E., Bisschop, J., and Dysthe, D. K. (2009). Dissolution-precipitation recrystallization of miscut crystal surfaces under stress. Journal of Crystal Growth 311, 1576-1583.

Joffe, A., Kirpitschewa, M. W., and Lewitsky, M. A. (1924 ). Deformation and strength of crystals. Z. Phys. 22, 286-302.

Jordan, G., Lohkamper, T., Schellewald, M., and Schmahl, W. W. (2005). Investigation of loaded halite-SiO2 interfaces undergoing dissolution-precipitation processes. European Journal of Mineralogy 17, 399-409.

Kamb, W. B. (1959). Theory of preferred crystal orientations developed by crystallization under stress. Journal of Geology 67, 153-170.

Kamb, W. B. (1961). The Thermodynamic Theory of Nonhydrostatically Stressed Solids. Journal of Geophysical Research 66, 259-271.

Kanagawa, K. (2002). Frictional behavior of synthetic gouge-bearing faults under the operation of pressure solution. Earth Planets and Space 54, 1147-1152.

Karcz, Z., Aharonov, E., Ertas, D., Polizzotti, R., and Scholz, C. H. (2006). Stability of a sodium chloride indenter contact undergoing pressure solution. Geology 34, 61-63. 
Karcz, Z., Aharonov, E., Ertas, D., Polizzotti, R., and Scholz, C. H. (2008). Deformation by dissolution and plastic flow of a single crystal sodium chloride indenter: An experimental study under the confocal microscope. Journal of Geophysical Research-Solid Earth 113, B04205, doi:10.1029/2006JB004630

Karcz, Z., and Scholz, C. H. (2003). The fractal geometry of some stylolites from the Calcare Massiccio Formation, Italy. Journal of Structural Geology 25, 1301-1316.

Karner, S. L., Marone, C., and Evans, B. (1997). Laboratory study of fault healing and lithification in simulated fault gouge under hydrothermal conditions. Tectonophysics 277, 41-55.

Kassner, K., , Misbah, C., , Muller, J., Kappey, J., , and Kohlert, P. (2001). Phase-field modeling of stress-induced instabilities Physical Review E 63.

Katsman, R. (2010). Extensionnal veins induced by self-similar dissolution at stylolites: analytical modeling Earth and Planetary Science letters 299, B04205, doi:10.1029/2006JB004630

Kay, M. A., Main, I. G., Elphick, S. C., and Ngwenya, B. T. (2006). Fault gouge diagenesis at shallow burial depth: Solution-precipitation reactions in well-sorted and poorly sorted powders of crushed sandstone. Earth and Planetary Science Letters 243, 607-614.

Kellogg, A. T., and Pohl, R. O. (1964). Penetration of Water into Plastically Deformed Nacl. Journal of Applied Physics 35, 1359-1360.

Kennedy, B. M., Kharaka, Y. K., Evans, W. C., Ellwood, A., DePaolo, D. J., Thordsen, J., Ambats, G., and Mariner, R. H. (1997). Mantle fluids in the San Andreas fault system, California. Science 278, 1278-1280.

Kerrich, R. (1977). An historical review and synthesis of research on pressure solution Zentbl. Mineralogie, Geologie, Paläontologie, H5-6, 512-550.

Kerrich, R. (1986). Fluid infiltration into fault zones: chemical, isotopic and mechanical effects. Pure and Applied Geophysics 124, 225-268.

Kingery, W. D., Bowen, H. K., and Ulhmann, D. R. (1976). "Introduction to ceramics, 2nd edition." Wiley, New York.

Kjellander, R., and Marcelja, S. (1984). Correlation and Image Charge Effects in Electric DoubleLayers. Chemical Physics Letters 112, 49-53.

Kjelstrup, S., Bedeaux, D., Johannssen, E., and Gross, J. (2010). "Non-Equilibrium thermodynamics for engineers."

Koehn, D., , Arnold, J., , Jamtveit, B., , and Malthe-Sørenssen, A. (2003). Instabilities in stress corrosion and the transition to brittle failure. American Journal of Science 303, 956-971

Koehn, D., Dysthe, D. K., and Jamtveit, B. (2004). Transient dissolution patterns on stressed crystal surfaces. Geochimica Et Cosmochimica Acta 68, 3317-3325.

Koehn, D., Renard, F., Toussaint, R., and Passchier, C. W. (2007). Growth of stylolite teeth patterns depending on normal stress and finite compaction. Earth and Planetary Science Letters 257, 582-595.

Kohlstedt, D. L., Evans, B., and Mackwell, S. J. (1995). Strength of the lithosphere: constraints imposed by laboratory experiments. Journal of Geophysical Research-Solid Earth 100, 17587-17602.

Konstantinidis, D. A., and Herrmann, H. J. (1998). Morphological phenomena during superplastic deformation. Physica A 256, 499-513.

Kristiansen, K., Valtiner, M., Greene, G. W., Boles, J. R., and Israelachvili, J. N. ( 2011). Pressure solution - The importance of the electrochemical surface potentials. Geochimica et Cosmochimica Acta 75, 6882-6892.

Labaume, P., Carrio-Schaffhauser, E., Gamond, J. F., and Renard, F. (2004). Deformation mechanisms and fluid-driven mass transfers in the recent fault zones of the Corinth Rift (Greece). Comptes Rendus Geoscience 336, 375-383.

Laubsher, H. B. (1975). Viscous component in Jura. Tectonophysics 27, 239-254.

Lawn, B. R. (1993). "Fracture of brittle solids." Cambridge University Press, Cambridge ; New York.

Le Guen, Y., Renard, F., Hellmann, R., Brosse, E., Collombet, M., Tisserand, D., and Gratier, J. P. (2007). Enhanced deformation of limestone and sandstone in the presence of high PC02 fluids. Journal of Geophysical Research-Solid Earth 112, doi: 10.1029/2006JB004637. 
Lehner, F. K. (1990). Thermodynamics of rock deformation by pressure solution. In "Deformation processes in minerals, ceramics and rocks." (D. J. Barber, and P. G. Meredith, Eds.), pp. 296333. Unwim Hyman, London.

Lehner, F. K. (1995). A model for intergranular pressure solution in open systems. Tectonophysics 245, 153-170.

Lehner, F. K., and Bataille, J. (1985). Nonequilibrium thermodynamics of pressure solution. PAGEOPH 122, 53-85.

Lehner, F. K., and Leroy, P. (2003). Sandstone compaction by intergranular pressure solution. In "Mechanics of fluid saturated rocks." (Y. Gueguen, and M. Bouteca, Eds.). Elsevier Academic Press.

Lemée, C., and Gueguen, Y. (1996). Modelling of porosity loss during compaction and cementation of sandstones. Geology 24, 875-878.

Liteanu, E., and Spiers, C. J. (2009). Influence of pore fluid salt content on compaction creep of calcite aggregates in the presence of supercritical CO2. Chemical Geology 265, 134-147.

Lockner, D. A., Morrow, C., Moore, D., and Hickman, S. (2011). Low strength of deep San Andreas fault gouge from SAFOD core. Nature 472, 82-U107.

Lockner, D. A., Summers, R., and Byerlee, J. D. (1986). Effect of temperature and sliding rate on frictional strength of granite. Pure and Applied Geophysics 124, 446-469.

Lohkamper, T. H. K., Jordan, G., Costamagna, R., Stockhert, B., and Schmahl, W. W. (2003). Phase shift interference microscope study of dissolution-precipitation processes of nonhydrostatically stressed halite crystals in solution. Contributions to Mineralogy and Petrology 146, 263-274.

Magdar, J. J., Tirrell, M., and Davis, H. T. (1985). Molecular-dynamic of narrow liquid-filled pores. Journal of Chemical Physics 83, 1888-1901.

Malani, A., Ayappa, K. G., and Murad, S. (2006). Effect of confinement on the hydration and solubility of $\mathrm{NaCl}$ in water. Chemical Physics Letters 431, 88-93.

Marone, C. (1998). Laboratory-derived friction laws and their application to seismic faulting. Annual Review of Earth and Planetary Sciences 26, 643-696.

Marquer, D., and Burkhard, M. (1992). Fluid circulation, progressive deformation and mass-transfert processes in the upper crust: the example of basement-cover relationships in the external crystalline massifs, Switzerland. Journal of Structural Geology 14, 1047-1057.

Marshall, D. J., and Mariano, A. N. (1988). "Cathodoluminescence of geological materials." Unwin Hyman (Boston).

Martin, B., Roller, K., and Stockhert, B. (1999). Low-stress pressure solution experiments on halite single-crystals. Tectonophysics 308, 299-310.

Mc Ewen, T. J. (1981). Brittle deformation in pitted pebble conglomerate. Journal of Structural Geology 3, 25-38.

McCaig, A. M. (1988). Deep fluid circulation in fault zones. Geology 16, 867-870.

Means, W. (1987). A newly recognized type of slickenside striation. Journal of Structural Geology 9, 585-590.

Meer, S. d., and Spiers, C. J. (1997). Uniaxial compaction creep of wet gypsum aggregates. Journal of Geophysical Research-Solid Earth 102, 875-891.

Merino, E., Ortoleva, P., and Strickholm, P. (1983). Generation of evenly spaced pressure solution seems during late diagenesis: a kinetics theory. Contributions to Mineralogy and Petrology 82, 360-370.

Meyer, E. E., Greene, G. W., Alcantar, N. A., Israelachvili, J. N., and Boles, J. R. (2006). Experimental investigation of the dissolution of quartz by a muscovite mica surface: Implications for pressure solution. Journal of Geophysical Research-Solid Earth 111, doi: 10.1029/2005JB004010.

Milliken, K. L. (1994). The widespread occurrence of healed microfractures in siliclastic rocks: Evidence from scanned cathodoluminescence imaging. In "Rock Mechanics." (B. K. Nelson, and S. E. Laubach, Eds.). Balkerna, Rotterdam. 
Mittempergher, S., Di Toro, G., Gratier, J.-P., Hadizadeh, J., Smith, S. A. F., and Spiess, R. (2011). Evidence of transient increases of fluid pressure in SAFOD phase III cores. Geophysical Research Letters 38, LO3301.

Moore, D. E., and Rymer, M. J. (2007). Talc-bearing serpentinite and the creeping section of the San Andreas fault. Nature 448, 795-797.

Morel, J., and den Brok, S. W. J. (2001). Increase in dissolution rate of sodium chlorate induced by elastic strain. Journal of Crystal Growth 222, 637-644.

Mosher, S. (1976). Pressure solution as a deformation mechanism in Pennsylvanian conglomerates from Rhode Island. The Journal of Geology 84, 355-363.

Muller, W., Aerden, D., and Halliday, A. N. (2000). Isotopic dating of strain fringe increments: Duration and rates of deformation in shear zones. Science 288, 2195-2198.

Mullis, J. (1975). Growth condition of quartz crystals from Val d'Illiez (Valais, Switzerland) Schweizer Mineralogische und Petrographische Mitteilungen 55, 419-429.

Nabarro, F. R. N. (1948). Deformation of crystals by the motion of single ions. In "Conference on the strength of solids, Proceeding of the Physical Society of London." pp. 75.

Nakatani, M., and Scholz, C. H. (2004). Frictional healing of quartz gouge under hydrothermal conditions: 1. Experimental evidence for solution transfer healing mechanism. Journal of Geophysical Research-Solid Earth 109, doi:10.1029/2001jb001522.

Nicolas, A., and Poirier, J. P. (1976). "Crystalline plasticity and solid-state flow in metamorphic rocks." J. Wiley Interscience Publications, London.

Niemeijer, A. R., Marone, C., and Elsworth, D. (2008a). Healing of simulated fault gouges aided by pressure solution: Results from rock analogue experiments. Journal of Geophysical ResearchSolid Earth 113, doi:10/1029:2007JB005376.

Niemeijer, A. R., Marone, C., and Elsworth, D. (2010). Frictional strength and strain weakening in simulated fault gouge: Competition between geometrical weakening and chemical strengthening. Journal of Geophysical Research-Solid Earth 115.

Niemeijer, A. R., and Spiers, C. J. (2002). Compaction creep of quartz-muscovite mixtures at 500 degrees C: Preliminary results on the influence of muscovite on pressure solution. Geological Society of London Special Publication 200, 61-71.

Niemeijer, A. R., and Spiers, C. J. (2005). Influence of phyllosilicates on fault strength in the brittleductile transition: insights from rock analogue experiments. High-Strain Zones: Structure and Physical Properties 245, 303-327.

Niemeijer, A. R., and Spiers, C. J. (2006). Velocity dependence of strength and healing behaviour in simulated phyllosilicate-bearing fault gouge. Tectonophysics 427, 231-253.

Niemeijer, A. R., Spiers, C. J., and Bos, B. (2002). Compaction creep of quartz sand at 400-600 degrees C: experimental evidence for dissolution-controlled pressure solution. Earth and Planetary Science letters 195, 261-275.

Niemeijer, A. R., Spiers, C. J., and Peach, C. J. (2008b). Frictional behaviour of simulated quartz fault gouges under hydrothermal conditions: Results from ultra-high strain rotary shear experiments. Tectonophysics 460, 288-303.

Nino, F., Chéry, J., and Gratier, J. P. (1998). Mechanical modeling of compressional basins: origin and interaction of faults, erosion and subsidence in the Ventura Basin, California. Tectonics 17, 955-972.

Noiriel, C., Renard, F., Doan, M. L., and Gratier, J. P. (2010). Intense fracturing and fracture sealing induced by mineral growth in porous rocks. Chemical Geology 269, 197-209.

Pachon-Rodriguez, E. A., Piednoir, A., and Colombani, J. (2011). Pressure solution at the molecular scale. Physical Review Letters 107, 146102.

Park, W. C., and Schot, E. H. (1968). Stylolites, their nature and origin. Journal of Sedimentary Petrology 38, 175-1.

Parks, G. A. (1984). Surface and interfacial free energies of quartz. Journal of Geophysical Research 89, 3997-4008. 
Pashley, R. M., and Israelachvili, J. N. (1984). Molecular layering of water in thin films between mica surfaces and its relation to hydration forces. Journal of Colloid and Interface Science 101, $510-522$.

Paterson, M. S. (1973). Nonhydrostatic thermodynamics and its geologic applications. Reviews of Geophysics and Space Physics 11, 355-389.

Paterson, M. S. (1978). "Experimental rock deformation: the brittle field." Springer-Verlag, Berlin.

Pennock, G. M., Drury, M. R., Peach, C. J., and Spiers, C. J. (2006). The influence of water on deformation microstructures and textures in synthetic $\mathrm{NaCl}$ measured using EBSD. Journal of Structural Geology 28, 588-601.

Pharr, G. M., and Ashby, M. F. (1983). On creep enhanced by liquid phase. Acta Metallurgica 31, 129-138.

Pinho, S. P., and Macedo, E. A. (2005). Solubility of $\mathrm{NaCl}, \mathrm{NaBr}$, and $\mathrm{KCI}$ in water, methanol, ethanol, and their mixed solvents. Journal of Chemical and Engineering Data 50, 29-32.

Piper, J. D. A., Mesci, L. B., Gursoy, H., Tatar, O., and Dabies, C. J. (2007). Palaeomagnetic and rock magnetic properties of travertines: its potential as a recorder of geomagnetic palaeosecular variaton, environmental change and earthquake activity in the Sicak Cermik geothermal field, Turkey. Physics of the Earth and Planetary Interiors 161, 50-73.

Poirier, J. P. (1985). "Creep of crystals." Cambridge University Press.

Railsback, L. B. (1993). Lithologic controls on morphology of pressure-dissolution surfaces (stylolites and dissolution seams) in paleozoic carbonate rocks from the mideastern united-states. Journal of Sedimentary Petrology 63, 513-522.

Raj, R. (1982). Creep in polycrystalline aggregates by matter transport through a liquid phase. Journal of Geophysical Research-Solid Earth 87, 4731-4739.

Raj, R., and Chyung, C. K. (1981). Solution-precipitation creep in glass ceramics. Acta Metallurgica 29, 159-166.

Ramm, M. (1992). Porosity-depth trends in reservoir sandstones: theoretical models related to Jurassic sandstones offshore Norway. Marine and Petroleum Geology 9, 553-567.

Ramsay, J. G. (1967). "Folding and fracturing of rocks." MacGraw-Hill Book Company.

Ramsay, J. G. (1980a). The crack-seal mechanism of rock deformation. Nature 284, 135-139.

Ramsay, J. G. (1980b). Shear zone geometry a review. Journal of Structural Geology 2, 83-100.

Ramsay, J. G., and Huber, M. I. (1987). "The Techniques of Modern Structural Geology. Volume 2: Folds and Fractures." Academic Press, London.

Ramsay, J. G., and Wood, D. S. (1974). The geometric effects of volume change during during deformation processes. Tectonophysics 16, 263-277.

Rehbinder, P. A., and Shchukin, E. D. (1972). Surface phenomena in solids during deformation and fracture, . Progress in Surface Science 3, 97-188.

Renard, F., Beaupretre, S., Voisin, C., Zigone, D., Candela, D., Dysthe, D. K., and Gratier, J. P. (2012). Strength evolution of a reactive frictionnal interface: an analogue experiment. Earth and Planetary Science letters , 341-344, 20-34.

Renard, F., Bernard, D., Thibault, X., and Boller, E. (2004a). Synchrotron 3D microtomography of halite aggregates during experimental pressure solution creep and evolution of the permeability. Geophysical Research letters 31, doi:10.1029/2004GL019605.

Renard, F., Brosse, E., and Gratier, J. P. (2000a). The different processes involved in the mechanism of pressure solution in quartz-rich rocks and their interactions. International Association Sedimentologists Special Publication 29, 67-78.

Renard, F., Dysthe, D., Feder, J., Bjorlykke, K., and Jamtveit, B. (2001). Enhanced pressure solution creep rates induced by clay particles: Experimental evidence in salt aggregates. Geophysical Research Letters. 28, 1295-1298.

Renard, F., Dysthe, D. K., Feder, J. G., Meakin, P., Morris, S. J. S., and Jamtveit, B. (2009). Pattern formation during healing of fluid-filled cracks: an analog experiment. Geofluids 9, 365-372.

Renard, F., Gratier, J. P., and Jamtveit, B. (2000b). Kinetics of crack-sealing, intergranular pressure solution, and compaction around active faults. Journal of Structural Geology 22, 1395-1407. 
Renard, F., and Ortoleva, P. (1997). Water films at grain-grain contacts: Debye-Huckel, osmotic model of stress, salinity, and mineralogy dependence. Geochimica et Cosmochimica Acta 61, 1963-1970.

Renard, F., Ortoleva, P., and Gratier, J. P. (1997). Pressure solution in sandstones: influence of clays and dependence on temperature and stress. Tectonophysics 280, 257-266.

Renard, F., Park, A., Ortoleva, P., and Gratier, J. P. (1999). An integrated model for transitional pressure solution in sandstones. Tectonophysics 312, 97-115.

Renard, F., Schmittbuhl, J., Gratier, J. P., Meakin, P., and Merino, E. (2004b). Three-dimensional roughness of stylolites in limestones. Journal of Geophysical Research-Solid Earth 109, doi: $10.1029 / 2003$ JB002555

Renton, J. J., Heald, M. T., and Cecil, C. B. (1969). Experimental investigation of pressure solution of quartz. Journal of sedimentary Petrology 39, 1107-1117.

Revil, A. (1999). Pervasive pressure-solution transfer: a poro-visco-plastic model. Geophysical Research Letters 26, 255-258.

Revil, A. (2001). Pervasive pressure solution transfer in a quartz sand. Journal of Geophysical Research-Solid Earth 106, 8665-8686.

Rice, J. R. (1992). Fault stress states, pore pressure distributions, and the weakness of the San Andreas fault In "Fault Mechanics and Transport Properties of Rocks." pp. 475-503. Academic Press.

Richard, J. (2009). "Processus de développement de la schistosité ", University Joseph Fourier, Master, 27p

Rimstidt, J. D., and Barnes, H. L. (1980). The kinetics of silica-water reactions. Geochimica et Cosmochimica Acta 44, 1683-1699.

Robin, P.-Y. (1978). Pressure solution at grain-to-grain contacts. Geochimica et Cosmochimica Acta 42, 1383-1389.

Røyne, A., and Dysthe, D. K. (2012). Rim formation on crystal faces growing in confinement. Journal of Crystal Growth 346, 89-100.

Rutter, E. H. (1972). The influence of interstitial water on the rheological behavior of calcite rocks. Tectonophysics 14, 13-33.

Rutter, E. H. (1976). The kinetics of rock deformation by pressure solution. Philosophical Transactions of the Royal Society of London 283, 203-219.

Rutter, E. H. (1983). Pressure solution in nature, theory and experiment. Journal of the geological Society of London 140, 725-740.

Rutter, E. H., Maddock, R. H., Hall, S. H., and White, S. H. (1986). Comparative microstructures of natural and experimentally produced clay-bearing fault gouges. Pure and Applied Geophysics 124, 3-30.

Rutter, E. H., and Mainprice, D. H. (1978). The effect of water on stress relaxation of faulted and unfaulted sandstones. Pure and Applied Geophysics 116, 634-654.

Safaricz, M., and Davison, I. (2005). Pressure solution in chalk. American Association of Petroleum Geologists Bulletin 89, 383-401.

Schenk, O., Urai, J. L., and Piazolo, S. (2006). Structure of grain boundaries in wet, synthetic polycrystalline, statically recrystallizing halite - evidence from cryo-SEM observations. Geofluids 6, 93-104.

Schleicher, A. M., Tourscher, S. N., van der Pluijm, B. A., and Warr, L. N. (2009). Constraints on mineralization, fluid-rock interaction, and mass transfer during faulting at 2-3 km depth from the SAFOD drill hole. Journal of Geophysical Research-Solid Earth 114, doi: 10.1029/2008JB006092.

Schmid, S. M., Pfiffner, O. A., Froitzheim, N., Schonborn, G., and Kissling, E. (1996). Geophysicalgeological transect and tectonic evoloution of the Swiss-Italian Alps. Tectonics 15, 10361034.

Schmidt, S. M., Pfiffner, O. A., Froitzheim, N., Schonborn, G., and Kissling, E. (1996). Geophysicalgeological transect and tectonic evoloution of the Swiss-Italian Alps. Tectonics 15, 10361034. 
Schmittbuhl, T., Renard, F., Gratier, J. P., and Toussaint, R. (2004). The roughness of stylolites implications of 3D high resolution topography measurements. Physic Research Letters 93, doi:10.1103/PhysRevLett.93.238501

Scholz, C. (1998). Earthquakes and friction laws. Nature 391, 37-42.

Schutjens, P. (1991). Experimental compaction of quartz sand at low effective stress and temperature condition. Journal of the Geological Society of London 148, 527-539.

Schutjens, P., and Spiers, C. J. (1999). Intergranular pressure solution in $\mathrm{NaCl}$ : Grain-to-grain contact experiments under the optical microscope. Oil \& Gas Science and Technology-Revue De L Institut Francais Du Petrole 54, 729-750.

Sclater, J. G., and Christie, P. A. F. (1980). Continental stretching - an explanation of the post-midcretaceous subsidence of the central north-sea basin Journal of Geophysical Research-Solid Earth 85, 3711-3739.

Shimamoto, T., Kanaori, Y., and Asai, K.-I. (1991). Cathodoluminescence observations on lowtemperature mylonites: potential for detection of solution-precipitation microstructures. Journal of Structural Geology 13, 967-973.

Shimizu, I. (1992). Nonhydrostatic and nonequilibrium thermodynamics of deformable materials. Journal of Geophysical Research-Solid Earth 97, 4587-4597.

Sibson, R. H. (1982). Fault zone models, heat flow, and the depth distribution of earthquakes in the continental crust of the United States. Bulletin of the Seismological Society of America 72, 151-163.

Sibson, R. H. (1990). Faulting and fluid flow. In "Fluids in tectonically active regimes of the continental crust." (B. E. Nesbitt, Ed.), pp. 93-132. Short Course Handbook. Mineralogical Association of Canada.

Sibson, R. H., Robert, F., and Poulsen, K. H. (1988). High angle reverse fault, fluid-pressure cycling and mesothermal gold quartz deposits. Geology 16, 551-555.

Siddans, A. W. B. (1972). Slaty cleavage - a review of research since 1815. Earth-Science Reviews 8, 205-232.

Simon, J. L. (2007). Analysis of solution lineations in pebbles: Kinematical vs. dynamical approaches. Tectonophysics 445, 337-352.

Sinha-Roy, S. (2004). Antitaxial fibrous bands in differentiated stylolites. Journal of the Geological Society of India 63, 387-405.

Skvortsova, Z. N. (2004). Deformation by the mechanism of dissolution-reprecipitation as a form of adsorption plasticization of natural salts. Colloid Journal 66, 1-10.

Skvortsova, Z. N., Kas'yanova, I. V., and Traskine, V. Y. (2003). Indentation study of adsorption plastification of sodium chloride single crystals. Colloid Journal 65, 366-369.

Solum, J. G., Hickman, S. H., Lockner, D. A., Moore, D. E., van der Pluijm, B. A., Schleicher, A. M., and Evans, J. P. (2006). Mineralogical characterization of protolith and fault rocks from the SAFOD Main Hole. Geophysical Research Letters 33, doi: 10.1029/2006GL027285.

Sorby, H. C. (1863). On the direct correlation of mechanical and chemical forces. Proceeding of the Royal Society of London 12, 538-550.

Sorby, H. C. (1865). On impressed limestone pebble. Proceedings of the Geological and Polytechnic Society of the West Riding of Yorkshire, 4, 458-461.

Spiers, C. J., and Brzesowsky, R. H. (1993). Densification behaviour of wet granular salt: Theory versus experiment. In "Seventh Symposium on salt." pp. 83-91.

Spiers, C. J., and Schutjens, P. M. (1990). Densification of crystalline aggregates by fluid phase diffusional creep. In "Deformation process in minerals, ceramics and rocks." (D. J. Barber, and P. G. Meredith, Eds.), pp. 334-353. Unwin Hyman.

Spiers, C. J., Schutjens, P. M. T. M., Brzesowsky, R. H., Peach, C. J., Liezenberg, J. L., and Zwart, H. J. (1990). Experimental-Determination of Constitutive Parameters Governing Creep of RockSalt by Pressure Solution. Geological Society of London Special Publication 54, 215-227.

Sprunt, E. S., and Nur, A. (1976). Reduction of porosity by pressure solution: Experimental verification. Geology 4, 463-466. 
Sprunt, E. S., and Nur, A. (1977). Experimental study of the effects of stress on solution rate. Journal of Geophysical Research-Solid State 32, 3013-3022.

Stockdale, P. B. (1922). "Stylolites: Their nature and origin,." Indiana University Studies.

Stromgard, K. E. (1973). Stres distribution during formation of boudinage and pressure shadow. Tectonophysics 16, 215-243.

Tada, R., and Siever, R. (1986). Experimental knife-edge pressure solution of halite. Geochimica et Cosmochimica Acta 50, 29-36.

Tada, R., and Siever, R. (1989). Pressure solution during diagenesis. Annual Review of Earth and Planetary Sciences 17, 89-118.

Taron, J., and Elsworth, D. (2010). Constraints on compaction rate and equilibrium in the pressure solution creep of quartz aggregates and fractures: Controls of aqueous concentration. Journal of Geophysical Research-Solid Earth 115, doi:10.1029/2009JB007118.

Tenthorey, E., and Cox, S. F. (2006). Cohesive strengthening of fault zones during the interseismic period: An experimental study Journal of Geophysical Research-Solid Earth 111, 59-72.

Thomas, A. R., Dahl, W. M., Hall, C. M., and York, D. (1993). 40Ar/39Ar analyzes of authigenic muscovite, timing of stylolitization, and implications for pressure solution mechanisms: Jurassic Norphlet formation, offshore Alabama. Clays and Clay Minerals 41, 269-279.

Thomson, J. (1861). Collected papers in physics and engineering, 1912. Cambridge university press.

Titus, S. J., DeMets, C., and Tikoff, B. (2006). Thirty-five-year creep rates for the creeping segment of the San Andreas fault and the effects of the 2004 Parkfield earthquake: Constraints from alignment arrays, continuous global positioning system, and creepmeters. Bulletin of the Seismological Society of America 96, S250-S268.

Traskin, V. Y. (2009). Rehbinder effect in tectonophysics. Izvestiya-Physics of the Solid Earth 45, 952-963.

Traskin, V. Y., Abdrakhimov, M. Z., and Skvortsova, Z. N. (1998). Observation of the Rehbinder effect under conditions of superdeep drilling. Colloid Journal 60, 606-608.

Traskine, V. Y., Skvortsova, Z., Muralev, A., and Zubov, D. (2009). Pressure solution creep under cyclic loading. Mineralogy and Petrology 97, 265-274.

Trurnit, P. (1968). Pressure solution phenomena in detrital rocks. Sedimentary Geology 2, 89-114.

Urai, J. L., Spiers, C. J., Zwart, H. J., and Lister, G. S. (1986). Weakening of rock-salt by water during long-term creep. Nature 324, 554-557.

Valtiner, M., Kristiansen, K., Greene, G. W., and Israelachvili, J. N. (2011). Effect of Surface Roughness and Electrostatic Surface Potentials on Forces Between Dissimilar Surfaces in Aqueous Solution. Advanced Materials 23, 2294-2299.

van Noort, R., Spiers, C., and Peach, C. (2007). Effects of orientation on the diffusive properties of fluid-filled grain boundaries during pressure solution. Physics and Chemistry of minerals 34, 95-112.

van Noort, R., Spiers, C. J., and Peach, C. J. (2011). Structure and properties of loaded silica contacts during pressure solution: impedance spectroscopy measurements under hydrothermal conditions. Physics and Chemistry of minerals 38, 501-516.

van Noort, R., Spiers, C. J., and Pennock, G. M. (2008a). Compaction of granular quartz under hydrothermal conditions: Controlling mechanisms and grain boundary processes. Journal of Geophysical Research-Solid Earth 113, doi:10.1029/2008JB005815

van Noort, R., Visser, H. J. M., and Spiers, C. J. (2008b). Influence of grain boundary structure on dissolution controlled pressure solution and retarding effects of grain boundary healing. Journal of Geophysical Research-Solid Earth 113, doi:10.1029/2007JB005223

Vigil, G., Xu, Z.-H., Steinberg, S., and Israelachvili, J. (1994). Interaction of silica surfaces. Journal of Colloid and interface science 165, 367-385.

Voisin, C., Renard, F., and Grasso, J. R. (2007). Long term friction: From stick-slip to stable sliding. Geophysical Research Letters 34, doi:10.1029/2007GL029715.

Wangen, M. (1998). Modeling porosity evolution and cementation of sandstones. Marine and Petroleum Geology 15, 453-465. 
Watanabe, Y., Nakai, S., and Lin, A. M. (2008). Attempt to determine U-Th ages of calcite veins in the Nojima fault zone, Japan. Geochemical Journal 42, 507-513.

Weibel, R., and Keulen, N. (2008). Diagenesis influencing the porosity of Upper Jurassic reservoir sandstones, Danish North Sea. Geological Survey of Denmark and Greenland Bulletin 15, 912.

Weyl, P. K. (1959). Pressure solution and the force of crystallization: a phenomenological theory. Journal of Geophysical Research-Solid Earth 64, 2001-2025.

Wheeler, J. (1992). Importance of pressure solution and Coble creep in the deformation of polymineralics rocks. Journal of Geophysical Research-Solid Earth 97, 4579-4586.

Wheeler, J. (2010). Anisotropic rheology during grain boundary diffusion creep and its relation to grain rotation, grain boundary sliding and superplasticity. Philosophical Magazine 90, 28412864.

Wintsch, R. P., and Dunning, J. (1985). The effect of dislocation density on the aqueous solubility of quartz and some geologic implications: A theoretical approach. Journal of Geophysical Research-Solid Earth 90, 3649-3657.

Wintsch, R. P., Kvale, C. M., and Kisch, H. J. (1991). Open-system, constant-volume development of slaty cleavage, and strain-induced replacement reactions in the Martinsburg formation, Lehig Gap, Pennsylvania. Geological Society of America Bulletin 103, 916-927.

Wood, D. S. (1974). Current Views of the Development of Slaty Cleavage. Annual Review of Earth and Planetary Sciences 2, 369-400.

Yasuhara, H., Elsworth, D., and Polak, A. (2003). A mechanistic model for compaction of granular aggregates moderated by pressure solution. Journal of Geophysical Research-Solid Earth 108, doi:10.1029/2003JB002536

Yasuhara, H., Marone, C., and Elsworth, D. (2005). Fault zone restrengthening and frictional healing: The role of pressure solution. Journal of Geophysical Research-Solid Earth 110, doi: 101029/2004JB003327.

Yeats, R. S., and Huftile, J. G. (1994). Late Cenozoic Tectonics of the East Ventura Basin, Transverse Ranges, California. American Association Petroleum Geologists Bulletin 78, 1040-1070.

Zhang, X. M., Salemans, J., Peach, C. J., and Spiers, C. J. (2002). Compaction experiments on wet calcite powder at room temperature: evidence for operation of intergranular pressure solution. Geological Society of London, Special Publication 200, 29-40.

Zhang, X. M., and Spiers, C. J. (2005a). Compaction of granular calcite by pressure solution at room temperature and effects of pore fluid chemistry. International Journal of Rock Mechanics and Mining Sciences 42, 950-960.

Zhang, X. M., Spiers, C. J., and Peach, C. J. (2010). Compaction creep of wet granular calcite by pressure solution at 28 degrees C to 150 degrees C. Journal of Geophysical Research-Solid Earth 115, doi: $10.1029 / 2008 J B 005853$

Zhang, X. M., Spiers, C. J., and Peach, C. J. (2011). Effects of pore fluid flow and chemistry on compaction creep of calcite by pressure solution at 150 degrees C. Geofluids 11, 108-122.

Zhang, X. M., and Spiers, C. J. T. (2005b). Effects of phosphate ions on intergranular pressure solution in calcite: An experimental study. Geochimica et Cosmochimica Acta 69, 5681-5691.

Zoback, M., Hickman, S., and Ellsworth, W. (2010). Scientific drilling into the San Andreas Fault Zone. EOS, Transactions, American Geophysical Union, 91, 197-199.

Zubtsov, S., Renard, F., Gratier, J. P., Dysthe, D. K., and Traskine, V. (2005). Single-contact pressure solution creep on calcite monocrystals. Geological Society of London Special Publication 243, 81-95.

Zubtsov, S., Renard, F., Gratier, J. P., Guiguet, R., Dysthe, D. K., and Traskine, V. (2004). Experimental pressure solution compaction of synthetic halite/calcite aggregates. Tectonophysics 385, 45-57. 